\title{
Laser doppler imaging in dermatology: experimental and clinical applications : time to replace the dermatologist's eye?
}

Citation for published version (APA):

Sommer, A. (2001). Laser doppler imaging in dermatology: experimental and clinical applications : time to replace the dermatologist's eye? [Doctoral Thesis, Maastricht University]. Universiteit Maastricht. https://doi.org/10.26481/dis.20010907as

Document status and date:

Published: 01/01/2001

DOI:

10.26481/dis.20010907as

Document Version:

Publisher's PDF, also known as Version of record

Please check the document version of this publication:

- A submitted manuscript is the version of the article upon submission and before peer-review. There can be important differences between the submitted version and the official published version of record.

People interested in the research are advised to contact the author for the final version of the publication, or visit the DOI to the publisher's website.

- The final author version and the galley proof are versions of the publication after peer review.

- The final published version features the final layout of the paper including the volume, issue and page numbers.

Link to publication

\footnotetext{
General rights rights.

- You may freely distribute the URL identifying the publication in the public portal. please follow below link for the End User Agreement:

www.umlib.nl/taverne-license

Take down policy

If you believe that this document breaches copyright please contact us at:

repository@maastrichtuniversity.nl

providing details and we will investigate your claim.
}

Copyright and moral rights for the publications made accessible in the public portal are retained by the authors and/or other copyright owners and it is a condition of accessing publications that users recognise and abide by the legal requirements associated with these

- Users may download and print one copy of any publication from the public portal for the purpose of private study or research.

- You may not further distribute the material or use it for any profit-making activity or commercial gain

If the publication is distributed under the terms of Article $25 \mathrm{fa}$ of the Dutch Copyright Act, indicated by the "Taverne" license above, 
Laser Doppler Imaging in Dermatology: experimental and clinical applications. Time to replace the dermatologist's eye? 


\section{A. Sommer, Maastricht 2001}

ISBN 90-5681-112-6

Vormgeving en druk: Unigraphics, Universiteit Maastricht

Omslag: Geerdjan van Zonnenveld 


\section{Laser Doppler Imaging in Dermatology:}

\section{experimental and clinical applications. \\ Time to replace the dermatologist's eye?}

\section{PROEFSCHRIFT}

ter verkrijging van de graad van doctor aan de Universiteit Maastricht,

op gezag van de Rector Magnificus,

Prof. Dr. A.C. Nieuwenhuijzen Kruseman, volgens het besluit van het College van Decanen, in het openbaar te verdedigen

op

vrijdag, 7 september 2001 om 12.00 uur

door

Anja Sommer 


\section{Promotor:}

Prof. dr. H.A.M. Neumann

\section{Beoordelingscommissie:}

Prof. dr. ir. A.P.G. Hoeks (voorzitter)

Prof. dr. ir. M.J.C. van Gemert (Universiteit van Amsterdam)

Prof. dr. F. Hendrikse

Dr. A.J.H.M. Houben

Prof. dr. ir. G.E. Nilsson (University of Linköping, Sweden)

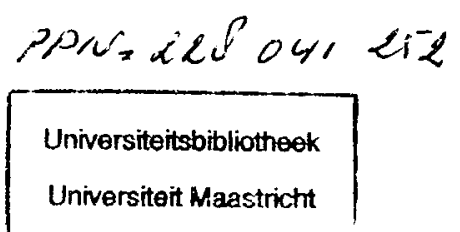

Financial support by H.R. Sommer, Sporex (product of Intec BV), Medi Nederland, ScheringPlough, Stiefel Laboratories BV, Varodem, BSN medical, Novartis Pharma BV, Yamanouchi, Abbott BV, Aventis Pharma, Coloplast, Galderma, Glaxo Wellcome BV, Leo Pharma, Varitex, Will-Pharma, Bipharma BV, Roche Nederland BV, Sanofi-Synthelabo, Smith\&Nephew Hoofddorp, UCB Pharma, Johnson\&Johnson medical BV, Fujisawa Holland BV. 
The finger and the eye are archaic instruments on which dermatologists have too long depended

(A. M. Kligman,

The invisible dermatoses.

Arch Dermatol 1991;127:1375.) 


\begin{tabular}{|c|c|}
\hline AB: & atrophie blanche \\
\hline Adr: & adrenaline \\
\hline aU: & arbitrary units \\
\hline BRF: & basic resting flux \\
\hline CBV: & capillary blood-cell velocity \\
\hline CP: & Clobetasol-17-propionate \\
\hline CVI: & chronic venous insufficiency \\
\hline DRS: & diffuse reflectance spectroscopy \\
\hline EI: & erythema index \\
\hline Hist: & histamine \\
\hline LDI: & laser Doppler Imager \\
\hline LDF: & laser Doppler fluxmetry \\
\hline MED & minimal erythema dose \\
\hline $\mathrm{mV}:$ & milli-Volt \\
\hline $\mathrm{NaCl}:$ & sodium chloride \\
\hline NTS: & non treated skin \\
\hline P: & partial pressure \\
\hline $\mathrm{Pa}_{\mathrm{O} 2}$ & Oxygen pressure in arterial blood \\
\hline $\mathrm{Rm}:$ & mean reflectance \\
\hline s: & $\operatorname{second}(s)$ \\
\hline TA: & triamcinolonacetonide \\
\hline TENS: & transcutaneous electrical nerve stimulation \\
\hline $\mathrm{TcPO}_{2}$ & transcutaneous oxygen measurement \\
\hline UV: & ultraviolet \\
\hline $\mathrm{V}:$ & vehiculum \\
\hline VOC: & venous occlusion \\
\hline
\end{tabular}




\section{Table of Contents}

List of abbreviations

Chapter I

Chapter II

Chapter III

Chapter IV

Chapter V

Chapter VI

Chapter VII

Samenvatting

Dankwoord

Curriculum Vitae

Publications
Investigation of skin microcirculation

9

Microcirculation of the skin assessed by Laser-Doppler-

Imaging: Review of the literature and clinical relevance from a dermatological point of view

Red and blue telangiectasias. Differences in oxygenation?

55

Changes in microcirculation in patients with

65

Atrophie blanche visualised by laser Doppler

Imaging and transcutaneous oxygen measurements.

Evaluation of the Vasoconstrictive Effects of topical steroids by Laser-Doppler-Imaging

Vasoconstrictive effect of topical applied corticosteroids measured by Laser-Doppler Imaging and reflectance spectroscopy

General Discussion and Summary 


\section{Chapter I}

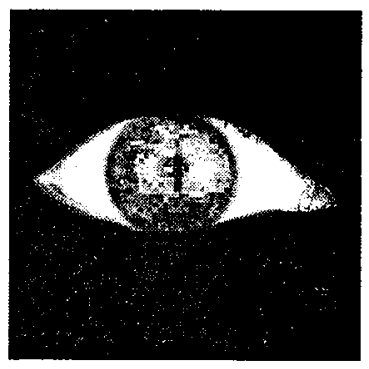

INVESTIGATION

OF

SKIN MICROCIRCULATION 


\section{General Introduction}

The first approaches to describe microcirculation were made by William Harvey in 1628 (von Brunn, 1967). He explained the aspects of the blood circulation. In his idea the blood poured from the arteries directly into the veins. Then in 1661, Malpighi described the capillary connection between arteries and veins in the pulmonary circulation (Landis, 1964) and, subsequently, van Leeuwenhoek introduced the non-invasive investigation of microcirculation by inspecting erythrocyte moving in tadpoles under a self-built microscope.

Skin microcirculation plays a major role in the human circulatory circuit as well as in the maintenance and survival of the human skin. Information about function in normal condition and under pathological situations is essential for our insight in the skin microcirculation and also for our knowledge of the skin function as a whole. Preferable for monitoring skin microcirculation are non-invasive techniques that can also be used for continuous measurement to evaluate the changes in skin microcirculation during a certain time period. Skin microcirculation is partly autonomous, but a strong relation with macrocirculation does exist.

Microcirculation can be assessed invasively and non-invasively. Invasive methods include astrup measurements of the capillaries to determine the oxygen saturation and the carbon dioxide concentration of the samples (Astrup, 1993), widely used in monitoring oxygen saturation in neonates. Fluorescence microscopy visualises the capillaries, but informs us also about the function (Bollinger et al, 1982). Jünger et al developed a technique suitable for direct capillary pressure measurements (Jünger et al, 2000). Invasive techniques are partly difficult to perform (e.g. intracapillary pressure measurements) and more or less painful for the patient. In case of fluorescent microscopy the risk on a fatal anaphylaxis exists (Wienert et al, 1995). In addition, invasive techniques are not suitable for continuous measurements. Therefore, if possible, non-invasive techniques are preferred. The number of non-invasive devices for the quantification of the cutaneous microcirculation increased continuously over the last 20 years. While means as capillary microscopy and transcutaneous oxygen measurement formerly played the prevailing role, today other means as the laser Doppler technique are widely distributed as well. Laser Doppler Imaging (LDI), which is an advanced laser Doppler technique, is a promising hi-tech tool (Wårdell et al, 1995) to study alterations in skin microcirculation in specially inflammatory skin diseases and after pharmacological stimuli. This technique therefore seems a good tool for investigating the role of the cutaneous microcirculation under inflammatory conditions as well as for analysing the effect of (topical) applied drugs. This is of great interest for the so widely prescribed corticosteroids of which many effects on the skin are presently unknown. The objective assessment of physiologic and pathophysiologic alterations in human skin microcirculation has always been a field of investigation in medicine. 
The cutaneous microcirculation plays an important role in nutrition of the skin and temperature regulation of the body. Alterations of the microcirculation are involved in many pathologic conditions like inflammatory dermatoses (e.g. psoriasis, eczema, lichen planus, necrobiosis lipoidica etc.), inflammatory reactions after application of vasoactive substances and in diseases affecting the macro/microcirculation, such as chronic venous insufficiency and arterial insufficiency. Symptoms like venous leg ulcer and atrophic blanche are the direct consequence of an altered microcirculation. An objective assessment of cutaneous blood flow in physiological conditions and pathological disorders as well as in reactions to pharmacological stimuli is of considerable interest to dermatologists.

\section{Microcirculation of the skin}

\section{Anatomy}

The arterioles and venules of the cutaneous microcirculation form two important plexus in the dermis: a deep dermal plexus at the dermal/subcutaneous interface formed by perforating vessels from the underlying muscles and subcutaneous fat and a superficial plexus in the papillary dermis from which the nutritive capillary loops of the dermal papillae arise (Braverman, 1997). The capillary loop consists of an ascending limb, an intrapapillary loop with a hairpin turn (apex), and a descending limb that connects with a postcapillary venule in the superficial plexus (fig. 1). Beside the capillaries, arterioles and venules are also directly connected via a shunting system.

Most of the microvasculature is contained in the papillary dermis 1 to $2 \mathrm{~mm}$ below the epidermal surface (Braverman et al, 1977). The thickness of the epidermis is about 30-300 $\mu \mathrm{m}$ depending on the area of the body. The capillary network extending into the dermal papillae has a mean length of approximately $0.2-0.4 \mathrm{~mm}$ and each network supplies an average of 0.04 to $0.27 \mathrm{~mm}^{2}$. The underlying superficial dermis contains $8-10$ arterioles/venules per $\mathrm{mm}^{3}$ with a diameter of 10-35 $\mu \mathrm{m}$ each. In the deep dermal plexus the vessel diameter is in the order of $40-50 \mu \mathrm{m}$.

\section{Physiology}

The microcirculatory blood flow is regulated by central and local mechanisms, implying both the autonomic nervous system and vegetative stimuli. Local metabolic activity plays a role in microcitculation as well as physical factors.

Although the microcirculation contains only about $5 \%$ of the total blood volume, it fulfils vital functions: metabolic exchanges, homeostasis of interstitial fluids, regulation of blood pressure and thermoregulation. Its main goal, however, is to ensure tissue nutrition. Tissue viability is threatened when nutritional circulation is compromised. Cutaneous microcirculation 
Fig 1: Anatomy of microcirculation

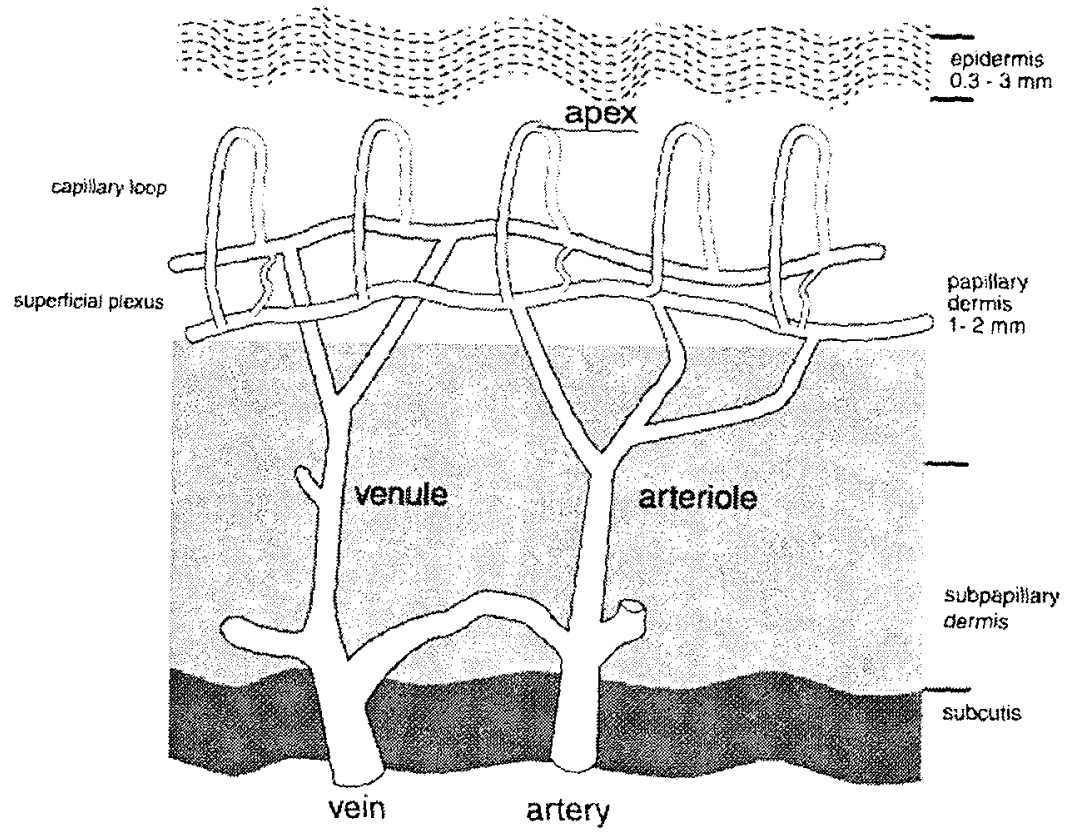

can be divided into a major thermoregulatory blood flow via shunt vessels $(95 \%)$ and a minor nutritive blood flow via skin capillaries $(5 \%)$.

Apart from its physiological function, the dermal microcirculation also plays an important role in the uptake of topical applied medication. The medication itself can influence the tonus of the vessels and consecutively the microcirculation, e.g. in dermatology topically applied corticosteroids, but also in other fields of medicine (e.g. nitro-glycerine or oestrogen plasters). For the uptake of topically applied medicine, their lipophilic/hydrophilic base is of importance in order to pass the stratum comeum. Once passed the stratum corneum drugs will be taken up by the microcirculation.

\section{Pathological states}

The evaluation of the physiology and pathology of the cutaneous microcirculation requires indepth knowledge of the underlying anatomy and function of the microcirculation. Pathology can be anatomic alteration, functional disturbances and a combination of both.

The density and form of the capillaries can be pathologic, as for example in port-wine stains, whereby the number of capillaries is increased but capillaries are dilated as well. On the other hand, a reduction of capillary density can be found, e.g. in atrophie blanche with the most 
distinct abnormalities in the vessels of mainly the superficial dermis. The capillaries are dilated and show tortuous loops.

There can also be a functional disturbance of the microcirculation. A common disturbance is an altered filtration due to the overloaded Starling mechanism. The balance between intravasal and interstitial liquid exchange is in imbalance leading to peripheral oedema as, for instance, in decompensatio cordis or hypalbuminism.

A functional disturbance in livedo reticularis leads to the typical mottling following the pattern of underlying arterioles. The colour changes are believed to be due to the dilatation (erythema) and stagnation of blood within (pale skin) the capillaries and minute vessels in areas of anastomosis between two cones of vessels, each supplied by an arteriole (Braverman et al, 1977).

A functional disturbance of the microcirculation may also result from intracapillary coagulation, often leading to destruction of the vessel and its surrounding nutritional unit. Intracapillary coagulation can be primary or secondary. Most cases are due to secondary factors. Leucocytoclastic vasculitis is a classic example of this. Preexisting disturbances in the clotting cascade, such as factor V Leiden can be a co-factor for microcirculatory thrombosis as in chronic venous insufficiency/leg ulcers (Maessen-Visch et al, 1999). In hypertensive leg ulcers (ulcer of Martorell) microvascular thrombosis leads to severe skin damage.

In chronic venous insufficiency exists a combination of anatomical alterations (low capillary density), a tortuous or glomerulous like aspect and functional disturbances, such as an altered filtration rate and leucocyte trapping.

\section{Measurement of microcirculation}

The skin microcirculation is the most studied topic, because of its accessibility and frequent involvement in various pathological conditions, e.g. peripheral arterial occlusive disease and connective tissue diseases. New horizons have been opened the last decades by the development of new investigation techniques addressing specifically the microcitculation and providing a very localised assessment of the skin microcirculation that conventional (macrocirculatory) techniques cannot provide.

By varying examination techniques it is necessary to establish their diagnostic usefulness and their agreement amongst each other. Differing sites of examination, non-standardised examination parameters and accordingly non-comparable study results from various working groups can interfere with the possibility to compare results from one or several techniques used. Part of the difficulty is also attributable to the structural complexity (e.g. horizontal versus vertical oriented vessels), physiologic fluctuations of erythrocyte flow velocity and the morphologic differences with respect to the site of examination. Standardisation of microcirculatory measurements therefore is of utmost importance.

Skin microcirculation is altered in many physiological and pathological conditions in dermatology and therefore microcirculatory monitoring has a great potential field of 
application. Measuring microcirculation can provide useful and objective information. Besides, for instance, arterial occlusive disease and chronic venous insufficiency, changes in microcirculation can be monitored in inflammatory skin diseases, such as psoriasis and eczema. The dynamic monitoring of treatment effects is also a field of interest. During the last 20 years most of these application fields have been studied using different devices measuring skin microcirculation. Up to now no single device can combine all the attributes necessary for measuring microcirculation (Table 1 ).

\section{Capillary microscopy (videomicroscopy)}

Capillary microscopy was first introduced by Basler in 1919 (Basler, 1919) for the actual measurement of the blood cell velocity in human nailfold capillaries. Zimmer et al refined this technique (Zimmer et al, 1964) utilising a microscope connected to a video camera to allow for non-invasive viewing of superficial blood vessels in the skin. The skin area of interest is placed on the investigation plate and lightly fixated. A drop of immersion oil is applied to make the skin as transparent as possible. The image can be seen on a monitor. All recordings are stored on videotape for further analysis. Computerised set-ups also allow for analysis of capillary morphology and blood flow by a framc-to-frame analysis (Bollinger et al, 1974). Recently, capillary microscopy was coupled with a videophotometric system and used with software (Capiflow(B) to analyse the capillary blood-cell velocity (CBV)(Fagrell et al, 1988). This technique makes it possible to non-invasively study skin capillaries under physiological and pathphysiological conditions. Some applications have been quickly developed to evaluate the dynamic microcirculatory status in peripheral vascular disorders including arterial occlusive disease (Fagrell, 1973), collagen vascular diseases (Ohtsuka et al, 1994), chronic venous insufficiency (Weindorf et al, 1995) and Diabetes mellitus (Chazan et al, 1970).

The advantage of capillary videomicroscopy is that it can visualise capillary flow of the skin. Its disadvantage is that the objective of the microscope is in contact with the skin surface and that the data sets recorded on video(tape) first have to be analysed by special integrated software. Only certain skin areas can be measured, such as the nailfold or the lower leg in, for instance, chronic venous insufficiency.

\section{Transcutaneous oxygen measurement}

So-called cutaneous respiration, which means the absorption of oxygen and the elimination of carbon dioxide through the skin surface, was discovered over a century ago and vigorously studied in the early 1930s by Shaw et al (Shaw et al, 1931). Transcutaneous oxygen measurement $\left(\mathrm{TCPO}_{2}\right)$ measures the partial pressure $(\mathrm{P})$ of oxygen supply of the skin and particularly the perfusion of the papillary capillaries (Huch et al, 1981). It reflects the function of the nutritive skin capillaries, representing the partial pressure of oxygen diffusing from capillaries in the skin. The measurement principle is based on the polarographic technique using the Clark-type electrode, which consists of a cathode, an anode, and electrolyte solution permeable only for gases. Resulting values are proportional to the concentration of arterial 
oxygen measured in mmHg. In order to supply heat to the skin and to regulate the temperature of the electrode, a heating element is placed in the electrode. The measurement probe is attached to the skin and $\mathrm{tcPO}_{2}$ measurement is usually performed at a heated site, because the value is nearly zero in the normal condition as the pressure gradient between normal heated skin and surrounding air is too small. When the skin temperature rises to about $43^{\circ} \mathrm{C}, \mathrm{tcPO}_{2}$ values become close to the $\mathrm{PO}_{2}$ in arterial blood $\left(\mathrm{Pa}_{\mathrm{O}_{2}}\right)$ initialising oxygen perfusion. Therefore, tc $\mathrm{PO}_{2}$ measurement is most advantageously urilised for a non-invasive monitoring to detect sudden changes in $\mathrm{Pa}_{\mathrm{O} 2}$. The device quantifies the cutaneous oxygen content and allows inferences onto the function of the nutritive vessel bed of the skin area under study. The $\mathrm{tcPO}_{2}$ value is determined by many factors related to the supply, diffusion, and consumption of oxygen. $\mathrm{TcPO}_{2}$ measurement is reasonably applied for quantitative estimation of the efficient cutaneous circulation and for the evaluation of the severity of leg ulcers (Franzeck et al, 1984) and decreased $\mathrm{tcPO}_{2}$ values have been found in chronic venous insufficiency (Neumann et al, 1984). In arterial occlusive disease several scientists have reported that $\mathrm{tcPO}$ values of the lower limb can be a good predictor of failure in wound healing (White et al, 1982). It has been applied to several skin diseases, such as atopic dermatitis, psoriasis, lupus erythematodes and many others (Takiwaki et al, 1991).

The disadvantage of $\mathrm{tcPO}_{2}$ is that it is measured under non-physiologic circumstances heating the skin to $43^{\circ} \mathrm{C}$. It is recommended to measure not only resting tc $\mathrm{Po}_{2}$ values, but also its dynamic responses to some stimuli. This makes it a time consuming technique and is, consequently, less suitable for clinical use but more for experimental settings. The advantage of a non-invasive $\mathrm{PaO}_{2}$ monitoring device is its practical use in prematures and sick neonates.

\section{Diffuse reflectance spectrophotometry}

This method has been refined for more than a century, starting with the studies of Bunsen in 1861 (Abel et al, 1896). Diffuse reflectance spectrophotometry (DRS) has been designed for operation in either the ultraviolet (UV), visible, or infrared part of the optical spectrum. This instrument illuminates the skin with rapidly alternating beams of several light wavelengths and measures the reflectance of each. However, the vast majority of clinical experimental data has been obtained from scanning in the visible spectrum where characteristic absorption peaks can be found for a series of important chromophores, e.g. melanin, haemoglobins, bilirubine, and carotene. Changes in skin colour, being interpreted as representing changes in microcirculation can be indirectly assessed by DRS (Merschbrock et al, 1994). It uses the average of the reflected wavelength to derive an erythema index/melanin index. This ratio reflects the oxyhaemoglobin/melanin content in the skin. The erythema index is expected to have a roughly linear relationship with the content of red blood cells in the upper dermis. It is a useful tool to evaluate cutaneous oxyhaemoglobin and deoxyhaemoglobin, the potency of topically or systemically administered vasoactive compounds, to quantify treatment effects 


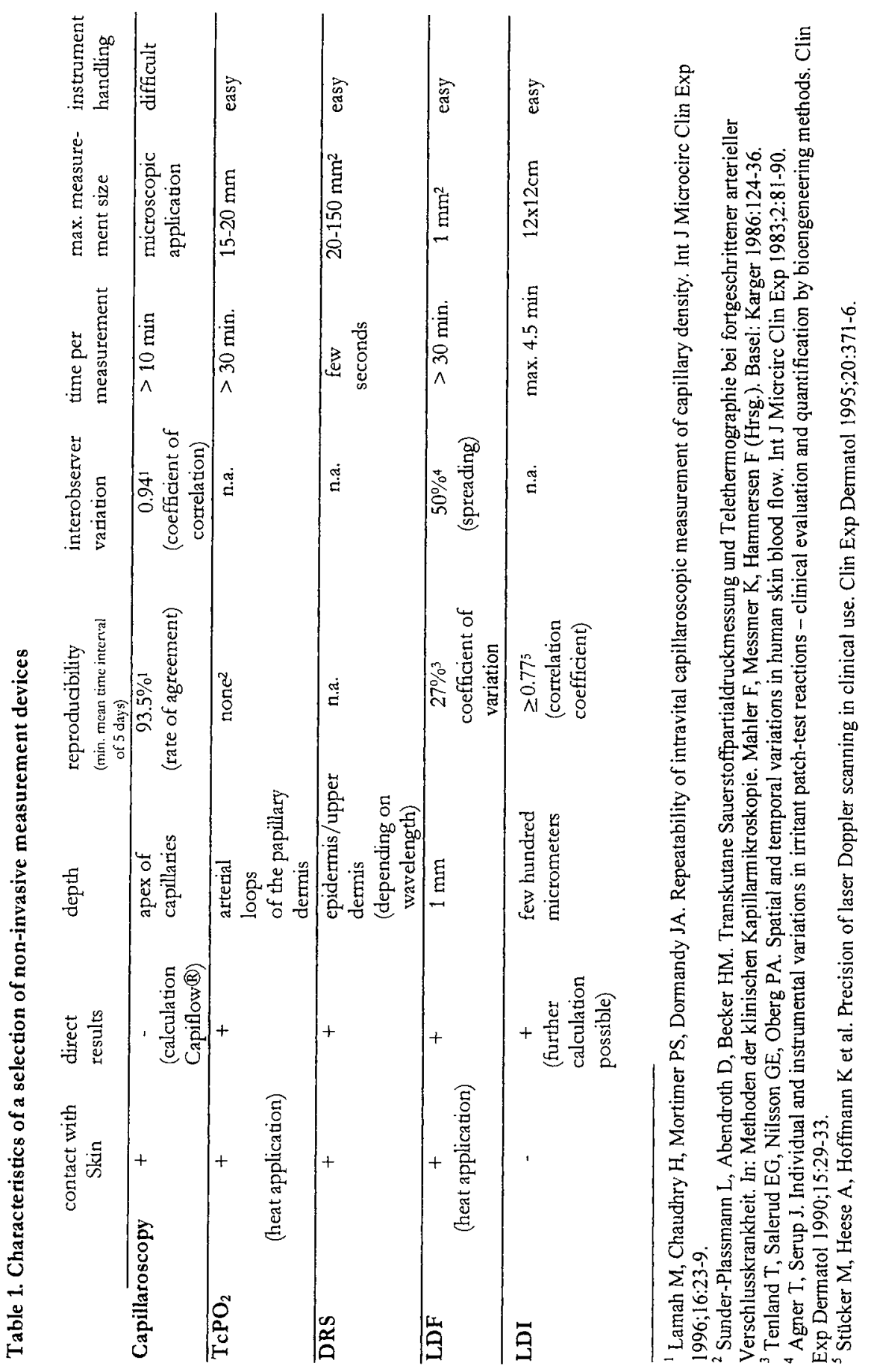


and to evaluate sunscreens after standardised UV-irradiation (Bjerring, 1995).

The disadvantage of DRS is that it has to be positioned on the skin surface with slight pressure in order to perform the measurements. An advantage is that results are directly displayed and that data storage and further software analysis are possible as well. Furthermore, it is possible to measure changes in microcirculation on different levels of the skin blood supply.

\section{Laser Dopplet techniques}

Direct methods, such as non-invasive laser Doppler techniques, as developed in the late 1970s, are no longer a research tool, but are widely used in clinical investigations (Nilsson 1997). Conventional laser Doppler flow device (laser Doppler fluxmetry, LDF) measures a skin surface of $1 \mathrm{~mm}^{2}$ and can readily track fast changes in perfusion, but the small measuring volume prevents assessment of the spatial variability in skin blood flow (Nilsson et al, 1980). Most of the current laser Doppler devices use helium-neon lasers with a wavelength of $632.8 \mathrm{~nm}$. Cutaneous blood flow is measured to an estimated depth of $1 \mathrm{~mm}$, resulting in a theoretical total measured tissue volume of $1 \mathrm{~mm}^{3}$. The penetration depth of laser radiation, however, is somewhat variable. The incident laser light is absorbed, scattered, and only to a small extent reflected by the skin tissue structures (figure 1). Tissue components such as red blood cells moving with a mean estimated of $1 \mathrm{~mm} / \mathrm{s}$, reflect the light with a shifted frequency (optical Doppler effect). The blood flow signal measured by laser Doppler instruments is an indicator of the cutaneous perfusion. However, due to the

Fig 2: laserbeam penetrating the skin

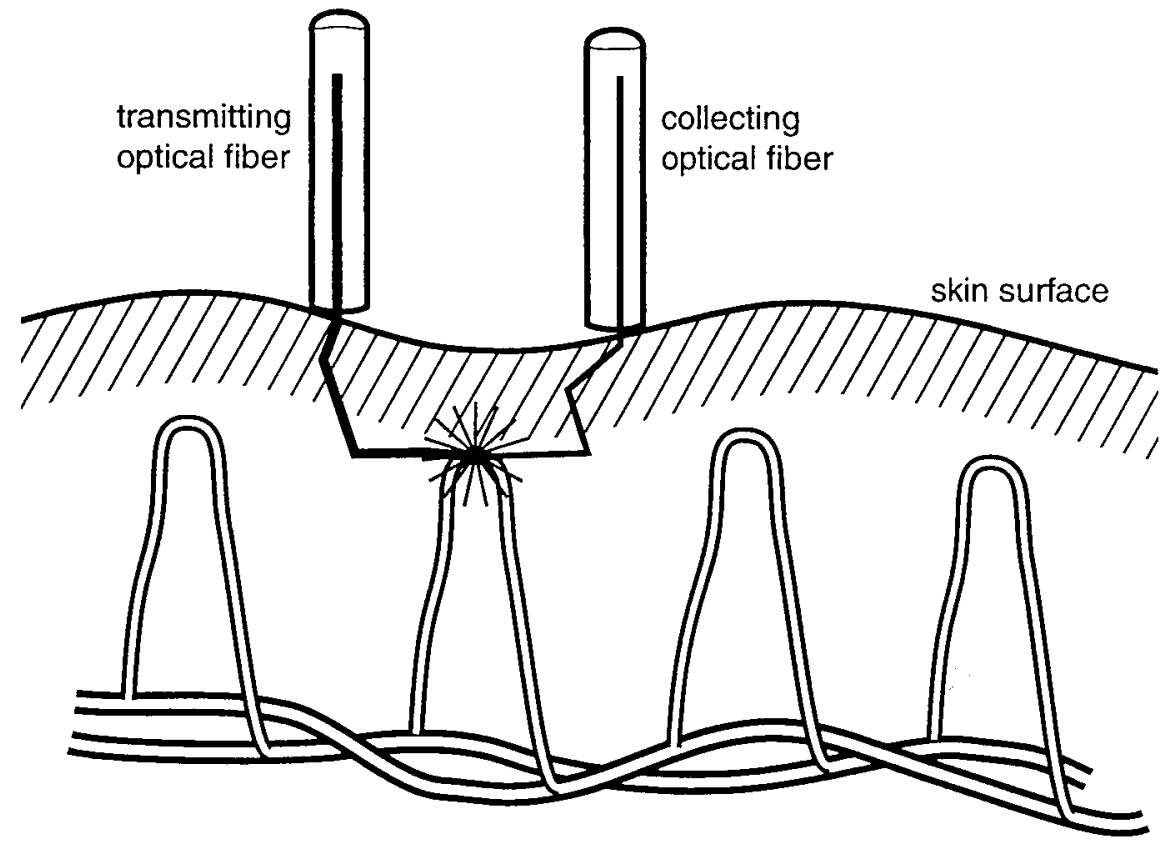


complex structure of the skin texture and somewhat random orientation of the cutaneous vessels, only semi-quantitative, relative measurements of cutaneous blood flow can be made with this technique (Holloway, 1983). LDF has been applied in peripheral arterial occlusive disease (Kvernebo et al, 1988), chronic venous insufficiency (Cheatle et al, 1991), diabetes mellitus (Franzeck et al, 1990), scleroderma (Klycsz et al, 1995) and in plastic and reconstructive surgery (Clinton et al, 1991). Psoriasis, atopic dermatitis (Hull et al, 1989) and the response to patch testing (Staberg et al, 1984) have also been studied.

In order to overcome the limitation of the small measuring volume of LDF, laser Doppler imaging (LDI) was developed in the late 1980s. With this advantage of the new method, it became possible to create two-dimensional flow maps of a specific tissue and to visualise the spatial variation of its perfusion (Wardell et al, 1993). Since then, multiple studies have been conducted and a selection is presented in chapter II as well as a description of the laser Doppler techniques. Just like with every newly introduced technique, its usefulness in experimental and clinical settings has to be proven.

\section{Laser Doppler Imaging measurements}

Recently, a laser Doppler Imager for mapping the 2-dimensional tissue perfusion was developed based on the principle of LDF. The operating principle is described in chapter II. As LDI can be regarded as an important, yet not ideal non-invasive technique to evaluate the skin microcirculation, the major aspects are discussed according to measurement procedure, experimental settings and clinical application.

\section{Scanner head}

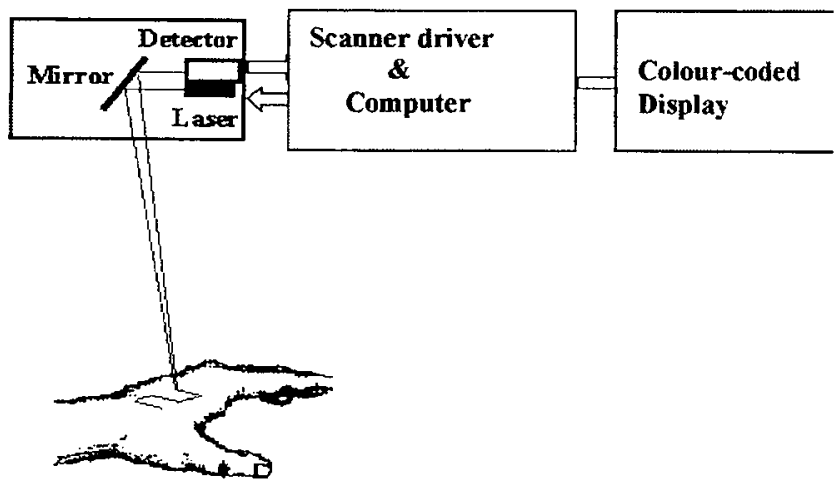

Fig. 3: Split drawing of the LDI scanner head showing laser, mirrors, beam path, object, scanning pattern and detector. 


\section{Measurement standardisation}

Routine use of bioengineering devices may look simple, but proves to be a field with multiple pitfalls. Especially microcirculation is influenced by several factors. Such variables include individual, interindividual, environmental and technical factors. Individual-related variables include age, gender and ethnic background, but also the variability of anatomical location, skin temperature, the subject's position, physical and mental activity, previous consumption of vasoactive substances and to some extent the considerable temporal variation of repeated measurements (Bircher et al, 1994).

To minimise those influences it is important to perform measurements under standardised conditions including a constant ambient temperature $\left(21-25^{\circ} \mathrm{C}\right)$, acclimatisation of the subject before performing the measurement (20-30 $\mathrm{min}$.) and no consumption of vasoactive beverages, drugs or smoking.

Since LDI does not make contact with the skin during measurement, it is likely that interobserver variation does not influence the measurement results. However, this has not been studied yet.

\section{Reproducibility}

The reproducibility of a test method is basic requirement for their use in clinic and science. Several groups investigated the precision of LDI measurements. Values of repeated measurements and measurements performed on different days showed a good reproducibility $r \geq 0.77$ (Stücker et al, 1995). The coefficient of variation for measurements in one subject at rest was 13\% and interindividual 25\% (Svedman et al, 1998). Gschwandtner et al (Gschwandtner et al, 1998) measured arterial and venous leg ulcers and found "an excellent" reproducibility of LDI measurements on a single day (coefficient of variation $9.8 \%$ ) and a poorer reproducibility on 5 different days (coefficient of variation $28.6 \%$ ).

It can be concluded that LDI is suitable for repeated measurements on a single day or subsequent days. Data of different measurements can be compared intraindividually and to a lesser extent interindividually.

\section{Correlation with other methods}

LDF is intended for continuous recordings at a single site, whereas LDI records the perfusion within a specific tissue area. In order to evaluate the device, it was applied to imaging flux changes induced in human skin during the tuberculin reaction (Harrison et al, 1993). Flux values were compared directly with those from conventional lightguide laser Doppler flowmetry, and parameters measured using two other methods for assessment of tissue perfusion, dynamic thermographic imaging and tissue spectrophotometry. The results showed very good correlation between the various methods. It has been demonstrated that LDI and LDF techniques show a significant linear correlation $(r=0.93, p<0.001)$ and that a combination of both facilitate studies of the temporal and spatial variations in skin 
perfusion. Comparing LDI with thermographical mapping, Harrison demonstrated that the regional temperature profile resembled the perfusion values, but the heterogeneity of LDI pixels was not to be seen in thermography. This could be explained by the fact that temperature only is one parameter of skin perfusion, while LDI directly senses the velocity and concentration of the blood cells in the microvascular network. Comparing laser Doppler techniques with spectrophotometry has shown a good correlation $(r=0.88)$.

Seifalian et al compared three non-invasive methods of measuring skin perfusion, thermographic imaging, LDF and LDI (Seifalian et al, 1994). In seven normal volunteers measurements of the left hand were recorded. The measurements were then repeated for a hot $\left(37^{\circ} \mathrm{C}\right)$ and then a cold $\left(10^{\circ} \mathrm{C}\right)$ challenge. A significant linear correlation $(r=0.96)$ was found between LDF and LDI. However, in this study LDF and LDI did not correlate well with thermographic imaging ( $\mathrm{r}=0.577$ ) (either).

In conclusion, LDI measurements show a good correlation with other techniques (LDF and spectroscopy). The discrepancy between LDI and thermography results from the fact that they measure different compartments of microcirculation.

\section{Prospective aspects in laser Doppler imaging and demands of bioengineering devices measuring skin microcirculation}

In 1996, Bornmyr et al (Bornmyr et al, 1996) described a new method for acquisition and analysis of skin perfusion. They combined LDI with a digital photograph of the area scanned. Photographs were obtained with a commercial digital video camera. Software was developed to assess blood flow distribution in detail in relation with the visual appearance of the skin. This method is of use in the follow-up of treatment of chronic skin ulcers or in post-operative evaluation of vascularised grafts.

A new development in laser Doppler measurements is the laser duplex scanning (Wårdell et al, 1996). The duplex mode makes it possible to repetitively scan a single point or quadratic patterns of $2 \times 2$ or $4 \times 4$ pixels. By using the Duplex mode of the laser Doppler imaging system, the temporal variation of the local skin can be recorded. The laser beam is moved to an area of interest at which the temporal variations in tissue perfusion are continuously recorded and presented as a time trace.

In laser Doppler anemometry the laser beam is strongly focused by optical means (Seki, 1990). To measure flow in capillaries and arterioles, laser Doppler anemometry is combined by microscopy and commercially available as CAM-1 (KK-technology, England). In order to be able to measure the blood flow in a single vessel, the diameter of the laser beam must be focused so strongly that it strikes only a single vessel and that all Doppler frequencies are generated in a single vessel. Vessel diameters in the skin are between $8 \mu \mathrm{m}$ at the capillary loop up to $35 \mu \mathrm{m}$ in the arterioles (Braverman, 1989). One must reduce the laser beam by less than a tenth of the diameter of the employed laser beams in the traditional laser Doppler device's. Laser Doppler anemometry measures the flow in a single capillary. 
The advaniage of the new devices is their combination of visualising capillaries and measuring blood flow in one step. The disadvantage is their small area under measurement.

Lately optical coherence tomography (OCT) has been developed permitting non-invasive imaging of the skin (Kehlet et al, 1999). OCT uses a broad-band light source in a Michelson interferometer arrangement to measure light reflected from a small volume of tissue. Changing the length of the interferometer reference arm allows depth scans (analogous to ultrasound A-scans) to be made. By scanning laterally across the tissue, a two-dimensional image can be created. Theoretically visualisation of structures as deep as $1.5 \mathrm{~mm}$ in human skin is possible. The advantage of this newly developed method is the visualisation of the microcirculation, again the disadvantage is the small area under measurement.

\section{Discussion}

Information about function in normal condition and under pathological circumstances is essential for our insight in the skin microcirculation. Preferable for such tools are noninvasive techniques that can be used for continuous measurement to evaluate the changes in microcirculation during a certain time period. Apart from non-invasive, they should also be analytical, versatile, easy to use and cost effective. The non-invasiveness should, if possible, also be extended to imply that the measuring device does not have to be in physical contact with the tissue, because even the weakest external stimuli may disturb the flow conditions of the microcirculatory network under study. Besides, application of immersion oil or local heating as necessary in capillary microscopy, $\mathrm{tcPO}_{2}$ and LDF (not obligatory) both influence the microcirculation and should ideally be avoided. The methods should be analytical in the sense that the blood flow signals may be stored on a hatd disk for any later sophisticated analysis by means of dedicated software packages. In the first place, however, data should be available immediately after the measurement is performed avoiding time-consuming analysis to receive preliminary results. Versatility implies that the same device should be applicable to studies of microvascular perfusion under clinical as well as laboratory conditions. Ease of use and cost-effectiveness are important features, particularly in clinical situations where the measurements need to be done on a routine base. Furthermore, it would be of great advantage to compare quantitative and non-invasive visual skills in one and the same measurement device to gain exact information about the layer of microcirculation and about the number of capillaries involved. Besides that, it would be very useful to develop a depthselective device to focus on different levels of the skin microcirculation. Especially in the field of vasoactive substances it would be of gxeat value to gain depth selective samples. It could be investigated which compartment of the dermal microcirculation is involved and temporal changes during the experiment could be recorded in order to elucidate the underlying working mechanism of the vasoactive substance. 
Very few of the methods described in the literature over the years fulfil all these requirements. Although up to now no ideal microcirculatory non-invasive technique is available, LDI combines important features (Wardell et al, 1995), such as non-invasiveness and application to almost any site of the skin surface. LDI is easy to use, provides immediately the measured data set, but also offers the opportunity for image storage and further software analysis. LDI is applicable in clinical and in experimental settings.

For centuries, dermatology relied basically on visual evaluation of clinical appearance of diseases for diagnosis, in contrast to many medical specialities. In order to describe what one sees, the dermatological nomenclature was introduced basing on the "effluorescenties" which made it possible to group different dermatoses (Darier, 1908). The influence on microcirculation is known in terms as macula, livedo, urtica, purpura, etc. Until now the description of what we, the dermatologists, see on the skin, is the most important approach to diagnose skin diseases, although the eye only sees "the tip of the iceberg". As we know from histopathology, precise differentiation of what we see can often only be made by supporting information of underlying mechanisms in the skin. Between the visual and the histopathologic approach, between looking on and into the skin, there is a need for noninvasive bioengineering techniques providing objective information of microcirculation. 


\section{AIMS OF THE THESIS}

The aim of this thesis is to assess the place of LDI in experimental and clinical settings in dermatology.

LDI is a rather new technique to assess skin microcirculation. The first studies have been published in the 1990s. Since then, LDI has been used by different disciplines (e.g. surgery, neurology, rheumatology, and dermatology). Many questions about the role and place of skin microcirculation in relation to skin diseases remain. The use of this technique creates new possibilities to increase our knowledge in this field. The studies performed in this thesis attempt to answer some of these questions.

\section{Review of the literature}

Is LDI suitable for the assessment of microcirculation in dermatological settings? What are the fields of application of this device in dermatology? In answering those questions the literature of LDI will be reviewed following the method of evidenced based medicine (Bigby, 1998) (chapter II).

Microcirculation in dermatology is not only important in studying underlying pathomechanisms of skin diseases. The effect of treatment modalities such as topically applied agents influence the microcirculation as well. Therefore, both disturbed microcirculation in skin diseases and the effect on microcirculation after treatment will be evaluated by LDI. A choice was made to study chronic venous insufficiency (CVI) - clinical application - and the effect of topically applied corticosteroids - effect of treatment on the microcirculation -, especially because both play a major role in dermatology.

\section{Clinical application:}

All clinical signs of chronic venous insufficiency are the result of the alterations of the skin microcirculation induced by the increased walking venous pressure as a result of failing venous macrocirculation. Studying the microcirculation therefore is of great importance for understanding the clinical syndrome of chronic venous insufficiency.

Telangiectasias are a major part of the clinical manifestation of CVI. They can be one of the first symptoms of changes in skin microcirculation leading to a dilatation of the capillaries. Clinically they can be divided in red and blue telangiectasias. There is no clear understanding why some are red and others blue. There are speculations concerning the origin and oxygenation. The postulated difference in oxygenation was therefore investigated. Velocity in telangiectasias can be different from normal capillaries. Can telangiectasias be discriminated from the surrounding skin microcirculation measured with LDI? If the flux is altered can LDI differentiate between red and blue telangiectasias? (chapter III) 
Microcirculation in patients with CVI is disturbed. Atrophie blanche, as a result of severe CVI and a bad prognostic sign is characterised microcirculatory by morphological and numerous changes of the capillaries. In laser Doppler flux measurement it has been shown that in patients with atrophie blanche values are significantly higher than in healthy controls. Will this be true for a more representative skin surface as well? Is there a difference in flux, measured with LDI, in atrophie blanche lesions and healthy controls? What is the effect of (artificially induced) venous hypertension on the flux in atrophie blanche, and on transcutaneous oxygen values? Is there a different reaction pattern on venous hypertension in patients with CVI with and without atrophie blanche and healthy controls? What is the effect of venous hypertension in capillaries in patients with CVI? (chapter $\mathrm{N}$ )

\section{The effect of vasoactive substances on the microcirculation}

Topically applied corticosteroids induce the blanching phenomenon of the skin. The potency of the steroid is defined by its vasoconstrictive (blanching) effect normally scored visually. We therefore tried to evaluate whether LDI is suitable for a more objective assessment of the vasoconstrictive effect induced by weak and strong working corticosteroids. If so, can effects such as occlusion or the location of the application site on the volar aspect of the forearm be evaluated by LDI? Is LDI as useful as digital reflectance spectrophotometry in detecting the blanching effect? Do value changes of LDI and digital reflectance spectrophotometry correspond? (chapter V and VI)

The studies performed in this thesis were conducted under standardised circumstances to keep variations in LDI measurements as small as possible.

LDI measurements were performed by a single investigator (the promovenda) to exclude interobserver variance. All measurements were performed with the same measurement device (Pim Lisca 1.0, Linköping, Sweden). 


\section{References}

Abel JJ, Davis WS. On the pigment of the Negro's skin and hair. J Exp Med 1896;1:360-401. Astrup PB. Ole Siggard-Andersen - 60 years. Scand J Clin Lab Invest Suppl 1993;214:23-6. Basler A. Über die Bestimmung der Stömungsgeschwindigkeit in den Blutkapillaren der menschlichen Haut. Münch Med Wochenschr 1919;13:347-8.

Bigby M. Evidence-based medicine in a nutshell. Arb Dermatol 1998:134:1609-18.

Bircher A, de Boer EM, Agner'T et al. Guidelines for measurement of cutaneous blood flow by laser Doppler flowmetry. A report from the standardazation group of the European society of contact dermatitis. Contact Derm 1994;30:65-72.

Bjerring P. Spectrophotometric characterization of skin pigments and skin color. In: Handbook of non-invasize methods and the skin. Serup J, Jemec GBE. CRC Press 1995; Chapter 16.1:375.

Bollinget A, Butti P, Bartas JP et al. Red blood cell velocity in nailfold capillaries of man measured by by a television microscopy technique. Microvasc Res 1974;7:61-72.

Bollinger A, Jäger K, Geser A, Sgier F. Transcapillary and interstitial diffusion of Nafluorescein in chronic venous insufficiency with white atrophy. Int J Microcirc Clin and Exp 1982;1:5-17.

Bornmyr $\mathrm{S}$, Mårtensson $\mathrm{A}$, Svensson $\mathrm{H}$. et al. A new device combining laser Doppler perfusion imaging and digital photography. Clin Physiol 1996;16:535-41.

BravermanIM, Yen A. Ultrastructure of the human dermal microcirculation: II. The capillary loops of the dermal papillae. J Invest Dermatol 1977;68:44-52.

Braverman IM. The cutaneous microcirculation: ultrastructure and microanatomical organization. Microcirculation 1997;4:329-40.

Chazan BI, Balodimos MC, Larine RL et al. Capillaries of the nailfold in diabetes mellitus. Microvasc Res 1970;2:5047.

Cheatle TR, Shami SK, Stibe E et al. Vasomotion in venous disease. J Roy Soc Med 1991;84:2613.

Clinton MS, Sepka RS, Bristol D et al. Establishment of normal ranges of laser Doppler blood flow in autologous tissue transplant. Plastic Reconst Surg 1991;87:299-309.

Darier J. Morphologie des dermatoses. In: Massan,Paris;1908. Prícis de dermatologie.

Fagrell B. Vital capillary microscopy - a clinical method for studying changes of the nutritional skin capillaries in legs with arteriosclerosis obliterans. Scand J Clin Lab Invest 1973;Suppl 133.

Fagrell B, Eriksson SE, Maimstrom S, Sjolund A. Computerized data analysis of capillary blood cell velocity. Int J Microcirc Clin Exp 1988;7:276.

Franzeck UK, Bollinger A, Huch R et al. Transcutaneous oxygen tension and capillary morphologic characteristics and density in patients with chronic venous incompetence. Circulation 1984;70:806-11.

Franzeck UK, Stengele B, Panradl U et al. Cutaneous reactive hyperemia in short term type I diabetes - continous monitoring by a combined laser Doppler and transcutaneous oxygen probe. $V A S A$ 1990;19:8-15.

Harrison DK, Abbot NC, Swanson Beck J. et al. A preliminary assessment of laser Doppler perfusion Imaging in human skin using the tuberculin reaction as a model. Pbysiol Meas 1993;14:241-52.

Holloway G. Laser Doppler measurement of cutaneous blood flow. In: Rolfe P. Non-invasive pbysiological measurements. Academic Press, New York 1983:219. 
Hull SM, Goodfield M, Wood EJ et al. Active and inactive edges of psoriatic plaques: identification by tracing and investigation by laser-Doppler flowmetry and immunohistochemical techniques. I Invest Dermatol 1989;31:301-7.

Huch R, Huch A, Luebbers DW. Transcutaneous Po2. New York: Thieme-Stratton 1981.

Jansen-Genzel W, Wienert V, Wrobel K. Die Fluorescein-Clearance zum Nachweis der Wirkung von Kompressionsstruempfen auf die venolymphangische Drainage des Beines. Onthopaedie-Tecbnik 1995;5:443-8.

Jünger M, Steins A, Hahn M, Hafner HM. Microcirculatory dysfunction in chronic venous insufficiency (CVI). Microcinulation 2000;7:S3-12.

Kehlet, B., Izatt, J.A., and Kulkarni, M.D. (1999). Three-dimensional reconstruction of blood vessels from in vivo color Doppler optical coherence tomography images. Dermatology 1999;198:355-361.

Klycsz T, Hahn M, Jünger M. Laser-Doppler-Flux-Messungen zur Therapiekontrolle bei zirkumskripter Sklerodermie. Hautart 1995;46:421-4.

Kvernebo K, Slagsvold CE, Stranden E et al. Laser Doppler flowmetry in evaluation of lower limb resting skin circulation. A study in healthy controls and atherosclerotic patients. Scan J Clin Lab Invest 1988;48:621-6.

Landis EM. The capillary circulation. In: Fishman AP, Richard EW (Eds): Circulation of the blood. Oxford University Press, New York 1964, p. 355.

Maessen-Visch MB, Hamulyak K, Tazelaar DJ, Crombag N, Neumann HAM. The prevalence of factor $\mathrm{V}$ Leiden mutation in patients with leg ulcers and venous insufficiency. Arch Dermatol 1999;135:41-4.

Merschbrock U, Hoffmann J, Caspary L. et al. Fast wavelength scanning reflectance spectrophotometer for noninvasive determination of hemoglobin oxygenation in human skin. Int J Microcin 1994;14:274-81.

Neumann HAM, van Leeuwen M, van den Broek MJTB, Berretty, PJM. Transcutaneous oxygen tension in chronic venous insufficiency syndrome. $V A S A$ 1984;13:213-9.

Nilsson GE, Tenland T, Oberg BA. Evaluation of a laser Doppler flowmeter for measurement of tissue blood flow. IEEE Trans Biomed Eng 1980;27:597-604.

Nilsson G. Laser Doppler Perfusion imaging for assessment of cutaneous microcirculation. Phlebologie 1997;26:87-91.

Ohtsuka T, Ishikawa H. Statistical definition of nail fold capillary patterns in patients with systemic sclerosis. Dermatology 1994;73:317-24.

Shaw LA, Messer A. Cutaneous respiration in man. III. The permeability of skin to carbon dioxide and oxygen as affected by altering their tension in the air. Am J Pbysiol 1931;98:93.

Stücker M, Heese A, Hoffmann K et al. Precision of laser Doppler scanning in clinical use. Clin Exp Dermatol 1995;20:371-6.

Seifalian AM, Stansby G, Jackson A. et al. Comparison of laser Doppler perfusion Imaging, laser Doppler flowmetry and the thermographic imaging for the assessment of human blood flow in human skin. Eur J V asc Surg 1994;8:65-9.

Staberg B, Klemp P, Serup J. Patch test responses evaluated by cutaneous blood flow measurements. Arch Dermatol 1984;120:741-3.

Svedman C, Cherry GW, Strigini E et al. Laser Doppler Imaging of skin microcirculation. Acta Derm Venereol (Slockb) 1998;78:1148.

Takiwaki $\mathrm{H}$, Arase $\mathrm{S}$, Nakanishi $\mathrm{H}$ et al. Transcutaneous PO2 and PCO2 in various skin lesions. J Dermatol 1991;18:311. 
Von Brunn WL. Kreislauffunktion in William Harvey's Schriften. In: Springer, Heidelberg 1967.

Wårdell K, Jakobson A, Nilsson GE. Laser Doppler perfusion Imaging by dynamic light scattering. IEEE Trans Biomed Eng 1993;40:309.

Wårdell K, Nilsson GE. Laser Doppler Imaging of skin. In: Handbook of non-invasive methods and the skin. Serup J, Jemec GBE. CRC Press 1995; Chapter 17.4:421-8.

Weindorf NG, Schultz-Ehrenburg U. Capillary microscopic findings in patients with CVI under different hydrostatic conditions. J Cardiovasc Surg 1995;36:399-401.

White RA, Nolan L, Harley $D$ et al. Noninvasive evaluation of peripheral vascular disease using transcutaneous oxygen tension. Am J Surg 1982;144:68.

Zimmer JG, Demis DJ. The study of the physiology and pharmacology of the human cutaneous microcirculation by capillary microscopy and television cinematography. Angiology 1964;15:232-5. 


\section{Chapter II}

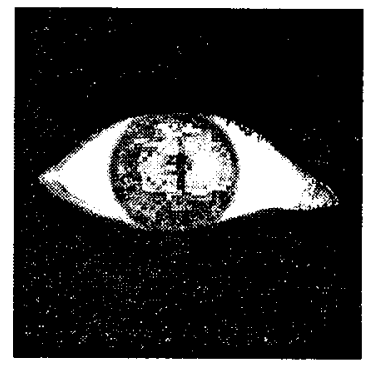

MICROCIRCULATION OF THE SKIN ASSESSED BY LASER -DOPPLER- IMAGING:

REVIEW OF THE LITERATURE AND CLINICAL RELEVANCE FROM A DERMATOLOGICAL POINT OF VIEW

A. Sommer, A.P.G. Hocks, H.A.M. Neumann

Submitted for Publication 


\begin{abstract}
Objective: Assessing microcirculation in dermatological diseases that go along with hyperand hypoperfusion can give insights in the underlying pathomechanisms. Objective information about the microcirculation can be obtained by non-invasive biotechnology.

Laser Doppler imaging is a recently developed technique to assess microcirculation of the tissue. Several studies have been performed using this technique. The question is what is the experimental and clinical use of LDI.
\end{abstract}

Data sources: Litetature searches were performed via the Lisca literature and reference service data base and via the Medline standard computer database (US National library of medicine, Bethesda, Md) and the Medline advanced (internet) database for the time period from 1980 until 2001 constraining on studies performed on human skin and on European languages with the key words laser Doppler, laser Doppler imaging, laser Doppler perfusion imaging.

Study selection: All studies performed in the field of dermatology or dermatology related fields were selected.

Methods: Therefore the literature was systemically reviewed and a critical selection of prospective studies related to dermatology was made (English and German, no exclusion because of the language was necessary).

Results: In total 59 articles were selected and reviewed. The content of these articles is summarised and the experimental and clinical use of LDI in dermatology is discussed.

Conclusions: While many instruments are available, these techniques are limited by small test site area, and/or inconclusive correlation with clinical response. LDI combines the most important qualities of those techniques to measure microcirculation offering a non-invasive technique with a reasonable test size area, good reproducibility and a good correlation with clinical observations. With a maximum time of 4 minutes per measurement it can be used in daily routine and it can help establish a quantitative assessment of diseases and their response to treatment. 


\section{Introduction}

Microcirculation of the skin plays an important role in the function and the maintenance of human skin. For that reason, objective information about the microcirculation is mandatory for our knowledge about the healing process of different skin diseases. 'The measurement of cutaneous blood flow is of importance in chronic diseases, such as chronic venous insufficiency and its symptoms like venous leg ulcer and atrophy blanche. But also acute dermatoses show a disturbed microcirculation, such as acute irritant dermatitis, crysipilas or in reconstructive flaps after dermato-surgical treatment.

The knowledge about the cutaneous microcirculation has developed during the past 25 years, but there is still a need of experimental research techniques to evaluate the ultrastructure and organisation of dermal skin blood flow in physiological and pathological states.

Methods for assessing the skin blood flow should preferably be non-invasive and easy to use. The non-invasiveness should also imply, that the measuring device does not have to be in physical contact with the tissue to avoid skin irritation and affecting the microcirculatory flow conditions. Moreover, it should reveal local inhomogeneity in the cutaneous circulation. Laser Doppler Imaging (LDI) is a method which combines these components all in one device. LDI influences the microvascular network only to a minimal extent during measurements and provides spatial and temporal flow information explaining its relevance in the laboratory and in clinical settings.

The aim of this article is to assess from a dermatological point of view the clinical relevance of laser Doppler imaging and its application based on a review of the literature.

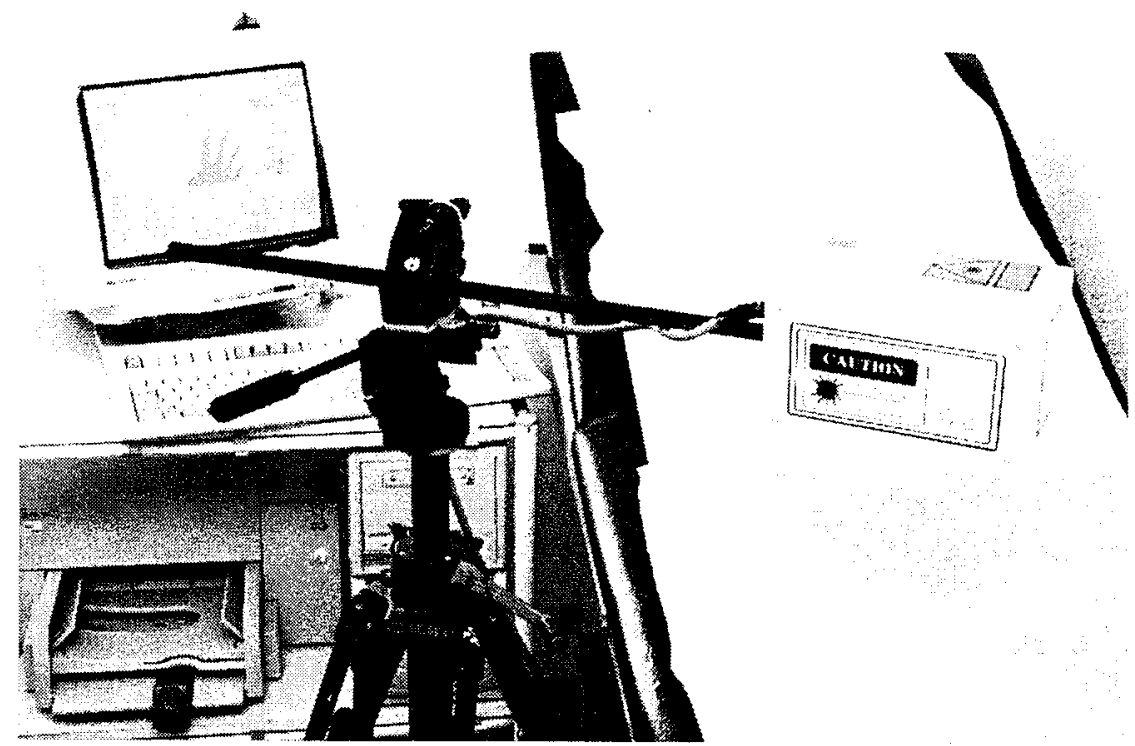

Fig I: Laser Doppler Imaging device (Pim Lisca, Linköping, Sweden) 


\section{Measurement of microcirculation}

The skin microcirculation is frequently involved in various pathological conditions, e.g. peripheral arterial occlusive disease and connective tissue diseases. Changes in microcirculation have been extensively investigated with different techniques. The last decades new horizons have been opened by the development of new investigation techniques addressing specifically the microcirculation and providing a very localised assessment of the skin microcirculation that conventional macrocirculatory techniques cannot provide. Changes in skin colour, being interpreted as representing changes in microcirculation can be indirectly assessed by reflectance spectrophotometry (Douven et al, 2000). Direct methods, such as non-invasive Laser Doppler techniques, as developed in the late 1970's, are no longer a research tool, but are used widely in clinical investigations (Nilsson 1997). Originally only single site laser Doppler flowmetry (LDF) was available but recently the application has been extended with 2-dimensional scanning techniques, known as laser Doppler imaging (LDI).

\section{A. Laser Doppler measurement (LDF and LDI)}

Common for all (laser) Doppler systems is that they can only assess the velocity component along the line of sight. Flow perpendicular to the laser beam, e.g. in the superficial and deep plexus, hardly contributes to the velocity output of the system. When the laser light enters the tissue it is scattered in a diffuse way throughout the tissue matrix and consecutively the individual photons interact with the red blood cells in the different vessels under random angles. Therefore flow both perpendicular to or parallel with the skin surface will contribute to the generation of the Doppler components. The magnitude of the laser Doppler signal and the absolute frequency shift are available for detection in the LDF and LDI receivers.

\section{Laser-Doppler-flowmetry $(L D F)$}

In the early $80^{\prime} \mathrm{s}$ Laser Doppler flowmetry (LDF) has been developed and has been used during the subsequent decades for cutaneous blood flow measurement (Nilsson, 1980). The technique is based on a laser beam for penetration of the tissue and gauging the skin perfusion by means of the Doppler shift of the reflected light. The sample volume in the skin is of the order of $1 \mathrm{~mm}^{3}$. This flowmetry, accomplished with a fine, fiberoptic conductor, is particularly suitable for determining acute temporal changes in perfusion induced by physiological and pharmacological stimuli. However, tissue perfusion exhibits a considerable degree of spatial heterogeneity such that measurements of flux only millimetres apart may yield very different results and repeated measurements are of no value. 


\section{Laser-Doppler-Imaging (LDI)}

Recently, a laser Doppler Imager (LDI) for mapping the 2-dimensional tissue perfusion has been developed based on the principle of LDF (Wårdell et al. 1993). Beside temporal changes in skin perfusion this technique is also able to determine spatial changes in skin microcirculation.

The non-invasive LDI eliminates the need of a probe affixed to the skin and allows measurement of a more representative sample of microvascular perfusion up to a skin area of $50 \times 50 \mathrm{~cm}$ (depending on the system used). A two-dimensional map of the skin perfusion, based on several thousand measurement sites is produced within minutes. A mean perfusion value is obtained for skin blood flow over the skin area.

\section{B. Definitions}

For the interpretation of the results some definitions are important to know. Especially since some of the terms are ambiguously used in literature.

Microcirculation: Microcirculation may be defined as the blood circulation in arterioles $(<300 \mu \mathrm{m})$, capillaries and venules (Rhodin, 1981). Some authors also included the lymphatic vessels and the interstitium in the definition (Ryan TJ, 1983).

Flow: Flow is defined as a volume moving per time interval (liters/min). Bloodflow is far from being constant, on the contrary, it is dynamically regulated to fulfil the requirements of the organism.

Perfusion: Perfusion is defined as flow through a tissue volume or tissue mass on a macroscopic scale (liter $/ \mathrm{min} / \mathrm{kg}$ )

Flux: Flux is defined as quantity going through a surface per unit of time (itcr $/ \mathrm{min} / \mathrm{m}^{2}$ ). Flux is a theoretically introduced term after the laser Doppler shift method to measure blood flow was introduced. Replacing, in an experimental setting, blood with saline, the laser Doppler device would give a zero output as there are no scattering particles to produce a Doppler shift. Other techniques, not basing on the Doppler principle would give approximately the same value of flow. However, it is reasonable to suppose that in most physiological and clinical situations even with a variable relationship - due to the fact that blood cells are not homogeneously distributed - laser Doppler flux and flow have a good correlation. For the daily use in terms of skin microcirculation measured by laser Doppler either the term flow or flux can be used, but should be used consistently.

Commonly measurement results attained by laser Doppler measurement are given in millivolts $(\mathrm{mV})$ or arbitrary units $(\mathrm{a} U)$. 
Vasomotion: Small arteries and arterioles present intrinsic, rhythmical variations of their calibre (4-6/min), where the frequency and relative amplitude increase as diameter decreases. Vasomotion is essential to regulate the distribution of blood flow in capillaries (Bongard et al, 1993).

Temporal resolution: Temporal resolution is the minimum time required to establish a value. On the short term the temporal variation is caused by the pulsatile blood stream caused by the cyclic variation in blood pressure. To measure this variation measurements of a single point must be shorter than $10 \mathrm{~ms}$. In addition, the mean blood flow gradually adapts to the need of nutritional supply, which also shows temporal variation. The duration of a single measurement (up to 4 minutes) masks the short-term temporal changes in blood flow, but the slow flow adaption is revealed by repeated scanning. Day-to-day recordings from the same skin area in the same subject may give rise to substantial variations in the assessed average perfusion, mainly due to real temporal variations in blood flow. The precision of LDI in clinical settings has been found to possess a day-to-day reproducibility with a correlation coefficient of 0.78 or better (Sörensen et al, 1996).

Spatial resolution: Spatial resolution is the minimum distance between capillaries that can be resolved. The spatial density of dermal capillaries among healthy individuals is strongly influenced by territorially differences - from 30 to 50 in the dorsum of the foot to approximately 70 capillaries $/ \mathrm{mm}^{2}$ in toes (representing a spacing of about $0.12 \mathrm{~mm}$ ), on the thigh $29 / \mathrm{mm}^{2}\left(0,25 \mathrm{~mm}\right.$ spacing) and in the face $155 / \mathrm{mm}^{2}(0.05 \mathrm{~mm}$ spacing) (Bollinger et $\mathrm{al}, 1986)$. In practice, the spatial resolution of single measurement points are restricted to the diameter of the laser beam $(1 \mathrm{~mm})$. Braverman et al (Braverman et al,1990) demonstrated through the use of biopsies that the observed heterogeneous laser Doppler patterns coincide with the underlying anatomical microvascular segments, which is described in literature as spatial heterogeneity.

According to a low- or high resolution mode of the LDI the acquisition resolution may be changed within the range of approximately $0.5 \mathrm{~mm}$ (overlapping measurements) to $2 \mathrm{~mm}$ (Wårdell et al, 1995).

The substantial spatial variation in skin blood flow makes it very difficult to demonstrate significant changes in perfusion by conventional Doppler flowmetry if the probe has to be removed and repositioned in stimuli-response experiments. Using LDI, this problem is eliminated by treating the image as a multi-point data set, the average value of which can easily be proven to be significantly altered as a response to the slightest stimuli.

Background signal: The device itself provokes a minimal signal even when the scanner head is not activated, known as electrical zero, instrumental zero or noise level. The noise limited resolution of the LDI system has been determined to be within $0.5 \%$ of maximum value. Besides, a tissue even can evoke a signal in the absence of vascular flow, known as the 
biological zero. The origin of the biological zero remains unknown but it is suggested that "residual movement of entrapped blood cells and other moving constituents of living tissue such as vessel wall activity, hair follicles and sweat gland production" contribute to the background signal (Fagzell et al, 1995). For LDI measurements the "zero"-level of the system is not identical for all pixels. Yet for all pixels the same correction for the background signal is applied to obtain a measurement value representing the laser Doppler signal (Wårdell et al, 1995).

Penetration depth: In literature the penetration depth of the LDI varies between $0.2 \mathrm{~mm}$ (Nilsson G., 1997) and a few millimetres (Wårdell et al, 1995). Though the sampling depth sensitivity function has a maximal value in the region of the superficial capillary network, the bulk of the skin blood flow perfusing the deeper dermal layers probably constitutes the source of the major part of the recorded Doppler signal (Jakobsson et al, 1992)

\section{Opetating principle $L D I$}

Presently two different companies distribute LDI devices: Moor LDI ${ }^{\mathrm{TM}}$ (Moor instruments Ltd, England) and Lisca Pim 1.0 (Linköping, Sweden) (table 1). Both operate on a $632.8 \mathrm{~nm}$ He-Ne laser beam. The main difference between the Lisca and the Moor system is that the Lisca system utilises step-wise scanning (and keeps the beam still when the Doppler signals are recorded), while the Moor system uses continuous scanning (which has a tendency to generate movement artefacts).

\section{Lisca Pim (Linköping, Sweden)}

The LDI scans the tissue using a $1 \mathrm{~mW}$ helium-neon laser beam with a wavelength of 632.8 $\mathrm{nm}$. The laser beam has a diameter of $0.8 \mathrm{~mm}$ and the beam is slightly divergent. A scan consists of maximal $4096(64 \times 64)$ points over an area of max. $120 \times 120 \mathrm{~mm}^{2}$ (sample spacing $1.8 \mathrm{~mm}$ ). Measurements are executed while the beam is stationary. A pair of mirrors, the positions of which are controlled by two stepping motors, directs the laser light to the tissue. The laser light penetrates the tissue a few hundred micrometers (Warrdell et al, 1995). The Doppler broadened light backscattered by moving red blood cells, is detected by a photodetector positioned in the scanner head. The photocurrent is processed to form a signal proportional to tissue perfusion. This procedure is repeated for each sample site. The measurements are stored in real time on a microcomputer and subsequently displayed as an image with each pixel colour-coded on a six-point scale. To extract the perfusion data, analysis functions are incorporated in the software. Values are displayed as arbitrary units or milli Volt (Wårdell et al, 1994). 


\section{Moor LDITM (Moor instruments Ltd, UK)}

The system is based on a $2 \mathrm{~mW}$ helium-neon laser with a wavelength of $632.8 \mathrm{~nm}$, the light reflected by a mirror on to an area of skin and the light remitted from the skin is returned by the mirror and a series of lenses to photodiodes. The signal from the photodiodes is processed following the same principle as described above. The distance between the mirror and the skin surface is not critical, allowing whole body or more detailed small-area scans to be performed. At the closest scanning distance of $60 \mathrm{~cm}$ a skin surface area of approximately $15 \times 15 \mathrm{~cm}$ is defined, each pixel then representing a skin surface area of approximately $1 \mathrm{~mm}^{2}$ (256x256 pixels, equivalent to an image approximately with 65.000 pixels). Each scan is completed in $6 \mathrm{~min}$. ( $6 \mathrm{~min}=6 \times 60=360 \mathrm{sec}$, corresponding with 256 lines) irrespective of the area under study. The sample time per pixel is at least $4 \mathrm{~ms}$. Using a continuous smooth scanning motion at this rate, the line time is $1 \mathrm{sec}$. (360 lines per measurement) (Essex et al, 1991).

Table 1. Commercially available laser Doppler devices

\begin{tabular}{|lcc|}
\hline & \multicolumn{1}{c}{ Lisca Development } & Moor Instrument \\
\cline { 2 - 3 } Laser/ wavelength & $632.8 \mathrm{~nm}$ & $632.8 \mathrm{~nm}$ \\
max. test size area (pixels) & $64 \times 64$ & $256 \times 256$ \\
max. test size area (cm) & $12 \times 12 \mathrm{~cm}^{2} *$ & $50 \times 50 \mathrm{~cm}^{2}$ \\
min. test size area (cm) & $1 \times 1 \mathrm{~cm}^{2}$ & $5 \times 5 \mathrm{~cm}^{2}$ \\
Scannet head distance & $15-30 \mathrm{~cm}$ & $20-100 \mathrm{~cm}$ \\
Speed/ pixel & $50 \mathrm{msec}$ & $4-50 \mathrm{msec}$ \\
Time/measurement & seconds- $4.6 \mathrm{~min}$ & $2-6 \mathrm{~min}$ \\
Ambient light during & should be kept to a & no influence \\
measurement & minimum & \\
\hline
\end{tabular}

\footnotetext{
*A new developed Lisca system allows for day-light scanning and larger skin areas.
} 


\section{Studies}

\section{Data Search}

Articles for this review were selected from the Lisca literature and reference service data base 3.0 (Linköping, Sweden). Secondly a search was performed via the Medline standard computer database (US National library of medicine, Bethesda, Md) and the Medline advanced (internet) database for the time period from 1980 until 2001 with the key words laser Doppler, laser Doppler imaging, laser Doppler perfusion imaging. Medical and bioscience literature was selected. References of so found articles were screened for articles about laser Doppler imaging. A selection of articles for dermatology and dermatological related fields was made. Prospective studies were included. All articles were written in either English or German. No articles had to be excluded because of the language. Only studies performed on human skin were included. Articles were split up in different sub disciplines and will be discussed separately. (Table 2). Unless otherwise stated, studies were performed by a PIM Lisca (Linköping, Sweden).

\section{General application}

Major potential fields of LDI application include dermatology (venous insufficiency, skin irritant and consumer product testing, evaluation of portwine stain therapy and psoriasis), plastic surgery (flap two dimensional mapping), general surgery (peroperative organ imaging), vascular surgery (peripheral skin perfusion), neuropathy assessment (axon reflex response), and vasoactive drug evaluation.

\section{Results}

\section{Allergology and skin irritation}

Objective assessment of patch-test reactions and patch-test optimisation through control of allergen purity, stability of the test materials, choice of vehicle and test systems has been the subject of recent developments. An objective method, such as LDI, can help in these efforts (Bjarnasson et al, 1999).

Ideally the patch-tests should be executed on a skin area allowing a flat scan for the LDI. The skin should be free from visible pathological skin conditions.

Fischer et al (Fischer et al, 1999) using the LDI studied the relation between different types of tape and the intensity of skin reactions, and found the tapes to be of importance of developing an irritant patch-test reaction. It was also pointed out, that erythema, obviously after tape removal, may interfere with assessment of perfusion caused by the test substances themselves. Because of this, an acclimatisation period should be encouraged between the detachment of tape and before reading. 
Bjarnason et al (Bjarnason et al, 1999) re-tested 20 subjects for a patch-test response to budesonide. Multiple readings were taken visually and with LDI up to $264 \mathrm{~h}$ after patch-test application. Different dose levels and application times affected unpredictably the highest reaction assessments. LDI provided the same information as visual scoring and, at all dose levels, both LDI and visual assessments distinguished between subjects who became visually positive at some time during the study and those who did not. Further, edge reactivity in budesonide patch-tests may be an indicator of a strong suppressed test response where LDI assessment helped to confirm early edge reactivity (Bjarnason et al, 1999).

In other studies (Bjarnason et al, 1998), reactions after nickel sulfate and kathon CG patchtesting were assessed by visual scoring and LDI. Compared to visual inspection LDI responded faster and more sensitive to the patch-test.

Möller et al (Möller et al, 1999) observed in 5 patients with contact allergy to gold positive reactions to patch tests with serial dilutions of gold sodium thiosulfate. Patients were given one intramuscular injection of gold sodium thiomalate which resulted in a flate-up of patch tests. The flaring test sites were observed by LDI. An increased cutaneous blood flow in the formerly positive patch tests was discernible within one hour after provocation, reaching a vigorous maximum after $4-6 \mathrm{~h}$ and subsiding during the following days. It is concluded tiat LDI provides a most suitable technique for studying the dynamics of this rapidly developing inflammation with a mainly dermal character.

Stücker et al (Stücker et al 1995) examined the microcirculatory pattern of cellular immunity reactions to recall antigens, which were applied using a test stamp (Multitest Merieux®). The measurements were performed before application as well as $10 \mathrm{~min}, 24,48$ and $72 \mathrm{~h}$ afterwards. The mean flux and the expansion of the hyperemia were at their peak after $48 \mathrm{~h}$. The flux values were at a maximum in the centre of the inflammatory reaction and dropped continuously towards the periphery. It is concluded, that the subclinical pattern of skin perfusion as a response to an inflammatory reaction can be measured with LDI.

By the use of a tuberculin reaction model it was demonstrated that during the reaction very large spatial gradients in tissue perfusion could be found within a range of only $2 \mathrm{~mm}$ and that focal centres of low perfusion values surrounded by higher values are present not only at the centre but also elsewhere within the lesion (Harrison 1993).

Irritant dermatitis, as seen after application of calcipotriol dilutions, were also studied with LDI (Fullerton et al 1998). Several dilutions were patch-tested on the back of 180 healthy subjects in order to establish a non-irritant patch-test concentration. The test sites were measured by LDI on the third day after application. A clear-cut dose-response relationship was found, with higher calcipotriol concentrations resulting in higher cutaneous blood flow (highest calcipotriol concentration $1.58 \mathrm{aU}$, lowest concentration $1.0 \mathrm{aU}$ ). The highest calcipotriol concentration without an increase in LDI value was considered to be the threshold for future allergy patch testing.

Summarising an agreement is found between visual and laser Doppler imaging assessment scoring reactions after patch test responses due to different substances testes, such as 
budesonide, nickel sulphate and kathon CG. It is shown that LDI can detect positive patchtest reactions faster and sometimes even more sensitive. It is not mentioned whether LDI gives additional information to interpret the severity of the reaction or that it helps to differentiate between a toxic and an allergic reaction. Still, in the future the interpretation of patch-test reactions could be facilitated by LDI because of its objective assessment of the spatial perfusional heterogeneity in patch-tests.

\section{Phlebology}

In phlebology chronic venous insufficiency (CVI) is an important clinical disorder. CVI is a complex of symptoms caused by venous reflux, due to valvular incompetence of deep, superficial and/or perforating veins, and leading to an increased ambulatory venous pressure. The increased venous pressure of the macrocirculation is transmitted retrogradely into the microcirculation of the skin, resulting in changed function and morphology of capillaries. All well-known skin changes in CVI are the result of the disturbed (macro-) and microcirculation. Laser Doppler flowmetry (LDF) readings are significantly increased in patients with CVI (Leu et al, 1995). Both a decreased vasoconstrictor response in standing patients with severe $C V I$, as an unchanged vasoconstrictor reaction in medium to severe CVI has been described (Cheatle et al, 1991). Only recently published articles studied CVI with laser-Doppler imaging (Maessen-Visch et al, 1998; Cheatle et al, 1995; He et al, 1997; Svedman et al, 1998; Gschwandtner et al, 1998, 1999).

He et al (1997) investigated the effect of postural change on the microcirculation of venous ulcers. A standard protocol of stabilisation ( 20 minutes), limb dependency (1 hour), and reelevation (2 hours) was used in 10 patients with venous leg ulcers. LDI was performed of the ulcer, respectively of the surrounding skin. The first measurement took place 20 minutes after stabilisation of the leg in a horizontal position. Measurements were repeated immediately beforc re-elevation and at 20,60, and 120 minutes thereafter. The results show that at all time points mean perfusion values in the ulcer were greater than those in the intact surrounding skin. When the leg position was changed from supine to dependency, the LDI perfusion values decreased significantly. After leg re-elevation, blood flow returned slowly to and often eventually exceeded baseline levels. It was concluded that the observed LDI values could be interpreted as relative ischemia induced by dependency followed by hyperperfusion during recovery.

Svedman et al (1998) investigated venous leg ulcers and adjacent skin with LDI in 12 patients and 8 age-matched controls. Measurements took place with the leg supine at a horizontal position and after 20 minutes of dependency. It was found that the level of perfusion in the ulcer and in the ulcer edge was higher than in the intact skin. Dependency of the lower leg resulted in vasoconstriction within the ulcer and in the adjacent skin. The relative magnitude of the veno-arteriolar reflex, determined in percent of the respective baseline value, was fairly similar for patients and controls. In conclusion this article supports 
the finding that LDI values are elevated in venous ulcers and that dependency of the lower leg resulted in vasoconstriction in the ulcer.

Maessen-Visch (Maessen-Visch et al,1998) investigated 16 patients with CVI and large lesions of Atrophie blanche (AB), 10 patients with $C V I$ without $A B$ and 10 healthy controls. LDI measurements were performed in and outside large lesions of $A B$ and in healthy controls. The aim was to quantify the deviation in microcirculation in $\mathrm{AB}$ in patients with chronic venous insufficiency (CVI) compared to healthy controls before and after venous occlusion. Median basic resting flow was higher in $A B$ than in healthy controls. The venoarteriolar response (VAR) was increased significantly in $A B$. Basic resting flux in $A B$ measured with LDI was increased compared with clinically normal skin. The decrease in flux in venous occlusion was larger in $A B$ than in healthy controls. In this study a significant increased resting flux, as measured with $\mathrm{LDI}$, was observed in areas with large $A B$ lesions in patients with CVI, compared to healthy controls and in clinical normal looking skin in patients with CVI.

Gschwandtner et al (Gschwandtner et al, 1999) studied microcirculatory disturbances in venous leg ulcers of 17 patients with LDI and capillary microscopy. They found low LDI flux and lowest capillary density in non-granulation tissue area and concluded that this could possibly be a sign of an ulcer area without healing tendency. Granulation tissue showed high LDI flux and second lowest capillary density interpreted as possible sign of wound healing. The adjacent skin area was characterised by a low flux and the highest capillary density representing the healing process. In a skin area distant to the ulcer they found a high flux and the second highest number of capillaries which was described as a sign of enhanced microcirculation in CVI.

Lipodermatosclerotic tissue was investigated by Cheatle et al (Cheatle et al, 1995). In 6 patients with lipodermatosclerosis they found an increased basal flux at rest compared with controles. An impairment of hyperaemic responsiveness to heat was also shown. Lipodermatosclerotic tissue was also investigated by Ahnlide et al (Ahnlide et al, 2000). Presuming that lipodermatosclerosis impairs the chance for the ulcer to heal, the lipodermatosclerotic skin area was excised in 6 non-healing venous ulcers and then covered by split-skin-graft. LDI scanning of the ulcer area was performed preoperatively and during 1-2 years postoperatively. LDI showed increased blood flow in the lipodermatosclerotic skin area, which decreased after the operation. It is concluded that surgical removal of lipodermatosclerotic tissue leads to flow reduction and even normalisation in the transplanted area.

In another study the effect of transcutaneous electrical nerve stimulation (TENS) on the healing process of ulcera cruris is described (Cosmo et al, 1998). LDI measurements of the ulcus and the surrounding tissue were performed before and every 5 minutes during and after TENS was given. After 60 minutes, mean blood flow in the ulcer had increased by $35 \%$, and in the intact skin surrounding the ulcer by $15 \%$. It is concluded that TENS has a stimulating effect on local blood circulation and thus in wound healing. 
Erythromelalgia, a rare disorder, is a condition consisting of red, warm and burning painful legs. An underlying pathophysiologic response in skin microvascular shunting is assumed. In a study of Mork (Mork et al, 2000) LDI measurements were performed in 14 patients and 11 controls before and after central body heating. In the plantar region of the patients foot the skin perfusion was significantly increased, supporting the hypothesis of a relation between clinical symptoms and increased perfusion in the region of numerous arteriovenous shunts.

Red and blue leg telangiectasias have been studied by our group (Sommer et al, 1997). Telangiectasias are associated with a high flow as measured with LDI, probably due to a high number of erythrocytes rather than to a high velocity.

Summarising LDI has been used in phlebology to investigate CVI in general or specially liposclerotic skin, telangiectasias or Atrophie blanche. Increased values are found in CVI compared to healthy skin. This could be explained by an increased resting flux. LDI measures up to a few hundred micrometers in depth, covering capillaries as well as arterioles and venules. In $\mathrm{AB}$ lesions the number of capillaries is decreased. To maintain perfusion the same blood volume can only pass through a decreased capacity if blood velocity is increased. Therefore the increased flux can be explained by a decreased number of capillaries in combination with an increase in blood flow and/or vessel/capillary diameter.

Until now LDI measurements cannot provide a prognostic factor fot healing tendencies of ulcera cruris or a severity scale for wound healing, which would be of clinical interest. Therefore LDI remains for study purposes until a parameter is defined that can answer those questions. It should be investigated whether LDI can provide a prognostic tool in estimating the severity of CVI.

\section{Ischemia}

In chronic critical ischemia of extremities the number of capillaries is reduced and in severe cases even avascular fields are found by capillary microscopy (Fagrell et al, 1984). Until now it has been impossible to study the morphology of capillary blood flow velocity within ischemic ulcers by means of ambient light microscopy. Laser Doppler analysis can be used for investigation of the changes in the microcirculation (Hoffmann et al, 1992). Especially the advantage of a laser Doppler scanner device, avoiding direct contact with the wound, makes LDI suitable for analysis of the underlying microcirculation. Gschwandtner et al examined with LDI the microcirculation within ischemic ulcers to compare it with the adjacent skin after a single intravenous infusion of a prostanoid (Gschwandtner et al, 1996). Before application of the prostanoid the centre and the majority of the ulcer area were poorly perfused. The edge of the ischemic ulcer and the adjacent skin were marked by a moderate hyperaemic zone. After 120 minutes of prostanoid application a moderate increase of LDI values could be seen in the centre of the ulcer. In contrast the LDI values of the adjacent skin remained unchanged. Comparing the LDI findings with macroscopic appearence of the ulcer, it was concluded that within the ulcers areas with granulation tissue showed higher fluxes than areas without granulation tissue. In a subsequent study 
(Gschwandtner et al, 1999) the same group investigated 25 ischemic leg ulcers with LDI and capillary microscopy. As in their former study in venous ulcers (Gschwandtner et al, 1999) they investigated again non-/granulation tissue, and adjacent skin. It is concluded that changes of perfusion of the deeper network of microcirculation, as measured by LDI, coincide with an increased number of visible surface capillaries within the ischemic ulcer, as blood of the skin capillaries is provided by subpapillary vessels. In the future it would be of great clinical use to assess the minimal flux required to initiate a healing process. Findings are not significantly different from those in venous ulcers.

In another study (Ruch et al, 1999) LDI measurements in 25 hands in multiple-level occlusive disease were compared with arteriography and questionnaires assessing symptoms such as cold sensitivity. Neither arteriography nor LDI served as an indicator of the severity of cold intolerance. It is concluded that LDI and arteriography provide complementary data in the evaluation of upper extremity ischemia.

\section{Diabetes}

Patients with type 1 and type 2 diabetes are prone to develop dysfunction of the autonomic nervous system. The autonomic regulation of the skin microcirculation is affected in diabetic patients. It has been shown that cutaneous vasoconstriction to indirect cooling is impaired (McDaid et al, 1994). Various disturbances in the autonomic nerve regulation of the blood perfusion were found to be associated with diabetes and tentatively may have pathophysiological importance for the development of diabetic complications. Therefore it would be of great interest to detect subclinical changes in autonomic sympathetic function. A study using LDI was performed to investigate signs of the disturbed teflex autonomic sympathetic nerve function in type 1 and type 2 diabetes (Bornmyr et al, 1999). The finger skin blood flow was evaluated by LDI of the skin, kept at a local constant temperature of $40^{\circ} \mathrm{C}$ before and after cold provocation. The response was quantified by an age-corrected vasoconstriction index (VAC), defined as the LDI value upon cooling divided by the LDI value before cooling. It could be shown that the VAC was slightly more impaired in type 1 than in type 2 diabetic patients, while compared to the control group both types of diabetic patients have impaired cutaneous blood flow regulation.

Blood flow responses in forearm skin to the vasodilators acetylcholine and sodium nitroprusside were evaluated in type 2 diabetic patients and a control group (Morris et al, 1995). Basal skin blood flow was not significantly different in the diabetic group compated with the control group. Introduction of the drugs increased forearm skin blood flow in all subjects, but the vasodilatation was lower in the patient group.

Abnormal skin temperature reactions have been reported in type I diabetic patients. The microcirculation in 17 type I diabetic patients and 17 age-matched controls was studied by means of LDI of hands and feet after arterial occlusion, cooling or heating (Bornmyr et al, 1997). Blood flow reactions after provocation were disturbed in the patients and it was 
concluded that diabetic patients display a vascular disturbance in their skin which is aggravated by thermal provocation.

Summarising disturbances in mictocirculation if diabetic patients can be quantified by LDI assessment. It remains to be investigated whether LDI can help in staging early changes.

\section{Dermatosurgery and skin cancer}

Objective non-invasive examination techniques in addition to clinical parameters are required to monitor the wound healing of flaps. With LDI it is possible to measure and visualise microcirculation continuously, non-invasively and without contact to the wound. Studies have been performed to investigate the clinical use of LDI in wound healing of flaps (Eichhorn et al, 1994). Twenty-two patients were investigated postoperatively after reconstruction procedures using random or axial pattern flaps. Necrotic areas, venous stasis and normal course of wound healing could be clearly visualised and differentiated from one another.

In the last few years a number of burn treatment centres have trialled the use of laserDoppler imaging to assess non-invasively assessment of the depth of thermal burns (Niazi et al, 1993). Scans were performed with a Moor Ldi ${ }^{\mathrm{TM}}$ and compared with clinical judgement and histological assessment. In 10 out of 13 patients the areas clinically diagnosed as superficial dermal or epidermal depth wounds showed a high flux while the deep dermal and/or full thickness burns showed a low flux. The scans were compared with histology reports and it was found that there was a consistently accurate correlation in all areas. Clinical assessment only agreed in $41 \%$ with the histological findings and led often to overdiagnosis.

In patients with skin tumours, the neovascularisation manifested as increased perfusion in the tumour area can be readily visualised by LDI. Mannor and co-workers (Mannor et al, 1996) investigated the perfusion of basal cell carcinoma in the eyelid region and found that malignant adnexal skin lesions can be distinguished from benign lesions by means of LDI. They found, that it was possible to establish the pathologic margins of lid tumours. Another group investigated whether LDI might allow differentiation between different types of skin cancer (Stücker et al, 1999). Basal cell carcinomas and malignant melanomas were examined before excision. Malignant melanomas were significantly more perfused than basal cell carcinomas. Perfusion pattern was higher in the centre than in the periphery for malignant melanomas but was the same throughout the basal cell carcinoma.

Enejder et al studied superficial blood perfusion using LDI in basal cell carcinomas treated either by photodynamic therapy or by cryotherapy (Enejder et al, 2000; Wang et al, 1997). Both treatment modalities induced an increased blood perfusion inside the lesions. The blood perfusion in successfully treated lesions approached normal values 2 months after photodynamic therapy, and about 1 year after cryotherapy. The tissue perfusion in recurrent lesions did not decrease to normal values after the treatment, suggesting that LDI can be used to monitor the healing process and discover possible persistent tumour growth. 
Summarising skin malignancies show a higher basal blood flow. It is possible to assess margins of the tumour by LDI measurement and the viability of flaps can be monitored.

\section{Heat-and cold-provocation}

Heat and cold provocation can be a useful tool to detect alterations in the nervous system concerning the regulation of the skin microcirculation. Thermal provocation, applicated directly or indirectly, induces a decrease or increase in tissue perfusion. Indirect thermal provocation influences the vasoregulatory effect of the sympathetic nervous system. Direct thermal provocation induces a primary local vasoactive process. Both forms of provocation can be tested by LDI. Former studies with LDF showed a vast variability and poor reproducibility (Netten et al, 1996). Finger skin blood flow was measured in 80 healthy volunteers during steady state of basal vasodilatation at a local temperature of $40^{\circ} \mathrm{C}$ (Bornmyr et al, 1998). The response to cooling of the contralateral hand at $15^{\circ} \mathrm{C}$ was studied. A uniform response was shown with a good reproducibility of measurements.

\section{Vasoactive substances /Topical drug application}

Vasoactive substances and their effect on dermal microcirculation can be studied by LDI. It has been shown that histamine plays an important tole in mediating the cutaneous vascular response to inflammation through its action on the microvasculature to cause vasodilatation and an increase in microvascular permeability which both contribute to an increased tissue perfusion. Clough et al showed (Clough et al, 1998) that after intradermal injection of histamine, mean values of perfusion within the flare areas induced by histamine were approximately double of those in resting skin. They used a Moor Ldi ${ }^{\mathrm{TM}}$ scanner and observed maximum values nearly 8 times higher than those in the surrounding tissue. Our own LDI measurements after intracutaneous histamine injection also showed 2 to 3 fold higher values compared with the baseline values (Sommer et al, submitted).

The Moor Ldi ${ }^{\mathrm{TM}}$ instrument has been applied in the measurement of experimentally induced cutaneous inflammation, such as histamine induced inflammation (Quinn et al, 1991). The Ldi measurement clearly defined the flare but not the wheal component of the response to injected histamine. Values were shown to increase linearly with the log dose of histamine. Despite the increase in flare area, the maximum blood flow within the flare showed no significant change with dose of histamine.

Nitric oxide concentration is elevated after histamine injection and is associated with increased dermal vascular perfusion as measured by LDI (Clough, 1999). Vasoconstriction as achieved by intradermal injection of an adrenaline dilution shows a slight decrease of LDI values compared with surrounding untreated skin (Sommer et al, submitted).

The vasodilator methyl nicotinate was tested on a group of 20 women divided into subjects with sensitive skin, as defined by the lactic acid stinging test, and in normal non-sensitive subjects (Issachar et al, 1998). Beside that LDI allowed objective observation of the onset, duration and decay of the local pharmacological response to the vasoactive stimulus, it also 
revealed the spatial heterogeneity of the inflammatory reaction (high perfusion areas were surrounded by areas with lower perfusion).

The effect of transdermal absorbed nicotine on digital perfusion in 10 reformed habitual smokers was evaluated (Fulcher et al, 1998). The digits of both hands were scanned before and after nicotine assisted smoking cessation to provide an image of the distribution of microvascular perfusion of each extremity. Measurements were compared with those of healthy non-smokers. Cutaneous microvascular perfusion was lower in smokers than nonsmokers. Smoking cessation supported by transdermal nicotine normalised digital microvascular perfusion within 7 days.

Intracutaneous capsaicin application can cause neurogenic vasodilatation. It was hypothesised that an intravenous regional block inhibits this phenomenon (Kalman 1998). The flare after capsaicin application was measured by LDI. The area of the flare was smaller than in the contralateral control arm. There was no difference between the arms concerning the mean blood flow within the flare.

Local topical analgesia changes basal skin perfusion. The response after local heating is altered to a delayed and persistent perfusion increase as measured by LDI (Arildsson et al, 2000). Twelve subjects were treated with topically applied Emiaß creme and thereafter local heating. Measurements were performed with capillary microscopy and LDI showing that perfusion increase does not occur in the capillaries but in the deeper lying vessels.

Topically applied corticosteroids induce a blanching at the application site. LDI has been used to quantify the blanching response after application of beclomethasone dipropionate in ethanol solution (Noon et al, 1996). LDI measurements were performed once after steroid application and it was concluded that LDI is not able to detect vasoconstriction. Our group investigated blanching up to $72 \mathrm{~h}$ after clobetasol-di-propionate application. The results show that LDI can easily detect changes in blood flow due to the vasoconstriction of the applied corticosteroid, with a maximum reaction $30 \mathrm{~h}$ after application (Sommer et al, 1997). Comparing the results with reflectance spectroscopy we found, that LDI probably measures deeper located changes in microcirculation and that the response after $30 \mathrm{~h}$ can be interpreted as the known hyperaemic response after steroid application (Sommer et al, submitted).

\section{Others}

Assessing microcirculation in dermatological diseases which go along with hyper- and hypoperfusion can give insights in the underlying pathomechanisms and could give an output value before starting a thexapy. LDI then can offer a quantitative analysis of treatment success. Port wine stains in most cases do not reveal any increase in basal tissue perfusion (Troilius et al, 1992). This can be explained by the fact that the blood cells are pooled in the portwine stain, giving the area its characteristic red-blue colour, although no true perfusion exists. After laser therapy LDI values decreased. It was shown that cutaneous blood flow failed to correlate well with the clinical response and it was concluded that I.DI is 
more useful in the research setting than as a predictive tool in the evaluation of treatment success (Troilus et al, 1996; Le et al, 1999).

The LDI presents a psoriatic plaque as a sharply demarcated hyperperfused atea (Auer et al, 1994). During dithranol-therapy the high perfusion drops significantly to values just slightly above those of normal skin (Auer et al, 1994). Speight et al, using the Ldir (Moor instrument, England) investigated plaque psoriasis (Speight et al, 1993 and 1994). They found that the mean blood flow within plaques was increased fourfold compared with mean background flow. They showed further that calcipotriol treatment in combination with PUVA therapy results in significantly lower blood flow compared to those only treated with PUVA. It could also be shown that psoriasis lesions have a reduced erythemal sensitivity during PUVA treatment, as confirmed by laser Doppler measurement. A combined treatment of psoriasis with dithranol and tazarotene revealed a significantly faster healing than the dithranol mono-therapy (Sander et al, 1999). The irritation of the combination therapy as evaluated by LDI was increased. The mechanism beyond the significantly increased blood flow in the psoriatic plaque might be attributed to neurogenic factors (axonreflex), because surface anaesthesia of the plaque evokes a marked reduction in perfusion and histamine is of no influence in the vasodilatation as recorded by LDI (Krogstad et al 1999).

In atopic dermatitis the reactivity of cutaneous microcirculation to external stimuli often show deviating responses compared to healthy controls. Intracutaneous histamine injection evokes a higher flow (measured by LDI) in the centre of reaction than normal controls because the wheeling is markedly reduced (Stücker et al, 1998). In the same study the application of nicotinic acid ester is found to lead to a significant smaller flow in the centre of the reaction. Phototherapy in patients with atopic dermatitis is known to be an effective therapeutic. UVA1 cold light phototherapy showed advantages due to the absence of potentially proinflammatory effects based on temperature-induced increase of blood flow (quantified by LDI) (Kobyletzki et al, 1999).

Test procedures in patients with photosensitivity after skin exposurc to well determined ultraviolet light doses lead to a classification of skin sensitivity based on the minimal erythema dose (MED) found for each patient. LDI is possibly a useful complement to the visual readings of the skin responses, since LDI gives a quantification of the grade of erythema, as opposed to visual readings that are subjective and at best semi-quantitative (Ilias et al, 1999).

In patients with scleroderma, increased cutaneous perfusion and greater use of microvascular reserve has been demonstrated using LDI (Aghassi et al, 1995). In another study in 24 patients suffering from systemic scleroderma and 10 healthy controls the distal phalanx of 
the hand was studied by LDI. Yet, flux was significantly lower in scleroderma patients (Stücker et al, 1995). A lower basal mean perfusion in 9 scleroderma patients compared with healthy controls is also found by Picart et al (Picart et al, 1998). These differences increased during cold exposure and even more during the re-warming period. In all studies it is shown that the phenomena are reproducible and are recognised to reflect defects in vascular regulation inherent to the disease and as such they could allow more precise monitoring of the progression of the disease. Analysing the 3 articles mentioned above it seems more likely that scleroderma induces a decrease of LDI flux, rather than an increase.

Summarising well-known diseases in dermatology as psoriasis and atopic dermatitis have been studied with LDI. The underlying increase respectively decrease in microcirculation could be measured. A possible clinical use of LDI could be the assessment of treatment success and graduation of the disease severity.

\section{Discussion}

One of the main features of LDI is that it is easy to use and that it provides a non-invasive measurement technique. Interpretation of the results, however, requires a thorough knowledge and understanding of the function and anatomy of the microcirculation. Besides, LDI values are a product of velocity and blood cell quantity. That can be a problem in interpreting results, when it is not known whether both parameters are affected or only one of them. When evaluating the results it must be borne in mind that each tissue perfusion value in the image represents an average over an area of a few square millimetres and has a depth sensitivity of a few hundred micrometers. At the time being it is not possible to extract selective flow information from different compartments of the tissue.

Since skin (and other tissue) perfusion possesses both temporal variation on different time scales and spatial heterogeneity, this parameter has to be studied both in terms of images and as time traces of temporal flow changes within regions of interest.

The measurement lasts, depending on the LDI instrument used and the area under study, up to 6 minutes. Compared to other methods for measuring microcirculation the relatively short application time of LDI is of advantage in experimental and clinical use.

Further it must be considered that the ambient light level may influence the results of the LDI device (Lisca, Linköping, Sweden). The Ldi ${ }^{\mathrm{TM}}$ (Moor, England) can be used in daylight settings without influencing the measurements. Particular attention must be paid to disturbing factors such as mental stress, which is known to influence the skin blood flow, while the influence of environmental factors such as ambient temperature can more easily be controlled. 
Tabel 2.

LDI measurements: Characteristics of reviewed articles

\begin{tabular}{|c|c|c|c|c|}
\hline & $\begin{array}{l}\text { Articles according } \\
\text { to references }\end{array}$ & $\begin{array}{l}\text { control-matched } \\
\text { study }+/-\end{array}$ & $\begin{array}{l}\text { No, of included } \\
\text { subjects }\end{array}$ & $\begin{array}{l}\text { No. of affected } \\
\text { lesions(without controls) }\end{array}$ \\
\hline \multirow[t]{2}{*}{ Allergology } & Bjamason et al. , 1999 & - & 3 & n.a. \\
\hline & Fischer et al, 1990 & + & 10 & n.a. \\
\hline \multirow{5}{*}{ (total: 10 ) } & Bjamason et al, 1999 & + & 10 & n.a \\
\hline & Bjarnason et al, 1998 & + & 9 & 45 \\
\hline & Bjamason et al, 1998 & + & 11 & n.a. \\
\hline & Harrison et al, 1993 & + & 6 & 6 \\
\hline & Fullerton et al, 1998 & + & 180 & n.a. \\
\hline \multirow[t]{2}{*}{ Phlebology } & Matessen-Visch et al, 1998 & + & 26 & 26 \\
\hline & Cheatle et al, 1995 & + & 6 & 11 \\
\hline \multirow[t]{4}{*}{ (total: 10 articles) } & He et al, 1997 & - & 10 & 10 \\
\hline & Cosmo et al, 2000 & - & 15 & 15 \\
\hline & Mork et al, 2000 & + & 14 & 14 \\
\hline & Sommcr et al, 1297 & - & 20 & 20 \\
\hline \multirow{3}{*}{$\begin{array}{l}\text { Ischemic ulcer } \\
\text { (total: } 3 \text { articles) }\end{array}$} & Gschwandtner et al, 1996 & - & 18 & 18 \\
\hline & Gschwandtner et al, 1999 & - & 25 & 25 \\
\hline & Ruch et al, 1999 & - & 23 & 25 \\
\hline \multirow[t]{2}{*}{ Diabetes } & Bornmyr et al, 1999 & + & 65 & n.a. \\
\hline & Morris et al, 1995 & + & 14 & n.a. \\
\hline (totai: 3 articles) & Bornmyr et al, 1997 & + & 22 & n.a. \\
\hline Dematosurgery & Eichhom et al, 1995 & - & 20 & n.a \\
\hline \multirow{2}{*}{ and skin cancer } & Niazi et al, 1993 & + & 13 & n.a. \\
\hline & Mannor et al, 1996 & + & 1 & n.a. \\
\hline \multirow{5}{*}{ (total: 9 articles) } & Fulcher et al, 1998 & - & 10 & n.a. \\
\hline & Kalman et al, 1998 & + & 16 & 32 \\
\hline & Arildsson et al, 2000 & + & 12 & 60 \\
\hline & Noon et al, 1996 & - & 6 & 24 \\
\hline & Sommer et al, 1997 & - & 10 & 80 \\
\hline Port wine stains & Troilius et al, 1996 & + & 19 & 38 \\
\hline \multirow{2}{*}{ (total: 3 articles) } & Troilius et al, 1992 & + & 13 & 13 \\
\hline & Le et al, 1999 & n.a. & n.z. & n.a. \\
\hline Psoriasts & Auer et al, 1994 & - & 20 & n.m. \\
\hline \multirow[t]{7}{*}{ (total: 8 articles) } & Speight et al, 1993 & - & 29) & 35 \\
\hline & Speight et al, 1994 & - & 13 & 20 \\
\hline & Speight et al, 1994 & + & 20 & 20 \\
\hline & Sander et al, 1999 & + & 50 & 50 \\
\hline & Krogstad et al, 1999 & + & 12 & 12 \\
\hline & Krogstad et al, 1998 & + & 21 & 21 \\
\hline & Krogstad et al, 1995 & + & 12 & 12 \\
\hline Atopic dermatitis & Stücker et al, 1998 & + & 27 & 52 \\
\hline (total: 2 articles) & Kobyletzki et al, 1999 & - & 70 & 70 \\
\hline Phototesting & Llias ct al, 1999 & + & 1 & 5 \\
\hline Scleroderma & Aghassi et al, 1995 & + & 10 & 10) \\
\hline \multirow[t]{2}{*}{ (total 3 articles) } & Stücker ct al, 1995 & + & 24 & 24 \\
\hline & Picart et al, 1998 & + & 25 & 25 \\
\hline
\end{tabular}

1 Articles are referred to as listed in the references, n.a.: not applicable; n.m.: not mentioned, (f): inconclusive 
The studies summarised above represent initial results of the potential usefulness of LDI in a variety of experimental and clinical settings. LDI offers the possibility to analyse physiological and pathological states of the skin as a response to different stimuli on the microcirculation. Its advantage above visual interpretation is the quantitative assessment of changes in microcirculation. It is therefore very suitable to establish measurement scales in e.g. patch test reactions, healing tendencies of ulcers or reactions to vasoactive substances. These scales could lead to a uniform international approach of interpreting changes in microcirculation. As seen in table 2 LDI most often has been used in phlebology and in order to monitor topically applied substances. These fields offer question formulations to that LDI can provide useful information. With a maximum time of 6 minutes per measurement it can be used in daily routine and it can help establish a quantitative assessment of diseases and their response to treatment.

Several techniques, including laser Doppler, reflectance spectroscopy, capillary microscopy or transcutaneous oxygen measurement, have been developed to address the need for objective measurement devices. While many instruments are available these techniques are limited by small test site area, and/or show inconclusive correlation with clinical response. LDI combines the most important qualities of those techniques to measure microcirculation offering a non-invasive technique with a reasonable test size area, good reproducibility and a good correlation with clinical observations. 


\section{References}

Aghassi D, Monoson T, Braverman I. Reproducible measurements to quantify cutaneous involvement in scleroderma. Arch Dermatol 1995;131:1160-6.

Ahnlide I, Bjellerup M, Åkesson H. Excision of lipodermatosclerotic tissue: an effective treatment for non-healing venous ulcers. Acta Derm Venereol 2000; 80:28-30.

Arildsson M, Asker CL, Salerud EG, Strömberg T. Skin capillary appearance and skin microvascular perfusion due to topical application of analgesia cream. Microvasc Res 2000;59:14-23.

Auer T, Bacharach-Buhles M, el-Gammal S et al. The hyperperfusion of the psoriatic plaque correlates histologically with dilatation of vessels. Acta Derm Venereal (Stockb) 1994;SuppI 186:30-2.

Bjarnason B, Flosadóttir E, Fischer T. Objective non-invasive assessment of patch tests with the laser Doppler perfusion scanning technique. Contact Dermatitis 1999;40:251-60.

Bjarnason B, Flosadóttir E, Fischet T. Assessment of budesonide patch test. Contact Dermatitis 1999;41:211-7.

Bjarnason B, Flosadóttir E, Fischer T. Reactivity at edges of corticosteroid patch tests may be an indicator of a strong positive test response. Dermatology 1999;199:130-4.

Bjarnason $B$, Fischer $T$. Objective assessment of nickel sulfate patch test reactions with laser Doppler perfusion imaging. Contact Dermatitis 1998;39:112-8.

Bollinger A, Koelbing HM, Kupferschmidt H. History of microcirculation from the clinical viewpoint. VASA 1986;15:335-9.

Bongard $\mathrm{O}$, Bounameaux $\mathrm{H}$. Clinical investigation of skin microcirculation. Dermatology 1993;186:6-11.

Bornmyx S, Castenfors J, Svensson $H$, et al. Detection of autonomic sympathetic dysfunction in diabetic patients. Diabetes Care 1999;22:593-7.

Bornmyr S, Svensson $\mathrm{H}$, Lilja B. Cutaneous vasomotor responses in young type I diabetic patients. J Diab Complic 1997;11:21-6.

Bornmyr $S$, Svensson $H$, Söderström $T$. et al. Finger skin blood flow in tesponse to indirect cooling in normal subjects and in patients before and after sympathectomy. Clin Pbysiol 1998;2:103-7.

Braverman IM, Keh A, Goldminz D. Correlation of laser Doppler wave patterns with underlying microvascular anatomy. J Invest Dermatol 1990;95:283-6.

Cheatle TR, Coleridge Smith PD, Scurr JH: Skin microcirculatory responses in chronic venous insufficiency: the effect of short-term venous hypertension. VASA 1991;20:63 69.

Cheatle TR, Quashie C, Villemur B, Carpentier P: Two-dimensional laser doppler-perfusion imaging and mictocirculatory function in patients with venous skin damage. Pblebology 1995;10:32-36

Clough GF, Bennett AR, Church MK. Effects of H1 antagonists on the cutaneous vascular response to histamine and bradykin: a study using scanning laser Doppler imaging. $\mathrm{BrJ}$ Dermatol 1998;138:806-14.

Clough GF. Role of nitric oxide in the regulation of microvascular perfusion in human skin in vivo. J Physiol 1999;15:549-57.

Cosmo P, Svensson H, Bornmyx S, Wikstrom SO. Effects of transcutaneous nerve stimulation on the microcirculation in chronic venous leg ulcers. Scand J Plast Reconstr Surg Hand Surg 2000;34:61-4.

Douven LFA, Lucassen GW. Retrieval of optical properties of skin from measurement and 
modelling the diffuse reflectance. Proc SPIE 3914, Progr in biomedical optics and imaging 2000:1:312-323.

Eichhorn W, Auer T, Vou ED. Bildliche Darstellung der Mikrozirkulation gestielter Lappenplastiken im Kiefer-Gesichtsbereich mit Hilfe des Laser-Doppler_scanners. Handchir Mikrachir Plast Chir 1995;27:176-80.

Enejder AM, Klinteberg C, Wang $I$ et al. Blood perfusion studies on basal cell carcinomas in conjunctive photodynamic therapy and cryotherapy employing laser-Doppler perfusion imaging. Acta Derm Venereol 2000;80:19-23.

Essex TJH, Byrne PO. A laser Doppler scanner for imaging blood flow in skin. J Biomed Eng $1991 ; 13: 189-94$.

Fagrell S, Nilsson G. Advantages and limitations of one point laser Doppler perfusion monitoring in clinical practice. Vasc Med Rev 1995;6:97-101.

Fagrell B, Lundberg G. A simplified evaluation of vital capillary microscopy for predicting skin viability in patients with severe arterial insufficiency. Clin Physiol 1984;4:403-11.

Fischer T, Dahlen A, Bjarnason B. Influence of patch-test application tape on reactions to sodium dodecyl sulfate. Contact Dermatitis 1999;40:32-7.

Fulcher SM, Koman LA, Paterson-Smith B et al. The effect of transdermal nicotine on digital perfusion in reformed habitual smokers. J Hand Surg 1998;23:792-9.

Fullerton A, Benfeldt E, Petersen JR et al. The calipotriol dose-irritation relationship: 48 hour occlusive testing in healthy volunteers using Finn chambers ${ }^{\circledR} . \mathrm{Br} J$ Dermatol 1998;138:259-65.

Gschwandtner ME, Ambrózy E, Fasching S, Willfort A, Schneider B, Boehler K, Gaggl U, Ehringer $H$. Microcirculation in venous ulcers and the surrounding skin: findings with capillary microscopy and a laser Doppler imaget. Eur J Clin Invest 1999;29:708-16.

Gschwandtner ME, Ambrózy E, Boehler K et al. Reproducibility of laser Doppler flux measurements within ischemic or venous ulcers and adjacent skin. Skin Research and Technology 1998;4:222-7.

Gschwandtner ME, Koppensteiner R, Maca T et al. Spontaneous laser Doppler flux distribution in ischemic ulcers and the effect of prostanoids: a crossover study comparing the acute action of prostaglandin $\mathrm{E}_{1}$ and iloprost vs saline. Microvasc Res 1996;51:29-38.

Gschwandtner ME, Ambrózy E, Schneider B et al. Laser Doppler imaging and capillary microscopy in ischemic ulcers. Atherosclerosis 1999;142:225-32.

Harrison D, Abbot NC, Swanson Beck J, McCollum PT. A preliminary assessment of laser Doppler perfusion imaging in human skin using the tuberculin reaction as a model. Pbysiol Meas 1993:14:241-52.

He CF, Cherry GW, Arnold F. Postural vasoregulation and mediators of reperfusion injury in venous ulceration. J Vasc Surg 1997;25:647-53.

Hoffmann U, Franzeck UK, Bollinger A. Laser-Doppler-Technik bei Krankheiten der peripheren GefäBe. Dtsche Med Wocbenscbr 1992;117:1889-97.

Ilias MA, Anderson C, Wårdell K. Single exposure phototesting utilizing a divergent ultraviolet beam. Skin Research Technol 1999;5:255-9.

Issachar N, Gall Y, Borrel MT et al. Correlation between percutaneous penetration of methyl nicotinate and sensitive skin, using laser Doppler imaging. Contact Dermatitis 1998:39:182-6.

Jakobsson A, Nilsson GE. Prediction of sampling depth and photon pathlength in laser Doppler flowmetry. Med Biol Eng Comput 1993;31:309.

Kalman S, Linderfalk C, Wårdell $\mathrm{K}$ et al. Differential effect on vasodilatation and pain after 
intradermal capsaicin in humans during decay of intravenous regional anesthesia with mepivacaine. Reg Anesth Pain Med 1998;23:402-8.

Kobyletzki G, Freitag M, Herde M. et al. Phototherapy of atopic dermatitis: comparison between conventional UVA 1 phototherapy, UVA 1 cold light phototherapy and combined UVA-UVB phototherapy. Hautary 1999,50:27-33.

Krogstad AL, Lönntoth P, Larson G, Wallin BG. Capsaicin treatment induces histamine release and perfusion changes in psoriatic skin. BrJ Dermatol 1999;141:87-93.

Krogstad AL, Plönnroth P, Larson $G$ et al. Nerve-induced histamine release is of little importance in psoriatic skin. BrJ Dermatol 1998;139:403-9.

Krogstad AL, Swanbeck G, Wallin G. Axon-reflex-mediated vasodilatation in the psoriatic plaque? J Invest Dermatol 1995;104:872-6.

Le KV, Shahidullah H, Frieden IJ. Review of modern techniques in detecting port-wine stain response to laser therapy. Dermatol Surg 1999;25:127-32.

Leu AJ, Leu HJ, Franzeck UK, Bollinger A: Microvascular changes in chronic venous insufficiency- a review. Cardiovasc Surg 1995;3:237-45.

Nilsson G. Laser Doppler Perfusion imaging for assessment of cutaneous microcirculation. Pblebologie 1997;26:87-91.

Nilsson G. A new instrument for continuous measurement of tissue blood flow by light beating spectroscopy. IEEE Trans. BME 1980; 27:12-9.

Möller H, Bjorkner B, Bruze M, Lundqvist K, Wollmer P. Laser Doppler perfusion imaging for the documentation of flare-up in contact allergy to gold. Contact Dermatitis 1999;41:131-5.

Maessen-Visch MB, Sommer A, De Paepe JA, Neumann HAM. Changes in microcirculation in patients with atrophie blanche visualized by laser Doppler perfusion imaging and transcutaneous oxygen measurements. Phlebology 1998;13:45-9.

Mannor GE, Wårdell K, Wolfley DE, Nilsson GE. Laser Doppler perfusion imaging of eyelid skin. Ophtal Plast Reconstr Surg 1996;12:178-85.

McDaid EA, Monaghan B, Parker AI et al. Peripheral autonomic impairment in patients newly diagnosed with type II diabetes. Diabetes Care 1994;17:1422-7.

Morris SJ, Shore AC, Tooke JE. Responses of the skin microcirculation to the acetylcholine and sodium nitroprusside in patients with NIDDM. Diabetologia 1995;38:1337-44.

Mørk C, Asker CL, Salerud EG, Kvernebo K. Microvascular arteriovenous shunting is a probable pathogenic mechanism in erythromelalgia. J Invest Dermatol 2000;114:643-6.

Netten PM, Wollersheim H, Vanden Broek P et al. Evaluation of two sympathetic cutaneous vasomotor reflexes using laser Doppler fluxmetry. Int J Microvasc 1996;16:124-8.

Niazi ZBM, Essex TJH, Papini R et al. New laser Doppler scanner, a valuable adjunct in burn depth assessment. Burns 1993;19:485-9.

Noon JP, Evans CE, Haynes WG et al. A comparison of techniques to assess skin blanching following the topical application of glucocorticoids. Br J Dermatol 1996;134:837-42.

Quinn AG, McLelland J, Essex T, Farr PM. Measurement of cutaneous inflammatory reactions using a scanning laser-Doppler velocimeter. Br J Dermatol 1991;125:30-7.

Rhodin JAG. Anatomy of the microcirculation. In Effros RM, Schmid-Schoenbein H, Ditzel J (eds): Microcirculation: Current physiologic, medical and surgical concepts. New York, Academic Press, 1981, pp11-7.

Ryan TJ. Cutaneous circulation. In: Biochemistry and physiology of the skin. (Goldsmith LA, ed), Oxford: Oxford University Press, 1983: 817-77.

Ruch DS, Smith TL, Smith BP, Holden M, Russel G, Koman LA. Anatomic and physiologic evaluation of upper extremity ischemia. Microsurgery 1999;19:181-8. 
Sander P, Happe M, Stücker M et al. Tazarotene increases the antipsoriatic effect of dithranol in chronic psoriasis. Hautaryt 1999;50:723-7.

Sommer A, Veraart J, Neumann M, et al. Evaluation of the vasoconstrictive effects of topical steroids by laser-Doppler-Perfusion-Imaging. Acta Derm Venereal (Stockh) 1997;77:15-8.

Sommer A, van Mierlo P, Veraart J, Neumann HAM. Red and blue telangiectasias. Differences in oxygenation? Dermatol Surg 1997;23:55-9.

Sörensen J, Bengtsson M, Malmqvist LA et al. Laser Doppler perfusion imager (LDPI) - for the assessment of skin blood flow changes following sympathetic blocks. Acta Anaestbesiol Scand 1996;40:1145-8.

Speight EL, Essex TJH, Farr PM. The study of plaques of psoriasis using a laser-Doppler velocimeter. BrJ Dermatol 1993;128:519-24.

Speight EL, Farr PM. Calcipotriol improves the response of psoriasis to PUVA. BrJ Dermatol 1994;130:79-82.

Speight EL, Farr PM. Erythemal and therapeutic response of psoriasis to PUVA using highdose UVA. BrJ Dermatol 1994;131:667-72.

Stücker M, Auer T, Hoffmann K, Altmeyer P. Two-dimensional blood flow determinations in allergic reactions using laser Doppler scanning. Contact Dermatitis 1995;33:299-303.

Stücker M, Horstmann I, Nüchel $C$ et al. Blood flow compared in benign melanocytic naevi, malignant melanomas and basal cell carcinomas. Clin Exp Dermatol 1999;24:107-11.

Stücker M, Heese A, Hoffmann K et al. Quantification of vascular dysregulation in atopic dermatitis using laser Doppler perfusion imaging. Skin Research Technol 1998;4:9-13.

Stücker M, Jeske M, Hoffmann K, Altmeyer P. Laser-Doppler-Scanning bei progressiver systemischer Sklerodermie. Phlebologie 1995;24:9-14.

Svedman C, Cherry GW, Ryan TJ. The veno-arteriolar reflex in venous leg ulcer patients studied by laser Doppler imaging. Acta Derm Venereol (Stockh) 1998;78:258-61.

Troilius AM, Ljunggren B. Evaluation of port wine stains by laser Doppler perfusion imaging and reflectance photometry before and after pulsed dye laser treatment. Acta Derm Venerool (Stockb) 1996;76:291-4.

Troilius A, Wårdell K, Bornmyr S, Nilsson GE, Ljunggren B. Evaluation of port wine stain perfusion by laser Doppler imaging and thermography before and after argon laser treatment. Acta Derm Venereol (Stockb) 1992;72:6-10.

Picart C, Carpentier PH, Brasseur S et al. Systemic sclerosis: blood rheometry and laser Doppler imaging of digital cutaneous microcirculation during local cold exposure. Clin Hemorheol Microcirc 1998:18:47-58.

Wang I, Andersson-Engels S, Nilsson GE, Wårdell K, Svanberg K. Superficial blood flow following photodynamic therapy of malignant non-melanoma skin tumours measured by laser Doppler perfusion imaging. Br J Dermatol 1997;136:184-9.

Wărdell K, Nilsson G. Laser Doppler Imaging of skin. In: Handbook of non-invasive methods and the skin (Serup J, Jemec GBE, eds) CRC Press, 1995: 421-8.

Wărdell K, Braverman IM, Silverman DG, Nilsson GE. Spatial heterogeneity in normal skin perfusion recorded with laser Dopplet imaging and flowmetry. Microvasc Res 1994;48:2638.

Wårdell K, Jakobsson A, Nilsson GE. Laser Doppler perfusion imaging by dynamic light scattering.IEEE-Trans-Biomed-Eng 1993;40:309 


\section{Chapter III}

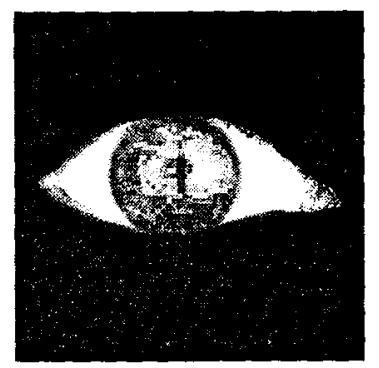

\section{RED AND BLUE TELANGIECTASIAS.}

\section{DIFFERENCES IN OXYGENATION?}

A. Sornmer, PLHMJ van Mierlo, AGH Kessels, HAM Neumann

Dermatol Surg 1997;23:55-9. 


\begin{abstract}
Background: Leg telangiectasias are visible, ectatic dermal arteriols, capillaries or veins with a diameter of 0.1 to 1 or $2 \mathrm{~mm}$. Their origin is still not known and different opinions have been published.
\end{abstract}

Objective: In our study we were interested in the different colours of telangiectasias and we wanted to demonstrate whether a difference in blood gases is causing the difference in colour between red and blue telangiectasias.

Methods: We measured a capillary astrup in 20 patients, who had as well red as blue telangiectasias on the lower limb. Therefore, we took two samples, one of a red and one of a blue telangiectasia. By this we measured the oxygen saturation and the carbon dioxide concentration of the samples. Furthermore, we introduced the appearance of telangiectasias in two rather newly developed techniques, such as high-frequency 20 - and 50-MHz ultrasound and laser Doppler imaging (LDI).

Results: Red telangiectasias of all 20 patients had an average oxygen concentration of $5.90 \mathrm{kPa}$ (range:3.94-7.46 kPa); their average CO2-concentration was $5.45 \mathrm{kPa}$ (range:4.54- $7.06 \mathrm{kPa}$ ). Blue telangiectasias had an average oxygen concentration of $5.11 \mathrm{kPa}$ (range:3.12-7.0 kPa), their average $\mathrm{CO} 2$-concentration was $6.07 \mathrm{kPa}$ (range: $5.38-7.36 \mathrm{kPa}$ ). Statistically work-up with a paired student's t-test showed a higher oxygen-saturation of the red telangiectasias and a higher carbon dioxide concentration of the blue vessels.

Conclusion: As telangiectasias are assumed to be located in the capillary bed, the reason for differences in oxygenation could possibly be found in underlying physiological and anatomical principles of the capillary loops with the red telangiectasia representing the arterial loop of the capillary and the blue telangiectasia representing the venous loop of the capillary. With high frequency ultrasound and LDI it is possible to get useful information about finding the underlying feeder veins, which "feed" the superficial telangiectasias. Injecting into the nutritional vessel telangiectasias can potentially decrease the number of side effects and, may reduce the number of necessary injections. 


\section{Introduction}

Telangiectasias can be divided into primary and secondary telangiectasias. The group of primary telangiectasias consists of vascular naevi, angiomas, generalised essential telangiectasias and others (Champion RH, 1994). Secondary telangiectasias are a heterogeneous group of red and blue telangiectasias. They commonly occur on the ageing skin, or following trauma or $\mathrm{X}$-ray. They are also seen in well-known dermatological diseases, such as rosacea, lupus erythematodes and often go together with basocellular carcinoma. In fact, they are found in most processes that cause atrophy of the skin whatever the etiology. Atrophy of the epidermis is associated with loss of the papillary capillaries and dilation of the subpapillaty plexus (Ryan TJ, 1969), which leads to visible telangiectasias. The term "teleangiectasia" was first coined in 1807 by Von Graf to describe a superficial vessel of the skin visible to the human eye (Merlen JF, 1970). Telangiectasias (Besenreiser-varicosis) are permanently dilated vessels, usually arising from the subpapillary plexus (Champion RH, 1994). They appear on the skin and mucous membranes as small, dull red, linear, stellate or punctate markings.

\begin{tabular}{|c|c|}
\hline Vessel cla & (Duffy, 1988) \\
\hline * type $I:$ & $\begin{array}{l}\text { spidet veins, } 0.1-1 \mathrm{~mm} \text { diameter } \\
\text { telangiectatic matting }<0.2 \mathrm{~mm} \text { diameter }\end{array}$ \\
\hline * type $I I:$ & venulectasia $1-2 \mathrm{~mm}$ \\
\hline * type III: & $\begin{array}{l}\text { reticular veins } 2-4 \mathrm{~mm} \text { diameter } \\
\text { feeder veins }\end{array}$ \\
\hline * type $I V:$ & nonsapheous varicous veins, $3-8 \mathrm{~mm}$ \\
\hline * Type $V$ : & saphenous varicous veins \\
\hline
\end{tabular}

Fig.1: Modificd from Duffy DM: Small vessel sclerotherapy: an overview.

In Callen et al, editors: Advances in dermatology, vol 3, Chicago: Year Book Medical Publishers, 1988.

There are many different pathological processes affecting the blood vessel endothelium and its supporting structures, which can lead to this end result. In only a few cases subjects with telangiectasias develop criteria's of chronic venous insufficiency (CVI). In $90 \%$ of the cases, the family history is positive for telangiectasias (Boehler-Sommeregger et al, 1992; Sadick N, 1990). Telangiectasias occur most often in middle-aged women (Engel A et al, 1988).

Telangiectasias reptesent either an expanded venule, capillary or arteriole (Boehler-Someregger et al, 1992). Telangiectasias that originate from arterioles on the arterial side of a capillary loop tend to be small, bright red, and do not protrude above the skin surface. Telangiectasias that originate from 
venules on the venous side of the capillary loop are blue, wider, and often protrude above the skin surface and some telangiectasias, especially those arising at the capillary loop, are at first red, but with time become blue (Merlen JF, 1970; Boehler-Sommeregger et al, 1994; Sadick N, 1990).

The underlying pathophysiology of telangiectasias has not been elucidated yet and is still a subject of discussion (Boehler-Sommeregger et al, 1994; Goldman MP, 1991; Bean WB, 1958). Sclerocompression therapy is based on clinical experience of the last 50 years, but until now the therapy has not been adapted to underlying pathognomonic factors. We would like to emphasise the need of basic investigation in this field.

In this study we investigated whether blue and red telangiectasias differ in colour due to a difference in blood gases, therefore suggesting a difference in arterial and venous loop of the dilated capillary. Furthermore we examined telangiectasias with high-frequency 20 - and $50-\mathrm{MHz}$ ultrasound (Altmeyer et al, 1991) to look for underlying feeder veins. The same was performed with laser Doppler imaging (LDI) (Serup J et al, 1995). A treatment of the underlying feeder vein is desirable in order to minimise the use of sclerosing agents.

\section{Patients and methods}

We studied 20 patients visiting our outpatient department for sclerocompression therapy (mean age: 55 years;range: $30-79$ years; 2 males and 18 females). They had spider veins, telangiectatic matting, venulectasia, reticular veins, and nonsaphenous varicous veins (Duffy: type 1-3) (Sadick N, 1990) on one or both lower limbs. They all underwent a routine examination to exclude severe underlying venous insufficiency. Doppler-sonography was used to exclude reflux of the superficial venous system. Light-reflex-sheography was also normal in all patients (Wienert et al, 1982).

Before undergoing sclerotherapy we punctured in each patient a red and a bluc telangiectasia of the same leg after desinfecting the skin with chlorhexidine $0.5 \%$. The blood drops were collected in two glass capillaries. A metallic tod, covered with heparine, was put into the glass capillary and directly closed from both sides to avoid a mixture with room air. Thereafter the probe was slowely shaken to avoid intracapillary coagulation. The samples were directly brought to the labatory where the blood gas analysis was done (Figure 1) (Radiometer ABL 505 and Hemioximeter OSM 3, Denmark). The results were tested with a paircd $t$-test.

With high-frequency 20 - and $50-\mathrm{MHz}$ ultrasound (Figure 2) (taberna pro medicum, Germany) the location of the telangiectasias in the dermis was visualised and with LDI (Figure 3) (PIM Lisca 1.0, version 2.4, Sweden), a technique to measure superficial microcirculation, the blood flow of telangiectasias and the surrounding skin was measured. 


\section{Results}

Red telangiectasias of all 20 patients had an average oxygen-concentration of $5.9 \mathrm{kPa}$ (range:3.94$7.46 \mathrm{kPa}$ ); their average $\mathrm{CO}_{2}$-concentration was $5.45 \mathrm{kPa}$ (range:4.54- $7.06 \mathrm{kPa}$ ). Blue telangiectasias had an average oxygen-concentration of $5.11 \mathrm{kPa}$ (rangc:3.12-7.0 kPa); their average $\mathrm{CO}_{2}$ concentration was $6.07 \mathrm{kPa}$ (range:5.38-7.36 kPa).

$\mathrm{HbO}_{2}$ concentration in red telangiectasias was $75.86 \%$ and in blue telangiectasias the $\mathrm{HbO} 2$ concentration was $68.77 \%$. Total carbondioxide concentration was $26.38 \mathrm{mmol} / 1$ in red and 28.08 $\mathrm{mmol} / \mathrm{l}$ in blue telangiectasias. Reference values are listed in Table 1.

In high-frequency 20 - and $50-\mathrm{MHz}$ ultrasound it could be shown that red and blue telangiectasias are located on the same level of the dermis. Underlying feeder veins were located in the deeper dermis.

With LDI a higher concentration of erythrocytes in telangiectasias compared with surrounding skin could be shown.

Table 1. Differences in Oxygenation in Red and Blue Telangiectasias

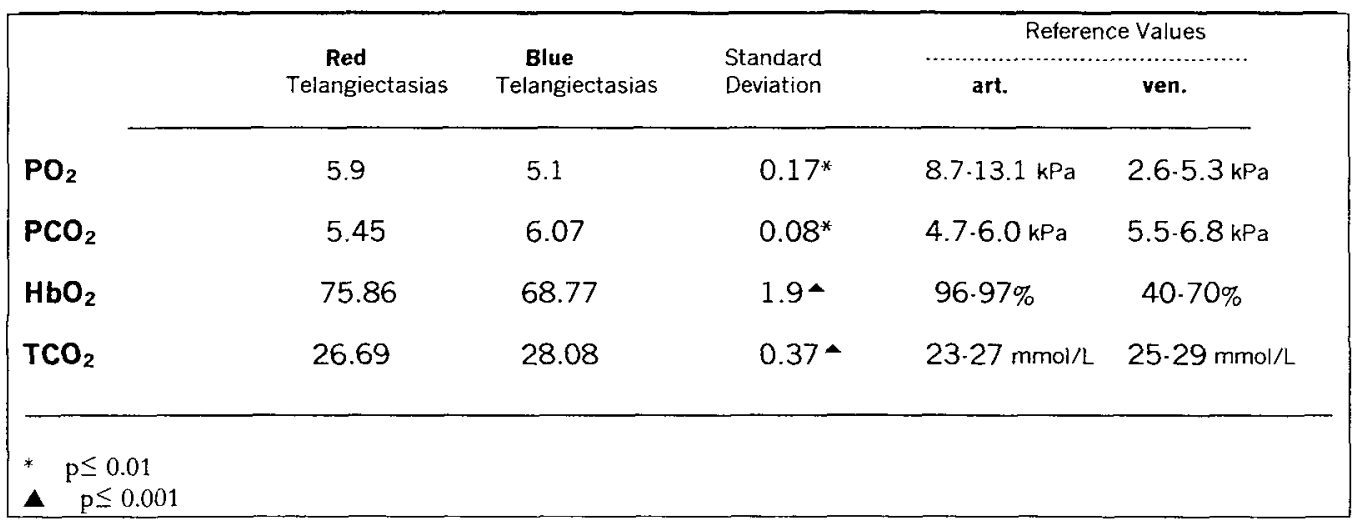

Red telangiectasias are higher oxygenated than blue telangiectasias. In blue telangiectasias a higher carbon dioxide concentration was measured. $\mathrm{PO}_{2}$ : partial oxygen pressure; $\mathrm{PCO}_{2}$ : partial carbon dioxide pressure; $\mathrm{HbO}_{2}$ : percent oxygen saturation of hemoglobine; $\mathrm{tCO}_{2}$ : total plasma carbon dioxide content. 
A)

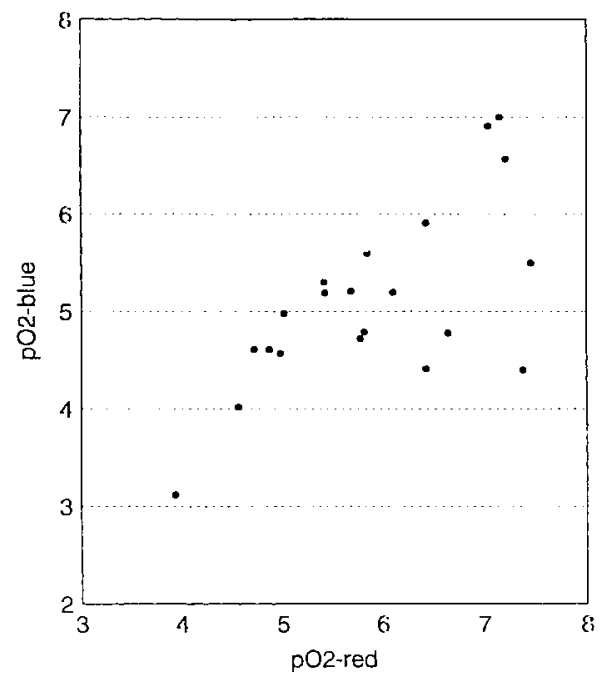

B)

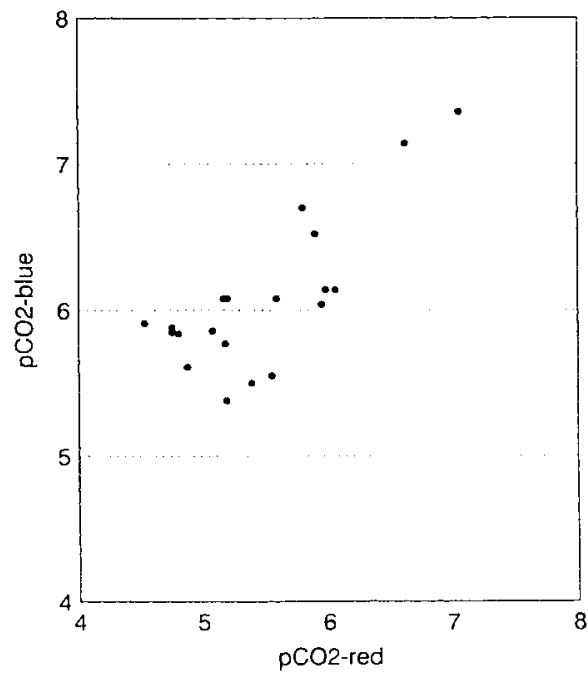

Fig 2: The A) $\mathrm{pO}_{2}$ and $\mathrm{B}$ ) $\mathrm{pCO}_{2}$ concentrations of red as well as blue telangiectasias were measured in each patient. The $\mathrm{pO}_{2}$ value of the red telangiectasia was compared with the $\mathrm{pO}_{2}$ value of the same patients blue telangiectasia. The same was done for $\mathrm{pCO}_{2}$ values. It could be seen that a high $\mathrm{pO}_{2}$ value in a red telangiectasia is associated with a lower $\mathrm{pO}_{2}$ value of the corresponding blue telangiectasia. $\mathrm{PCO}_{2}$ values in blue telangiectasias were found to be higher than in red telangiectasias.

\section{Discussion}

Clinically we classify telangiectasias due to their colour and size. During optical examination of the telangiectasias of our subjects we found different stadia of dilated vessels. According to Duffy (Sadick N, 1990), telangiectasias appear in several manners: as spider veins with a bright red colour and a diameter of 0.1-1 $\mathrm{mm}$, as cyanotic red to blue telangiectasias with a diameter of $1.2 \mathrm{~mm}$, or as blue reticular vessels with a diameter of $2-4 \mathrm{~mm}$ (Figure 1). The distribution patterns of the telangiectasias in our subjects were the parallel lineair pattern, usually found on the medial thigh and the arborising or cartwheel pattern, seen most often in the lateral thigh (Goldman MP, 1991). In some patients a clear-cut classification in red and blue telangiectasias was not possible, because often the difference in colour was not obvious. This fact surely has to be standardised, for example, with scoring the colour of telangiectasias of different observers.

Some authors assumed telangiectasias to be pre-existing capillaries, which are normally not visible according to their size (Bodian EL, 1985; Biegeleisen K, 1987). In patients, suffering from 
telangiectasias, the pre-existing capillaries are dilated and therefore become visible. The underlying pathognomonic factor is still not clear.

In our study we found a difference in oxygenation correlated with the colour of the telangiectasias. Blue and larger capillaries with a diameter $>0.5 \mathrm{~mm}$ had a higher carbon dioxide concentration and the red capillaries $(0.5 \mathrm{~mm})$ were higher oxygenated. Still the oxygenation was below the normal arterial oxygen values. The explanation for these values could be found in underlying physiological and anatomical principles of the capillary bed. As it is demonstrated in figure 3 , blood flows via the arteriole into the arterial loop of the capillary bed and subsequently via the venous loop of the capillary into the venule.

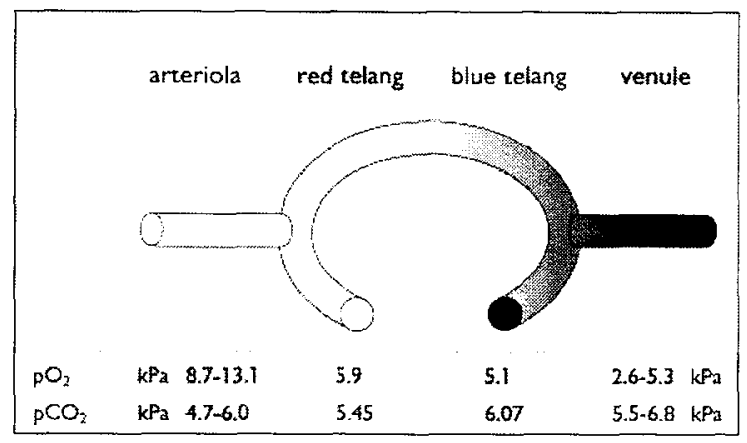

Fig 3: The capillary bed: telangiectasias are assumed to be located in the capillary bed with the red telangiectasia representing the arterial loop of the capillary and the blue telangiectasia representing the venous loop of the capillary.

In the capillary bed exchange of blood gases with the surrounding tissue takes place, so that in the arterial loop of the capillary a transmural contribution of oxygen and carbon dioxide take-up leads subsequently to the venous values of the venous value of the capillary. Therefore we assume the red telangiectasias to be the arterial loop of the dilated capillary and the blue telangiectasias to be the venous loop of the capillary. In theory a macroscopic distinguishable difference in colour of blood can be caused by three different mechanisms: difference in blood flow, arteriovenous shunts, and changes in surrounding tissue of the vessel. Changes in blood flow can be evaluated with capillary microscopy, where the amount of erythrocytes passing the capillary in a defined time-step can be counted. With LDI, microcirculation can be measured. Telangiectasias show a higher flow than the surrounding tissue. Still this method is not sensitive enough to make a distinction between different telangiectasias and therefore cannot detect differences in flow in red and blue telangiectasias. In histology and electron microscopy it could be shown that telangiectasias are dilated blood channels in normal dermal stroma (de Faria et al, 1963; Wokalek et al, 1989) with a single endothelial cell lining, limited muscularis, and adventitia. Most of them seem to evolve from venules and have possibly intimate and direct connection with underlying larger veins of which they are direct 
tributaries (de Faria et al, 1963; Wokalek et al, 1989). Also arteriovenous anastomoses have been described to result in the pathogenesis of telangiectasias (de Faria et al, 1963).

Van der Molen and Kimper (van der Molen et al, 1960) explained the change in colour with a loss of elasticity of the surrounding tissue, which leads to infiltration or sclerosis. As a hormonal factor seems to play an important role in the pathogenesis of telangiectasias (Goldman MP et al, 1987) (e.g. occurring of telangiectasias in pregnancy and after topical application of corticosteroids) it should be investigated whether this hypothesis could be found in collagen staining in histology of telangiectasias. From observation of telangiectasias it is assumed by several dermatologists (Merlen JF, 1970; Sadick N, 1990; Engel A et al, 1988) that telangiectasias come up as small reddish capillaries and turn into blue telangiectasias. The underlying mechanism therefore could be an increasing hydrostatic pressure and backflow from the venous side (Goldman MP et al, 1987; Ramelet AA, 1993). It seems to be possible that a slightly increasing pressure in the venous system leads to a backflow of venous blood into the arterial loop of the capillary. This could explain the rather low oxygen values of the red telangiectasias.

After Von Graf (Merlen JF, 1970) first mentioned the entity telangiectasia in 1807, it took another 120 years before first treatment methods were described. In 1925 Jausion had recommended chromated glycerine as a sclerosing agent for varicose veins, but because of the mild action of this agent it was eventually discarded for this purpose. In 1934 Biegeleisen (Biegeleisen K, 1987) described a microinjection technique for treating telangiectasias. He used sodium morrhuate, but frequently complications occured, such as necrosis, pigmentation, and allergic reaction. Polidocanol was developed in the $1950 \mathrm{~s}$ as an anaesthetic. Its use as an anaesthetic was discontinued when it was found to sclerose small-diameter blood vessels through intravascular injection. Its use as a therapeutic sclerosant for varicous veins was first described by Eichenberg in 1969 (Eichenberg H, 1969). Foley (Foley WT, 1975) and AIderman (Alderman DB, 1977) described their experiences with the use of hypertonic saline solution in concentrations of $18 \%$ and $20 \%$. Until now, solutions in different concentrations of the two last mentioned solutions are a widely used therapy in Europe and North America. Complications of sclerocompression therapy occur frequently. Hyper- and hypopigmentation of the treated areas are also described after injection of a sclerosing agent. Necrosis is a side effect of the therapy that in most cases leaves scars. It occurs when either the solution is too highly concentrated for injection of small vessels or the injection itself is placed paravasal. Furthermore, necrosis seems to occur more often when areas distal of the ankle region are treated (Bean WB, 1958; Partsch H, 1984; Thibault PK, 1993). This phenomenon has been explained by a higher incidence of arteriovenous shunts in this region (Bcan WB, 1958).

As we mentioned above, treatment of telangiectasias is not totally free of side effects. The three most common adverse sequelae include postsclerotic pigmentation, temporary ankle oedema, and telangiectatic matting. Necrosis is a severe side effect and fortunately rarely occurs after injection into an arterial vessel. The most common reason for requesting treatment, however, is for cosmetic improvement. Treatment therefore should be relatively free of any adverse sequelae. Although it is not a common side effect, it should be our aim to find a clinical classification of telangiectasias that could make it possible for the dermatologist to avoid necrosis at all. A better knowledge of the 
pathophysiology thcrefore is necessary. With additional examination, such as the high frequency 20and $50-\mathrm{MHz}$ ultrasound, the localisation of telangiectasias in the dermis can be measured. LDI could reveal an abnormal increased flow, due to an underlying vessel. 


\section{References}

Altmeyer P, El-Gammal S, Hoffmann K. Ultrasound in Dermatology. Springer Verlag, 1991.

Biegeleisen K. Primary lower extremity teleangiectasias- relationship of size to colour. Angiology 1987,10:760-8.

Boehler-Sommeregger K, Karnel F, Schuller-Petrovic S, Santler R. Do Telangiectasias Communicate with the Deep Venous System? J Dermatol Sung Oncol 1992;18:403-6.

Bodian EL. Techniques of sclerotherapy for sunburst venous blemishes. J Dermatol Surg Oncol 1985,11:696-704.

Champion RH. Disorder of Blood Vessels. In: Champion RH, Burton JL, Ebling FJG:Rook, Wilkinson,Ebling,Textbook of Dermatology, 1994, Blackwell,chapt. 41:1842-9.

Cornu-Thenard A, de Cottreau H, Weiss RA. Sclerotherapy - Continous Wave Doppler-Guided Injections. Dermatol Surg 1995;21:867-70.

De Faria JL, Moraes IN. Histopathology of the teleangiectasias associated with varicose veins. Dermatologia 1963;127:321-9.

Engel A, Johnson ML, Haynes SG. Health effects of sunlight exposure in the United States: Results from the first national health and nutrition examination survey: 1971-1974. Arch Dermatol 1988;124:72-9.

Goldman MP, Bennett RG: Treatment of telangiectasia: a review. I Am Acad Dermatol 1987;17:16770.

Goldman MP. Pathophysiology of telangiectasias. In: Goldman MP. Sclerotherapy. Treatment of Varicose and Telangiectatic Leg Veins. 1991;pp86.

Goldman MP, Sadick NS, Weiss RA. Cutaneous necrosis, telangiectatic matting, and hyperpigmentation following sclerotherapy. Etiology, prevention, and treatment. Dermatol Surg 1995; 21:19-29.

Marshall M. Besenreiser-nur ein kosmetisches Problem? Vasomed 1996;8:200-2.

Merlen JF. Red teleangiectasias, blue teleangiectasias. Soc Franc Pblebol 1970, 22:167.

Ramelet AA. Die Behandlung der Besenreiservarizen: Indikation der Phlebektomie nach Mueller. Phlebologie 1993;22:163-7.

Ryan TJ. The epidermis and its blood supply in venous disorders of the leg. Trans St Jobn's Hosp Dermatol Soc 1969;55:51-63.

Sadick NS, Niedt GW. A study of Estrogen and Progesterone Receptors in Spider Telangiectasias of the Lower Extremities. I Dermatol Sum Oncol 1990;16:620-3.

Sadick NS. Treatment of telangiectatic leg veins. J Dermat Surg Oncol 1990;16:24.

Serup J, Jemec GBE. Handbook of non-invasive methods and the skin. CRC Press, 1995.

Van der Molen HR, Kimper JF. Analyse fonctionelle iconographique de la stase veneuse. Congres International de Phlebologie, Chamberg, 6-8 may 1960. Chambery, Imprimeries Reunies, pp.267-77.

Weiss RA, Weiss MA. Continous Wave Venous Doppler Examination for Pretreatment Diagnosis of Varicose and Telangiectatic Veins. Dermatol Surg 1995;21:58-62.

Wienert $\mathrm{V}$, Blazek $\mathrm{V}$. Eine neue Methode zur unblutigen dynamischen Venendruckmessung. Hautaryt 1982,33:498.

Wokalek H. Morphology and localization of sunburst varicositas: an electron microscopic and morphometric study. J Dermatol Surg Oncol,1989;15:149. 
CHAPTER IV

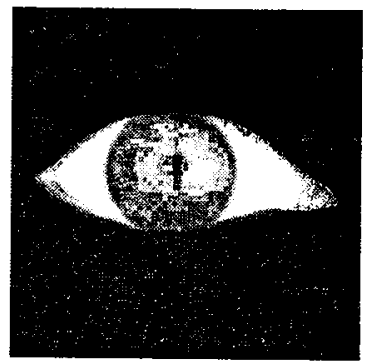

CHANGES IN MICROCIRCULATION IN PATIENTS

WITH ATROPHIE BLANCHE

VISUALISED BY LASER DOPPLER IMAGING

AND TRANSCUTANEOUS OXYGEN MEASUREMENTS

M.B. Maessen-Visch, A. Sommer , J.A. De Paepe, H.A.M. Neumann

Phlebology 1998; 13:45-49 


\section{ABSTRACT}

\section{Objective}

To quantify differences in microcirculation in atrophie blanche $(A B)$ in patients with chronic venous insufficiency (CVI) and in healthy controls before and after venous occlusion.

\section{Design}

Prospective study in a single patient group.

\section{Setting}

Department of Dermatology, University Hospital Maastricht, the Netherlands.

\section{Patients and methods}

16 patients with CVI and large lesions of $A B, 10$ patients with CVI without $A B$ and 10 healthy controls were enrolled in the study. Laser Doppler Imaging (LDI) measurements were performed in and outside large lesions of $\mathrm{AB}$ and in healthy controls. Transcutaneous oxygen $\left(\mathrm{TcPO}_{2}\right)$ measurements were performed in patients with CVI with and without $A B$ and in healthy controls.

\section{Results}

Median basic resting flow was higher in $A B$ than in healthy controls $(0.67 \mathrm{mV}$ versus $0.21 \mathrm{mV}$, $p=0.002$ ). The venoarteriolar response(VAR) was increased significantly in $\mathrm{AB}(58 \%$ versus $43 \%$, $p=0.04$ ). A significant decrease in $\mathrm{TcPO}_{2}$ values occurred in $\mathrm{AB}$ lesions with $40 \mathrm{mmHg}$, in CVI skin with $60 \mathrm{mmHg}$ and in healthy controls with $80 \mathrm{mmHg}$ artificially induced venous pressure.

\section{Conclusion}

Basic resting flux in $\mathrm{AB}$ measured with $\mathrm{LDI}$ is increased compared with clinically normal skin. The decrease in flux on venous occlusion is larger in $\mathrm{AB}$ than in healthy controls. 


\section{Introduction}

Atrophie Blanche $(A B)$ is a clinical disorder often seen by dermatologists and phlebologists. $A B$ is described in scleroderma, systemic lupus erythematodus and cryoglobulinaemia (Berge et al, 1970; Bard et al, 1967; Stevanovic, 1974). Most AB lesions seen in patients, however, are a result of chronic venous insufficiency (CVI) (Bollinger, 1981; Leu, 1990; Widmer et al, 1981; Fournier, 1952; van der Molen, 1953). In 10 - 30\% of patients with CVI, AB is seen (van der Molen, 1953; Frain-Bell, 1959; Folescu, 1994).

CVI is a complex of symptoms caused by venous reflux, due to valvular incompetence of deep, superficial and/or perforating veins, and leading to an increased walking venous pressure. The increased venous pressure of the macrocirculation is transmitted retrogradely into the microcirculation of the skin, resulting in changed morphology of the capillaries. All well-known skin changes in CVI are the result of the disturbed macro- and microcirculation.

In patients with $A B$, not only the morphology of capillaries is changed, but also the number of capillaries is reduced and the capillaries are often obstructed (Leu et al, 1980).

Changes in microcirculation can be studied with transcutaneous oxygen measurements $\left(\mathrm{TcPO}_{2}\right)$ (Franzeck et al, 1984), capillary microscopy (Leu et al, 1991), laser doppler flowmetry (LDF) (Leu et al, 1991) and laser Doppler perfusion imaging (LDI) (Cheatle et al, 1995). In the area of AB, values of $\mathrm{TcPO}_{2}$ are reduced, even to zero (Franzeck et al, 1984). Capillary microscopy in CVI, and especially in $A B$ shows dilated and elongated vessels with a winding, glomerulus-like appearance and an increase in the pericapillary leakage diameter (halo) (Leu et al, 1991). LDF shows increased flux in the skin of patients with CVI (Leu et al, 1984; Belcaro et al, 1989; Creutzig et al, 1994; Cheatle et al, 1991; Leu et al, 1995). Both a decreased vasoconstrictor response on standing in patients with severe CVI (Belcaro et al, 1989; Creutzig et al, 1994), as well as an unchanged vasoconstrictor reaction in medium to severe CVI have been described (Leu et al, 1991; Leu et al, 1995). No specific LDF measurements in AB are reported.

LDF, however, is limited in its clinical usefulness by its poor reproducibility (Cheatle et al, 1995). The main disadvantages are its spatial resolution $\left(1 \mathrm{~mm}^{2}\right)$, artefacts of movement and the difficulty in applying the probe exactly and directly to the previously measured tissue (Cheatle et al, 1995).

Recently LDI has been developed to avoid the disadvantages of LDF and is described as highly reproducible (Cheatle et al, 1995; Stücker et al, 1995; Seifalian et al, 1994). LDI measures perfusion of the skin in a much larger area and yields an average value of 4096 points. There is no contact between the scanner and the skin, so measurements do not influence the blood flow. LDI therefore has many advantages above LDF for assessment of microvascular perfusion of the skin (Seifalian et al, 1994).

The aim of this study was to determine alterations in flux and transcutaneous oxygen values in $\mathrm{AB}$ lesions and healthy looking skin in patients with $\mathrm{CVI}$ before, during and after venous occlusion. Decreased numbers of capillaries and arterioles in $A B$ lesions suggest an increased flux in $A B$ lesions at rest and an altered venoarteriolar response might be found. Our aim was to evaluate the flux in the capillaries in $\mathrm{AB}$. 


\section{Patients and methods}

\section{Patients}

Group A: Sixteen patients ( 8 males, 8 females, average age 61 (32-80) years), with CVI and AB plaque lesions at the medial ankle, larger than $2 \times 2 \mathrm{~cm}$.

Group B: 10 patients ( 5 male, 5 female, average age 65 (43-75) years) with CVI without $A B$ and dermatoliposclerosis.

Group C: ten healthy controls (5 males, 5 females, average age 53 (32-74) years).

CVI was defined as reflux in the superficial, deep and or perforating veins with doppler/duplex ultrasound, decreased venous refilling time $(<15 \mathrm{~s})$ as measured by light reflex theography and by clinical symptoms of corona phlebectatica, $\mathrm{AB}$ and dermatoliposclerosis. Exclusion criteria were arterial insufficiency, diabetes and coagulation disorders. All CVI patients were well compensated and had been wearing elastic compression stockings for at least the last six months. Three patients were known with mild, well-controlled hypertension.

LDI measurements were performed in $A B$ lesions in group $A$, control measurements were performed in the medial ankle region in group $C$ and in the knee region of group $A$.

$\mathrm{TcPO}_{2}$ measurements were performed in $9 \mathrm{AB}$ lesions of group $\mathrm{A}$ and in adjacent non-AB skin. Control measurements were performed at the medial ankle of patients in group B and C. The Ethics Committee of the University Hospital of Maastricht approved the study.

\section{Laser Doppler Imaging}

In order to measure skin perfusion all measurements were performed with the PIM.Lisca version 2.4 (Linköping, Sweden). A full description of the laser Doppler together with an evaluation of the laser technique is given elsewhere (Cheatle et al, 1995). In brief the instrument generates a colour-coded image of the spatial distribution of tissue perfusion (figure 1). The LDI comprises a 2 - $m$ W helium-neon laser whose beam is directed at the tissue via an optical scanner. This consists of two mirrors controlled by two stepping motors, which sequentially measure up to 4096 points. The back-scattered light is detected by a photo diode at a distance of about 15 to $20 \mathrm{~cm}$ from the tissue surface. An area of approximately $12 \times 12 \mathrm{~cm}$ can be scanned. Each colour-coded pixel represents approximately $1 \mathrm{~mm}^{2}$ of tissue. The scanner is controlled by a personal computer, which is also used for image display and storage. The images are displayed with colours representing a scale of mean blood velocity.

\section{Transcutaneous oxygen measurements}

$\mathrm{TCPO}_{2}$ measurements were performed with the transcutaneous TCM 2 (Radiometer, Copenhagen, Denmark) as described previously (Neumann et al, 1984). The $\mathrm{TcPO}_{2}$ electrodes were calibrated in room air. The probe temperature was set to $44^{\circ} \mathrm{C}$.

\section{Procedure}

Patients were placed on a couch in a comfortable supine position with the leg being measured, in a stable, relaxed position. A pneumatic tourniquet (width $18 \mathrm{~cm}$ ) was placed around the thigh of the leg being measured. The distance between the measured skin and the LDI was $20 \mathrm{~cm}$. After 
an acclimatisation period of 15 minutes in a room with a constant temperature of $22^{\circ} \mathrm{C}$, measurements with $\mathrm{LDI}$ were performed in a completely darkened room.

$\mathrm{TcPO}_{2}$ measurements were performed under the same conditions, either 20 minutes after LDI measurements or the next day.

\section{Venous occlusion test}

The first LDI measurement was performed in a square, measuring $36 \mathrm{~mm} \times 36 \mathrm{~mm}$ in an almost complete $\mathrm{AB}$ lesion. The pneumatic tourniquet was inflated to $70 \mathrm{mmHg}$ and measurements were performed after 2 and 5 minutes. The tourniquet was deflated and the last measurement was performed 30 seconds after deflation. Each measurement took 60 seconds.

Control measurements were petformed in the middle of the medial side of knee at the same limb in the healthy skin of 10 patients (group A) and in 10 healthy control patients in the medial ankle region (group C). For all scans, the computer calculated the mean perfusion in millivolts ( $\mathrm{mV}$ ) and the standard deviation (SD).

The venoarteriolar response (VAR) was defined as basic resting flux (BRF) minus flux during venous occlusion (VOC) as a ratio to basic resting flux (100*(BRF-VOC): BRF).

For $\mathrm{TcPO}_{2}$ measurements the tourniquet was inflated after stabilisation was reached (about 30 minutes). The tourniquet was inflated to $20,40,60$ and $80 \mathrm{mmHg}$, for 5 minutes each.

\section{Statistics}

A Graphpad instat software package was used. Results wete statistically compared using Wilcoxon's paired signed rank test, or in the case of inter group comparisons, the Mann-Whitney U test.

\section{Results}

Table 1 shows details of the perfusion in millivolts in AB lesions, healthy skin in CVI patients (knee region) and in healthy controls. Median basic resting flow was significantly higher in areas with $\mathrm{AB}$ lesions than in healthy controls $(0.67 \mathrm{mV}$ versus $0.21 \mathrm{mV} p=0.002)$. Median basic resting flow was also significantly higher in areas with $A B$ lesions, than in control measurements in the knee region $(0.67 \mathrm{mV}$ versus $0.31 \mathrm{mV}, p=0.008)$. 


\section{TABLE 1}

LDI measurements: mean (and mcdian) perfusion in millivolts $(\mathrm{mV})$ in Atrophie Blanche (AB), healthy control patients and normal skin in knee region of patients with $C V I$ and $\Lambda \mathrm{B}$ before, during and direct after venous occlusion.

\begin{tabular}{lccc}
\hline & AB lesions & $\begin{array}{l}\text { healthy control } \\
\text { patients }\end{array}$ & $\begin{array}{l}\text { normal skin in knee } \\
\text { CVI }\end{array}$ \\
\hline $\begin{array}{l}\text { Number of patients } \\
\text { Before venous } \\
\text { occlusion }\end{array}$ & $0.67(0.46)$ & $0.21(0.20)$ & 10 \\
\hline $\begin{array}{l}\text { After } 2 \text { min } 70 \\
\text { mmHg }\end{array}$ & $0.25(0.24)$ & $0.12(0.11)$ & $0.31(0.28)$ \\
\hline $\begin{array}{l}\text { After } 5 \text { min } 70 \\
\text { mmHg }\end{array}$ & $0.27(0.25)$ & $0.11(0.11)$ & $0.19(0.17)$ \\
\hline $\begin{array}{l}\text { After venous } \\
\text { occiusion }\end{array}$ & $0.67(0.49)$ & $0.19(0.20)$ & $0.33(0.34)$ \\
\hline
\end{tabular}

Venous occlusion with $70 \mathrm{mmHg}$ of two minutes, obtained by inflating the tourniquet on the upper leg to $70 \mathrm{mmHg}$, resulted in a decrease of flux. There was a significant difference between decrease in flux of $\mathrm{AB}$ lesions and normal skin [table 1].

\section{TABLE 2}

The venoarteriolar response (VAR): basic resting flux (BRF) minus flux during venous occlusion (VOC) as ratio from basic resting flux $\left(100^{*}(\mathrm{BRF}-\mathrm{VOC}): \mathrm{BRF}\right)$ and the reduction in flux on venous occlusion (VOC/BRF) in $\mathrm{AB}$, in normal skin (knee region) in patients with $\mathrm{AB}$, and in healthy controls.

\section{Normal skin knee region Atrophie Blanche Healthy controls}

\begin{tabular}{llll}
\hline VAR & $33 \%$ & $58 \%$ & $43 \%$ \\
& $p=0.003$ & & $p=0.04$ \\
\hline VOC/BRF & $67 \%$ & $42 \%$ & $57 \%$ \\
& $p=0.004$ & & $p=0.03$ \\
\hline
\end{tabular}

$P$ values, compared with $A B$ lesions 
The flux did not decrease further after 5 minutes of venous occlusion. Deflating the cuff resulted in the same flux as before venous occlusion in both groups.

$\mathrm{TcPO}_{2}$ resting values were significantly lower in $\mathrm{AB}$ lesions [table 3]. $\mathrm{TcPO}_{2}$ resting values were not significantly different in patients with CVI, perilesional measurements and healthy controls. A significant decrease in $\mathrm{TcPO}_{2}$ values compared with basic values occurred in $\mathrm{AB}$ lesions with $40 \mathrm{mmHg}$, in CVI skin with $60 \mathrm{mmHg}$ and in healthy controls with $80 \mathrm{mmHg}$.

\section{TABLE 3}

Average transcutaneous oxygen values (in $\mathrm{mmHg}$ ) in $\mathrm{AB}$ lesions, perilesional skin, $\mathrm{CVI}$ without $\mathrm{AB}$ lesions and healthy controls before, during and after venous occlusion

\begin{tabular}{|c|c|c|c|c|}
\hline & AB lesions & Perilesional & CVI without $\mathrm{AB}$ & Healthy controls \\
\hline Number of patients & 9 & 9 & 10 & 10 \\
\hline Resting values & 10.6 & 58.3 & 62.4 & 63.8 \\
\hline $20 \mathrm{mmHg}$ & 9.4 & 57.7 & 58.9 & 65.1 \\
\hline $40 \mathrm{mmHg}$ & $7.4 *$ & 56.3 & 58.6 & 67.1 \\
\hline $60 \mathrm{mmHg}$ & $5.1 *$ & $53 *$ & $55 *$ & 62.8 \\
\hline $80 \mathrm{mmHg}$ & $4.4 *$ & $46.9 *$ & $47.3 *$ & $52.7^{*}$ \\
\hline After & 7.4 & 53.3 & 59.9 & 67.7 \\
\hline
\end{tabular}

$*=$ significant compared with resting values

\section{Discussion}

Capillary microscopy, 'IcPO2 measurements and LDI measurements (Franzeck et al, 1984; Leu et al, 1991; Leu et al, 1995) can obtain information about the microcirculation. Recently, LDI is added for microcirculatory measurements (Cheatle et al, 1995). The technique of LDI is able to produce a two-dimensional image of the cutaneous microcirculation within a specific area and does not influence the skin because there is no contact between the scanner and the skin (Stuecker et al, 1995; 'Troilius et al, 1992). Although AB is a severe complication of CVI, measurements with LDI performed specifically in $\mathrm{AB}$ lesions have not been reported before. Increased basic flux in patients with CVI in general or liposclerotic skin is described (Leu et al, 1991; Belcaro et al, 1989; Creutzig et al, 1994; Cheatle et al, 1991), however nothing is known about $\mathrm{AB}$.

In this study a significantly increased resting flux measured by LDI has been measured in areas with large $\mathrm{AB}$ lesions in patients with CVI, compared with healthy controls ( $p=0.002$, Mann Whitney test) and in clinical normal looking skin in patients with CVI ( $p=0.008$, Mann Whitney test). 
An increased flux measured by LDI in patients with CVI has been described previously (Leu et al, 1991). An increased resting flux in areas with $A B$ lesions can be explained by the morphology of $\mathrm{AB}$. LDI measures to a depth of $1-1.5 \mathrm{~mm}$, where capillaries, arterioles and venules are present. In $A B$ lesions the number of capillaries is decreased so the blood volume has to pass through a decreased number of capillaries (Neumann, 1992). When the number of moving erythrocytes is increased or when the velocity of blood flow is increased, an increase of flux can be expected. The same volume can only pass through a decreased capillary bed, when the velocity is increased. So other capillaries, leading to an increased basic resting flux perform the function of the occluded capillaries. In summary the increased flux could represent a decreased number of capillaries, and an increase in flow and diameter.

The increase in flux can not only be found in $\mathrm{AB}$ lesions but probably also around $\mathrm{AB}$ lesions. As expected significantly decreased $\mathrm{TcPO}_{2}$ values in $\mathrm{AB}$ lesions were found. $\mathrm{T} C \mathrm{PO}_{2}$ values in CVI patients (both perilesional skin and CVI patients without $A B$ ) were decreased compared with healthy controls, although this difference was not statistically significant. These data are consistent with other studies, which show non-significantly decreased $\mathrm{TcPO}_{2}$ values in patients with CVI without clinical signs, whereas $\mathrm{TCPO}_{2}$ values in patients with $\mathrm{CVI}$ with clinical signs are significantly decreased (Franzeck et al, 1984; Creutzig et al, 1994). In our study $\mathrm{TcPO}_{2}$ measurements of patients with CVI showed no clinical abnormalities: in perilesional measurements $A B$ was avoided, while in patients with CVI, there was only mild CVI, without dermatoliposclerosis and $\mathrm{AB}$.

The contradiction of increased flux and decreased $\mathrm{TcPO}_{2}$ values in $\mathrm{AB}$ lesions can be explained as follows. $\mathrm{TcPO}_{2}$ values predominantly reflect the effects caused by the capillaries (comprising a considerable part of the nutritive vessels), which are partly occluded by microthrombi and might be influenced by fibrin cuffs, trapping of leucocytes and oedema, whereas the LDI mainly reflects the flux of blood in the deeper skin layers (which mainly serve the thermoregulation). Chronic venous hypertension may cause increased flux in the deep vessels, and because of vasodilatation a decreased flux in the superficial vessels, which increase the risk for developing microthrombi. Bollinger suggests that $\mathrm{AB}$ is a result of minor skin infarctions caused mainly by $\mathrm{CVI}$ (Bollinger et al, 1981). Decreased $\mathrm{TcPO}_{2}$ values and decreased numbers of capillaries in $\mathrm{AB}$ support this hypothesis. Other important theories causing CVI play a role such as disturbed fibrin formation and "trapping" of leucocytes are sustained by decreased flux (Browse et al, 1982; Coleridge Smith et al, 1988).

To simulate the high walking venous pressure, that exists in patients with CVI, a venous occlusion test was used. A statistically significant difference in venoarteriolar response, and so a difference in reduction in flux on venous occlusion between $A B$ and healthy skin was found. These data are consistent with other studies, where both Leu et al. and Creutzig et al. (Leu et al, 1991; Creutzig et al, 1994) found a greater decrease in flux on venous occlusion in CVI skin than in healthy controls. Belcaro et al. (Belcaro et al, 1989) described an impaired venoarteriolar response in CVI skin, while no difference was measured in other studies (Cheatle et al, 1995; Juenger et al, 1996). Differences in results might be explained by the different methods used. In most studies LDF is used instead of LDI. LDF, however, is limited in its clinical usefulness by its poor reproducibility (Cheatle et al, 1995). The main disadvantages are its spatial resolution $\left(1 \mathrm{~mm}^{2}\right)$, and the need to apply the probe directly to the tissue of interest (Stuecker et al, 1995). 
LDI has a high reproducibility and records the perfusion in a specific tissue area (Serup et al, 1995).

In addition to different techniques, a gxeater reduction in flux can be expected in CVI patients, because their basic flux is much higher than in healthy controls.

In our study venous hypertension is produced in the supine position by inflating a cuff around the limb, instead of standing position. This method is described by Kuiper and Brakkée and is of proven reliability (Kuiper et al, 1971) and has been used in several studies (Cheatle et al, 1995; Cheatle et al, 1991; Juenger et al, 1996). Venous occlusion by a cuff applied to the thigh results in equal pressures in the veins, causing venous occlusion with an unchanged arterial inflow.

In our study no rebound reaction after venous occlusion was seen in the LDI measurements, neither in CVI patients, nor in healthy controls. This might be caused by the long duration of measurement (about 1 minute).

It can be concluded that basic resting flux in AB lesions measured with LDI is increased compared with clinically normal skin and healthy controls, and that the flux is decreased more by venous occlusion in $\mathrm{AB}$ lesions. A strongly decreased flux on venous occlusion might lead to an increased risk in coagulation disorders of developing microthrombi and trapping of leucocytes, finally resulting in $\mathrm{AB}$ lesions. Because there is no rebound reaction, a lack of reserve capacity of the microcirculation is suggested. 


\section{REFERENCES}

Bard JW, Winkelmann RK. Livedo vasculitis, segmental hyalinizing vasculitis of the dermis. Arch Derm 1967; 96: 489-99.

Belcaro G, Christopoulos D, Nicolaides AN. Skin flow and swelling in post-phlebetic limbs. $V A S A$ 1989; 18: 136-9.

Berge $\mathrm{G}$, Brehmer-Andersson E, Rorsman $\mathrm{H}$. Thalassemia minor and painful ulcers of lower extremities. Acta Dermatovenereol (Stockholm) 1970;50:125-8.

Bollinger A. Atrophie blanche: Hautinfarkt verschiedener Pathogenese? VASA 1981;10:67-9.

Browse NL, Burnand KG. The cause of venous ulceration. Lancet 1982;2:243-5.

Cheatle TR, Quashie C, Villemur B, Carpentier P. Two-dimensional laser Doppler imaging and microcirculatory function in patients with venous skin damage. Phlebology 1995;10:32-6.

Cheatle TR, Coleridge Smith PD, Scurr JH. Skin microcirculatory responses in chronic venous insufficiency: the effect of short-term venous hypertension. $V A S A$ 1991;20:63-9.

Coleridge Smith PD, Thomas P, Scurr JH, Dormandy JA. Causes of venous ulceration: a new hypothesis. BrMed J 1988;296:1726-7.

Creutzig A, Caspary L, Alexander K. Changes of skin mictocirculation in patients with chronic venous insufficiency assessed by laser doppler flowmetry and transcutaneous oxymetry. Pblebology 1994; 9:158-63.

Folescu F. Venous disease: epidemiological and clinical aspects. Scripta Pblebologica 1994;2:42.

Fournier A. Atrophie blanche; hypodermite sclereuse et ulcères de jambe (considerations cliniques). Excerpta Med 1952; XIII 6: 353.

Frain-Bell W. Atrophie blanche. Transactions of the St John's bospital Dermatological Society, London (UK), 1959; 42:59-65.

Franzeck UK, Bollinger A, Huch R, Huch A. Transcutaneous oxygen tension and capillary morphologic characteristics and density in patients with chronic venous competence. Circulation 1984; 70: 806-11.

Jünger $M$, Klyscz $T$, Hahn M, Rassner $G$. Disturbed blood flow regulation in venous leg ulcers. Int J Microcirc 1996; 16: 259-65.

Kuiper JP, Brakkee AJM. Unblutige Venendruckmessung. Hautartt 1971; 21: 153-9.

Leu AJ, Leu H-J, Franzeck UK, Bollinger A. Microvascular changes in chronic venous insufficiency- a review. Cardiovasc Surg 1995; 3: 237-45.

Leu HJ. Chronisch-venöse Insuffizienz heute. VASA 1990; 19: 195-202.

Leu HJ, Yanar A, Pfister G, et al. Mikroangiopathie bei chronischer venöser Insuffizienz. DMW 1991;116:447-53.

Leu HJ, Wenner A, Spycher MA, Brunner U. Ultrastrukturelle Veränderungen bei der Atrophie blanche. VASA 1980; 9: 142-6.

Molen van der HR. Revascularisatie van de "atrophie blanche" van Milian. Ned Tijdschr Geneeskd 1953; 97: 2194-7.

Neumann HAM, van Leeuwen $M$, van den Broek MJTB, Berretty PJM. Transcutaneous oxygen tension in chronic venous insufficiency syndrome. $V A S A$ 1984; 13: 213-9.

Neumann HAM. Measurement of microcirculation. Haut- und Gescblechtskrankbeiten 1992; 4: 261-2.

Seifalian AM, Stansby A, Howell K, Hamilton G. Comparison of laser Doppler imaging, laser doppler flowmetry, and thermographic imaging for assessment of blood flow in human skin. Eur J Vas Surg 1994; 8: 65-9.

Serup J, Jemec GBE. Non-invasive methods and the skin. CRC Press Inc, Boca Raton/Florida (USA), 1995:421-9.

Stevanovic DV. Atrophie Blanche, a sign of dermal blood occlusion. Arch Dermatol 1974;109:85862. 
Stücker $M$, Jeske $M$, Hoffmann $K$, Altmeyer P. Laser-doppler-scanning bei progressiver systemischer Sklerodermie. Pblebologie 1995; 24: 9-14.

Troilius A, Wårdell $\mathrm{K}$, Bornmyr S, Nilsson GE, Ljunggren B. Evaluation of port wine stain perfusion by laser Doppler imaging and thermography before and after argon laser treatment. Acta Derm Venereol (Stockb) 1992; 72: 6-10.

Widmer LK, Stähelin HB, Nissen C, Silva da A. Venen-,Arterien-Krankheiten, koronare Herzkrankheit bei Berufstätigen. Verlag Hans Huber, Bern Switzerland, 1981. 
Chapter V

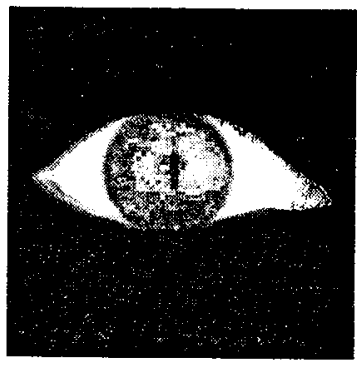

EVALUATION OF THE

VASOCONSTRICTIVE EFFECTS OF TOPICAL STEROIDS

\section{BY LASER-DOPPLER-IMAGING}

A. Sommer, F. Kessels, M. Neumann

Acta Dermatol Venereol (Stockh) 1998; 78: 15-18. 


\section{Summary}

Corticosteroids are one of the most frequently prescribed local therapeutic treatments. Their potency and bioavailability are tested with different methods. One of the most accepted methods is the skin-blanching test designed by McKenzie. In this study we investigated whether the skin-blanching test designed by McKenzie for screening topically active corticosteroids, producing vasoconstriction, is sufficiently detectable by a laserDoppler-perfusion-imager (LDI).

Eight sites in two rows on the right forcarm of 10 healthy volunteers were treated with a topical glucocorticosteroid (clobetasol-17-propionate 0.05\% (Dermovate ${ }^{\circledR}$ ), GLAXO, The Netherlands), and the blood-flow at each site was measured by the LDI at different timesteps. Four sites per row were chosen to evaluate the dependency of bioavailability according to anatomical differences due to skin changes within the forearm. Furthermore, half of the sites were occluded to demonstrate the difference between occluded and nonoccluded sites in bioavailability.

The results show that the LDI can easily detect changes in bloodflow due to the vasoconstriction caused by topical corticosteroid. The results showed significant changes during the different measurements, with a maximum reaction $30 \mathrm{~h}$ after the application of the corticosteroid. The sites under occlusion showed a slower decrease of laser values than those without occlusion, so that it can be pointed out that occlusion prolongs the bioavailability of corticosteroids but does not influence the speed of onset.

So far we conclude that this technique is a simple and non-traumatic method for assessing steroid potency. Blanching, as a result of vasoconstriction, can be quantified by LDImeasurement. However, LDI-measurements have to be compared with other techniques, such as the non-traumatic $133 \mathrm{Xe}$ washout technique, to find out if the two technologies respond in a similar way. 


\section{Introduction}

It is now generally accepted that all anti-inflammatory steroids act through a common mechanism, involving binding to specific glucocorticoid receptors (Baxter, 1976). Specific binding of glucocorticoids has been shown to take place in a wide variety of cells, including human fibroblasts and keratinocytes (Ponec et al, 1982). Ncxt to the anti-inflammatory effect, transmitted through releasing factors, glucocorticosteroids work antimitotically (Clarys et al, 1991), such as in psoriasis.

Skin blanching, assessed by the vasoconstrictor assay technique of McKenzie \& Stoughton (McKenzie et al, 1962), has been used for evaluation of percutaneous absorption of corticosteroids in humans. Different approaches to quantify the skin blanching have been more or less reliable and reproducible. In an attempt to record the degree of skin blanching at each site more quantitatively, the vasoconstrictor activity has been measured with several techniques, e.g. using instrumental colour-readings (tri-stimulus colorimeter) (Zaun et al, 1973; Altmeyer et al, 1976), the reflectance spectrophotometric quantification (Feather et al, 1982; Anderson et al, 1993; Blazek et al, 1980; Pershing et al, 1994; Aiche et al, 1980; Kristensen et al, 1976), thermography (Petersen et al, 1989), the 133Xe washout technique (Bisgaard et al, 1986; Falconi et al, 1972), laser-Doppler-flow (Blazek et al, 1980; Smith et al, 1995) and the paper-patch-test (Smith et al, 1982). These methods have often been supported by visual scoring of the blanching effect (Engel et al, 1974; Uhl et al, 1994; Trollius et al, 1992).

A new possibility was given by the LDI, which measures the perfusion of cutaneous microcirculation. In this study we wanted to investigate whether this rather new technique was sensitive enough to measure changes in microcirculation of the skin after applying corticosteroids.

The LDI is appropriate for measuring the microcirculatory changes of the skin of individual subjects after local corticosteroid application and is a technique that produces reliable and accurate data and determines the degree of vasoconstriction. Compared to the above mentioned tests for assessing vasoconstriction after corticosteroid application, the major advantage of the LDI is that it is easy to handle. Furthermore, the measurements take place without any physical skin contact. The LDI has been used quite often during the last years for determining advances in wound healing (Haigh et al, 1984) and for detecting abnormal bloodflow in pathologically changed skin.

The purpose of the study was to assess the changes in flow of the skin microcirculation after application of topical corticosteroid.

\section{Patients and Methods}

Ten healthy Caucasian subjects were studied, and consent was obtained in each case. The average age was 28 years (range 22 to 36 years; 5 females, 5 males). The subjects had no skin disease; nor had they used topical or systemic corticosteroid preparations in the previous 2 months. All patients were non-smokers. The skin blanching method used was a modification of that described by McKenzie \& Stoughton (McKenzie et al, 1962) and Haigh \& Kaufer (Haigh et al, 1984). A non-occluded and an occluded assay were used on two rows containing each four 
sites of the flexor aspect of the right forearm, avoiding the 4-cm strips of skin adjacent to the wrist and elbow, which Burdock ((Burdock, 1974)) reported to be poor test areas in the vasoconstrictor assay. The corticosteroid formulation (clobetasol-17-propionate, Dermovate ${ }^{\circledR}$ ointment, GLAXO) was drawn into a plastic syringe and $0.02 \mathrm{ml}$ steroid was applied to each of the test areas (with a diameter of $18 \mathrm{~mm}$ per test site) of forearm skin and spread evenly with a glass-rod. The application was repeated after 1,2 and $3 \mathrm{~h}$ to maximise the percutaneous absorption, as described earlier (Bisgaard et al, 1986; Falconi et al, 1972). Then one row, consisting of four test sites, was occluded with Tegaderm ${ }^{\circledR}$ (3M,Canada), which was removed at least half an hour before the measurements.

Laser-Doppler-measurement was performed before the first and 8,24,30,48 and $72 \mathrm{~h}$ after the last steroid application. Measurements were made under standard conditions with respect to posture and pre-measurement equilibration time $(30 \mathrm{~min})$ to room temperature $\left(25^{\circ} \mathrm{C}\right)$. All measurements were performed with the PIM Lisca 1.0 version 2.4 (Linköping, Sweden). A full description of the LDI together with its evaluation of the laser technique is given elsewhere (Harding et al, 1985). Briefly, the instrument generates a colour-coded image of the spatial distribution of tissue perfusion. The LDI comprises a $2-\mathrm{mW}$ helium-neon laser whose beam is directed at the tissue via an optical scanner. This consists of two mirrors controlled by two stepping motors which sequentially measure at maximum 4,096 points (pixels). The backscattered light is detected by a photo diode at a distance of about 15 to $20 \mathrm{~cm}$ from the tissue surface. A maximum area of $150 \mathrm{~cm}^{2}$ can be scanned by this technique with a spatial resolution of $2 \mathrm{~mm}$ corresponding to $4 \mathrm{~mm}^{2}$ (Ruetten et al, 1994). The scanner is controlled by a personal computer, which is also used for image display and storage. The images are displayed with colours representing a scale of average blood velocity.

In our study the distance between the scanner head and the test site was $18 \mathrm{~cm}$. A low resolution mode was used, with an image format of 36 X 36 pixels. The threshold background was 6.20 .

To determine the influence of location, the measurement time and occlusion status of the site on the laser measurement, a four-way Anova was performed with location, the patient, the moment of measurement and occlusion as independent factors. For the occluded and nonoccluded sites a three-way Anova with the three factors location, moment of measurement and patient was performed separately.

In four subjects the proximal occluded test site showed irritation due to Tegaderm ${ }^{\circledR}$ after $24 \mathrm{~h}$, lasting for 3 days, so that LDI-measurements of these test sites were not included in the study.

\section{RESUlTs}

In total, 480 measurements were performed. All values were compared with measurements before the application of the corticosteroid, revealing a mean flow of $0.38 \mathrm{mV}$ (arbitrary units, range: $0.25-0.48 \mathrm{mV}$ ). An increase of the laser values (arbitrary units) could be found until the third measurement $(8 \mathrm{~h}$ after last application). After this (the next measurement took place at 24 $\mathrm{h}$ after the last steroid application), the laser values decreased significantly to rise again with a second peak $30 \mathrm{~h}$ after last application $(0.534 \mathrm{mV}$, sd 0.017 ; without occlusion and $0.608 \mathrm{mV}$, sd 
0.018 under occlusion). From their maximum they decreased steadily within the following measurements until they reached the same values as in the beginning of the study $72 \mathrm{~h}$ after the last application of the corticosteroid $(0.37, \mathrm{sd} 0.018$ without occlusion and $0.47 \mathrm{mV}$, sd 0.02 under occlusion). These data are shown in Fig. 1.

The most obvious differences between occluded and non-occluded sites were found after 30 h (see Fig. 2).

Measurements on the distal sites showed higher laser values (mean:0.49 $\mathrm{mV}$ ) than on the proximal ones $(0.32 \mathrm{mV})$, which is also shown in Fig. 2.

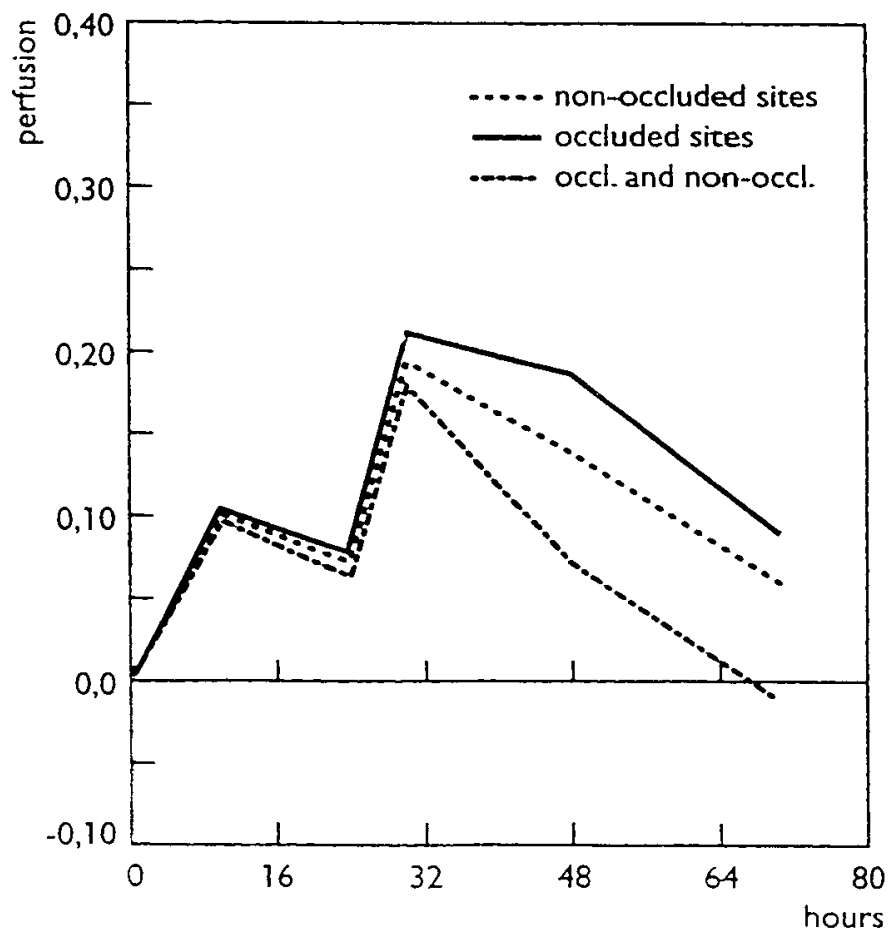

Fig. 1:

Perfusion: Change in perfusion compared to the baseline perfusion

An increase of the laser values (arbitrary units) could be found until the third measurement $(8 \mathrm{~h}$ after application). After this the laser values decreased significantly to rise again with a second peak $30 \mathrm{~h}$ after application $(0.534 \mathrm{mV}$, sd 0.017 ; without occlusion and $0.608 \mathrm{mV}$, sd 0.018 under occlusion). From theit maximum they decreased steadily within the following measurements until they reached the same values as in the beginning of the study $72 \mathrm{~h}$ after the application of the corticosteroid $(0.37$,sd 0.018 without occlusion and $0.47 \mathrm{mV}$, sd 0.02 under occlusion). 


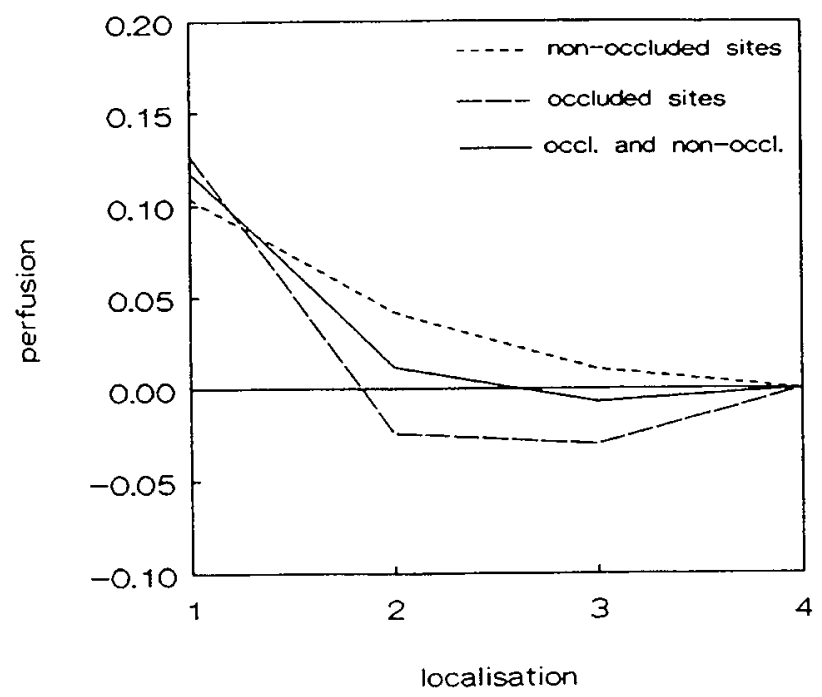

Fig. 2: Higher measurements are shown on the distal sites than on the proximal ones, which is seen at any time of measurement, but most obviously $30 \mathrm{~h}$ after application.

\section{Discussion}

It was our intention to evaluate in this study whether LDI can be used in the evaluation of skin blanching after local steroid application. When one interprets the results of LDI on the human skin several factors have to be borne in mind. The magnitude of blanching may be influenced by a number of variables, such as ambient temperature and relative humidity. Standard conditions before measuring are therefore important. Similarly, the differences in the vascularisation of the dominant and non-dominant arms may affect the degree of blanching induced by topical corticosteroids (Engel et al, 1974). Also the vehicle of the tested ointment could influence the microcirculation and should therefore always be tested separately. The vehicle used in our study, clobetasol-17-propionate (Dermovate ${ }^{\circledR}$ ointment excipient), was investigated in a former study and was reported to have no significant influence on the microcirculation(Falconi et al, 1972).

It is still a problem to visually classify changes in skin colour with the eye. The results of other studies obtained by visual scoring were largely comparable with our results. Also a biphasic vasoconstriction was found after topically applied steroids (Andersen et al, 1991). The authors explained the second peak as a reactive vasodilative phase. To exclude the possibility of an influence of the circadian steroid release we made control measurements with the time table shifted $12 \mathrm{~h}$. The decrease of the LDI signal remained the same. Other studies, however, did find an influence of blood cortisol levels on the skin colour changes after steroid application (Kristensen et al, 1978; Noon et al, 1996). In our opinion, so far no good explanation exists for this obvious biphasic curve, also found in earlier reports. 
At first the results of our measurements were surprising to us, since a decrease of LDI flow was expected after local steroid application. However, the measured flow represents a ratio of volume per time-unit (i.e. the product of the total amount of red blood cells multiplied with the amount of moving red blood cells). Vasoconstriction leads to a decrease in capillary diameter. Subsequently velocity increases and the blood volume decreases. The last two changes are in accordance with an increase in the product of blood cell volume and speed (and therefore the LDI signai), provided that the velocity increases more than the blood volume is reduced.

A second physical explanation could be that erythrocytes in a small blood vessel (10-20 $\mu \mathrm{m})$ pass one after the other and not in groups of adhesive erythrocytes. This leads to the phenomenon that the laser is counting relatively more erythrocytes in constricted blood vessels. This has been supported by in vitro studies on laser Doppler values within different haematocrits, showing an increase in signal with an increase of the haematocrit (McKenzie, 1962).

Furthermore a change in flow pattern in the capillaries can explain part of our results. The velocity of erythrocytes in the middle of a blood vessel is higher than at the margin. Vasoconstriction therefore induces an increased LDI signal.

Recently different techniques have been compared in one study (Meyer et al, 1992) in order to evaluate their sensitivity to assess skin blanching. Beside visual scoring and laser Dopplet velocimetry two measurements with LDI were performed (before application and $1 \mathrm{~h}$ after removal of the glucocorticoid). Glucocorticoids (betamethasone dipropionate) were also applied to the volar side of the forearm. The measured site included the test site and the surrounding skin. Afterwards the mean flux was calculated of the central $15 \times 15 \mathrm{~mm}$ square. The results of this investigation showed that LDI was of no use assessing skin blanching. Measurements before and after application of the steroid did not show a significant difference. In our opinion it is necessary to measure only the test sites to minimise the influence of physiological changes in blood flow. As we know that corticosteroids influence the blood flow of the skin for at least $72 \mathrm{~h}$, it is not sufficient to measure only before and after application of the corticosteroid.

In our study we also evaluated the effect of occlusion and the location on vasoconstriction due to local steroid application. Under occlusion the corticosteroid remains longer active on the skin. This is due to an increased percutaneous absorption as a result of epidermal maceration and increased skin temperature (Meyer et al, 1992). Occlusion does not seem to accelerate the bioavailability of the applied corticosteroid (Fig. 1). Nearly the same values for occluded and nonoccluded sites in the first $30 \mathrm{~h}$ were found. After this, the LDI signal of the occluded sites was significantly higher than that of the nonoccluded sites. We could therefore establish that occlusion prolongs the bioavaliability of corticosteroids without influencing the time of onset.

Concerning the site of steroid application we found a clear-cut gradient of decreasing blanching response from wrist to elbow. These differences in local reactions have been observed by others (Kirsch et al, 1982). The exact nature of this site-dependent response to topically applied steroids is not known. It is likely that factors relating to the vasculature are responsible. Another possible explanation could be local differences of subcutaneous fatty tissue. At this moment it should be therefore recommended to test each preparation at several sites along the 
forearm of each volunteer, in order to obtain an accurate comparative assessment of corticosteroid release from topical delivery vehicles.

In conclusion we can state that LDI is a simple and non-traumatic method for studying local skin blanching after steroid application. In contrast to visual scoring it is an objective method for assessing skin blanching, and especially when it becomes almost impossible for the observer to distinguish any blanching at all the LDI is of great advantage. It can become a valuable instrument for the assessment of stetoid potency in dermatology.

\section{ACKNOWLEDGEMENTS}

We thank Dr. Slaaf and Prof. Nilsson for their valuable help during the discussion of the results, and special thanks to Dr. Ruetten for his helpful suggestions. 


\section{References}

Aiche JM, Lafaze CL, Bouzat J. Evaluation de la disponibilite topique des corticoides par thermographie. J Pharm Belg 1980;35:187-95.

Altmeyer P, Zaun H. Ergebnisse reflexionsphotometrischer Bestimmungen der Vasokonstriktion nach topischer Steroidapplikation. V Arch Dermatol Res 1976;255:5156.

Andersen $\mathrm{P}$, Milioni $\mathrm{K}$, Maibach $\mathrm{H}$. The cutaneous corticosteroid vasoconstriction assay: a reflectance spectroscopic and laser-Doppler flowmetric study. Br J Dermatol 1993;128:660-665.

Baxter JD. Glucocorticoid hormone action. Pharm Therap Bulletin 1976; 2:605-609.

Bisgaard $\mathrm{H}$, Kristensen $\mathrm{JK}$, Sondergaard J. A new technique for ranking vasculature corticosteroid effects in humans using laser-Doppler velocimetry. I Invest Dermatol 1986;86:275-278.

Blazek V, Wienert V. Ein neues Verfahren zur Objektivierung des Vasokonstriktionstests nach topischer Anwendung von Kortikosteroiden. Akt Dermatol 1980;6:129-134.

Burdock KH. Various vagaries of vasoconstriction. Arch Dermatol 1974;110:238.

Clarys P, Wets L, Barel A, Gabard B. The skin blanching assay with halcinonide, influence of halcinonide concentration and application time.J Eur Acad Derm Venero 1995;5:250257.

Engel DJS, Marx AF, Rekker RF, v Wijk L. Topically active corticosteroids. Arch Dermatol 1974;109:863-865.

Falconi G, Rossi GL. Paper-patch test for evaluating vasoconstrictive activity of corticosteroids. Arch Dermatol 1972;105:856-858.

Feather JW, Ryatt KS, Dawson JB, Cotterill JA, Barker DJ, Ellis DJ. Reflectance spectrophotometric quantification of skin colour changes induced by topical corticosteroid preparations. Br J Dermatol 1982;106:437-444.

Haigh JM, Kaufer I. Assessment of topical corticosteroid preparations: the human shin blanching assay. Int J Pharm 1984;19:245-262.

Harding SM, Sohail S, Busse MJ. Percutaneous absorption of clobetasol propionate from novel ointment and cream formulations. Clin Exp Dermatol 1985;10:13-21.

Kirsch J, Gibson JR, Darley CR. Forearm site variation with the corticosteroid vasoconstrictor assay. Br J Dermatol 1982;106:495.

Kragballe K. Topical corticosteroids: mechanisms of action. Acta Derm Venereol (Stockb) 1989;69 (Suppl. 151):7-10.

Kristensen JK, Wadskov S, Henriksen O. Dose-dependent effect of topical corticisteroids on bloodflow in human cutaneous tissue. Acta Derm Venereol (Stockh) 1978;58:145-148.

McKenzie AW. Percutaneous absorption of steroids. Arch Dermatol 1962;86:91-94.

McKenzie AW, Stoughton RB. Method for comparing percutaneous absorption of steroids. Arch Dermatol 1962;86:608-610.

Meyer E, Smith EW, Haigh JM. Sensitivity of different areas of the flexor aspect of the human forearm to corticosteroid-induced skin blanching. Br J Dermatol 1992;127:379-381.

Nilsson GE, Wardell K. Laserdoppler- perfusion monitoring and imaging of blood microcirculation. SPIE 1994;2136:54-62.

Noon JP, Evans CE, Haynes WG, Webb DJ, Walker BR. A comparison of techniques to assess skin blanching following the topical application of glucocorticoids. Br J Dermatol 1996;134:837-842.

Pershing LK, Corlett JL, Lambert LD, Poncelet CE. Circadian activity of topical $0.05 \%$ betamethasone dipropionate in human skin in vivo. I Invest Dermatol 1994;102:734-739.

Petersen LJ, Kristensen JK. Time-course of corticosteroid-induced blood flow in normal cutaneous tissue - quantitative measurements during $72 \mathrm{~h}$ of treatment. Clin Exp Dermatol 1989;14:210-213. 
Ponec M, Kempenaar JA, De Kloet ER. Corticoids and cultured human epidermal keratinocytes: specific intracellular binding and clinical efficacy. I Invest Dermatol 1981;76:211-214.

Queille-Roussel C, Poncet M, Schaefer H. Quantification of skin-colour changes induced by topical corticosteroid preparations using the Minolta Chroma Meter. BrJ Dermatol 1991;124:264-270.

Ruetten W, ed. Untersuchung zu Laser-Doppler-Verfahren in stark streuenden Medien mit Hilfe der Monte-Carlo-Methode. Verlag Shaker,D 82, promot. RWTH Aachen,1994:5.

Smith EW. Four decades of topical corticosteroid assesment. Curr Probl Dermatol 1995;22:124131.

Troilius A, Wardell K, Bornmyr S, Nilsson GE, Ljunggren B. Evaluation of port wine stain perfusion by laser Doppler imaging and thermography before and after argon laser treatment. Acto Derm Venereal (Stockb) 1992;72:6-10.

Uhl E, Sirsjo A, Haapaniemi T, Nilsson G, Nylander G. Hyperbaric oxygen improves wound healing in normal and ischemic skin tissue. Plast Reconstr Surg 1994;93:835-841.

Warrdell K, Nilsson G. Laser Doppler imaging of the skin. In: Serup J, Jemec GBE, eds. Noninvasive methods and the skin. 1995. pp. 421-428.

Zaun H, Altmeyer P. Ergebnisse reflexionsphotometrischer Bestimmungen der Vasokonstriktion nach topischer Steroidapplikation - Methode, Aussagekraft, Fehlerquellen. Arch Derm Forsch 1973;247:379-386. 


\section{Chapter VI}

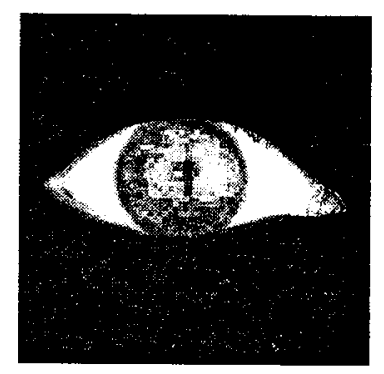

VASOCONSTRICTIVE EFFECT OF TOPICAL APPLIED CORTICOSTEROIDS MEASURED BY

\section{LASER DOPPLER IMAGING AND} REFLECTANCE SPECTROSCOPY

Anja Sommer, Gerald W. Lucassen, Alfons J.H.M. Houben, Martino H.A. Neumann 


\begin{abstract}
Topically applied corticosteroids induce blanching of the skin. The blanching effect is based on changes of the underlying skin microcirculation. Conventional measurement of the intensity of blanching after topically applied corticosteroids relies on subjective assessment by a trained observer using a visual score. Objective determination using non-invasive bioengineering techniques is desirable in order to quantify the blanching effect and to assess the underlying affection of the skin perfusion. The purpose of this paper was to assess changes in the vascular plexus during $72 \mathrm{~h}$ after topical applied corticosteroids of different potency and control sites by two non-invasive techniques, laser Doppler imaging (LDI) and diffuse reflectance spectroscopy (DRS). Clobetasol-di-propionate was the most potent vasoconstrictor. DRS shows after 8 $(1,49 \pm 0,6 \mathrm{SEM})$ and after $30 \mathrm{~h}(0,52 \pm 0,36)$ significant changes in blood flow (during blanching and reactive hyperemia). LDI shows a slight change after $8 \mathrm{~h}(-0,04 \mathrm{aU} \pm 0,02$ blanching $)$ and a second reaction after $30 \mathrm{~h}$ (LDI: $0,18 \mathrm{aU} \pm 0,04$ reactive hyperemia) is significant. In LDI higher values for men after $30 \mathrm{~h}$ were found than for women (clobetasol-17-propionate under occlusion $\Delta \mathrm{t}_{30}-\mathrm{t}_{0}$ men: $0.47 \mathrm{aU} \pm 0.18 ; \mathrm{n}=7 ; \Delta \mathrm{t}_{30}-\mathrm{t}_{0}$ women: $\left.0.14 \mathrm{aU} \pm 0.02 ; \mathrm{n}=10 ; \mathrm{p}=0.025\right)$. It can be concluded that DRS is of more value for detecting blanching, whereas LDI has its sensitivity in hyperperfused skin. Men and women showed clear differences during measurements with both devices, suggesting that sex differences should be taken into account.
\end{abstract}




\section{Introduction}

The "blanching"-effect after corticosteroid application to the skin is well known and described in literature (Mc Kenzie and Stoughton, 1962). This method is often used to assess the clinical potency of corticosteroid formulations. For the clinical use different topical corticosteroids have been developed that differ in strength of action. Depending on their potency they are said to induce slight to strong "blanching". The blanching is proposed to be a change in microcirculation of the skin, as corticosteroids are a potent vasoconstrictor. The precise mechanism of action is not yet fully elucidated. Until now it is postulated that corticosteroids produce vasoconstriction of the superficial small vessels, followed by a phase of rebound vasodilatation (Smith et al, 1976). Conventional measurement of the intensity of blanching relies on subjective assessment by a trained observer using a visual score as described by McKenzie (Mc Kenzie and Stoughton, 1962). Several objective techniques have recently been reported to detect skin blanching. Reflectance spectrophotometry has been used in different studies (Noon et al, 1996, Andersen et $a l, 1992)$. It has been shown that it is a useful tool to quantify individual changes in skin colour after steroid application (Noon $e t$ al, 1996) as skin colour is largely determined by the quantity of blood cells in the dermis (Feather et al, 1982). Reflectance spectroscopy records information from different skin depths as the penetration depth depends on the wavelengths used. Therefore it gives information on different layers of skin vascularisation. Hence, it attributes to the analysis of microcirculation with laser-Doppler imaging (LDI), which measures in one layer.

LDI has been used previously by our group for determining the effect of skin blanching (Sommer $e t a l, 1998$ ). The laser-Doppler device measures dermal microcirculation as a product of the number of erythrocytes and erythrocyte movement (velocity) with a penetration depth of several hundred micrometers into the skin (Wardell et al, 1993). Due to the fact that the measured laser value is a product of two parameters, both could be affected whilc its product remains the same. For example, in case that after steroid application superficial blood concentration is decreasing but the mean velocity is increasing (due to vasoconstriction), LDI values could be unchanged. To disentangle the changes in both parameters one of these parameters has to be measured independently. In this study this is done using diffuse reflectance spectroscopy (DRS), giving information on changes in erythrocyte concentration via the amount of light absorption in different skin layers. The aim of this study is to combine the information obtained by DRS and LDI in order to elucidate the blanching effect induced by topically applied corticosteroids.

\section{Methods}

\section{Volunteers:}

17 healthy Caucasian volunteers were recruited among the hospital employees and medical students after obtaining informed consent. The investigation was conducted according to Declatation of Helsinki principles in healthy individuals between 18-65 years old. The criteria for non-inclusion were skin diseases at the test site as well as the use of topical/systemic corticosteroids in the last 2 months prior to the measurements. 


\section{Corticosteroid application.}

The skin blanching used is a modification of that described by McKenzie \& Stoughton (McKenzie and Stoughton, 1962) and Haigh \& Kaufer (Haigh and Kaufer, 1984). A nonoccluded and an occluded assay were used on the flexor aspect of the left forearm on two rows containing each 4 sites, located in the middle of the wrist/elbow distance (Fig 1). The distance between the application sites was $1-2 \mathrm{~cm}$ depending on the length of the forearm. It is known that blanching inconsistencies occur along the human forearm (Meyer et al, 1992); therefore one preparation was applied consistently on the same site in each volunteer. Each row contained an untreated control site, the vehicle (70\% ethanol), triamcinolone acetonide $0.1 \%$ and clobetasol17-propionate solution (Dermovate ${ }^{\circledR}$ ointment, GLAXO) both in ethanol (70\%). The ointments were drawn into plastic syringes and $0.02 \mathrm{ml}$ steroid/vehicle was applied (with a diameter of 18 $\mathrm{mm}$ per test site) on the forearm skin and spread evenly with a glass rod. The application was repeated after 1,2 and $3 \mathrm{~h}$ to maximize the percutaneous absorption, as described earlier (Kristensen et al, 1978, Petersen and Kristensen, 1989). After the last application of the corticosteroids, occlusion of one row was performed with Tegaderm ${ }^{\circledR}$ (3M,Canada), which was removed half an hour before the measurements with the LDI and DRS.

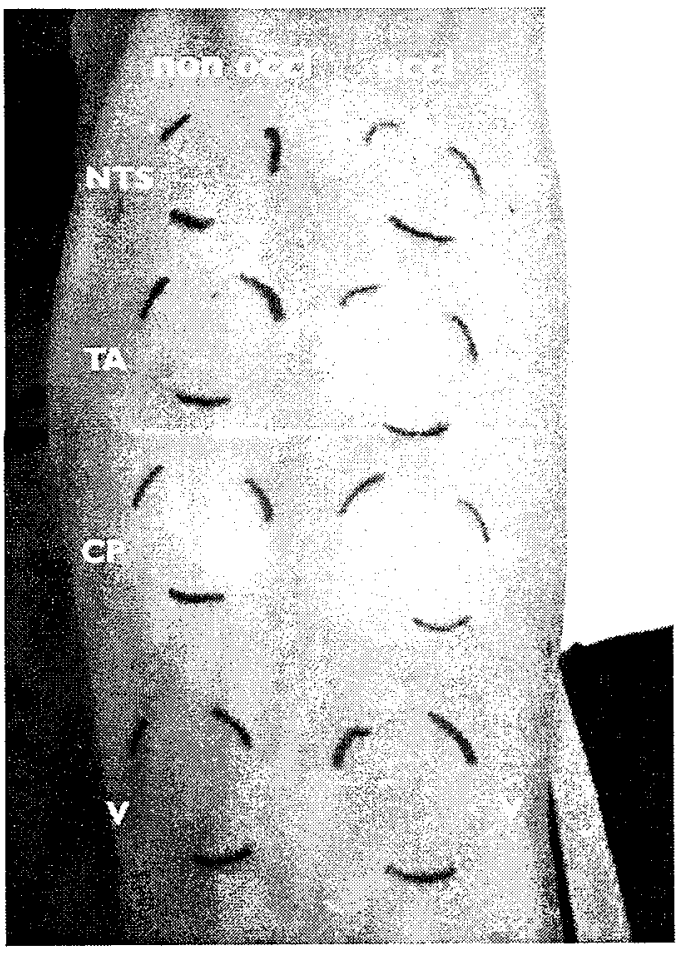

Fig 1: Occluded (occl) and non-occluded (non-occl) application sites of $\mathrm{CP}=$ clobetasol-17-propionate, $\mathrm{TA}=$ triamcinolon $0.1 \%, \mathrm{~V}=$ vehicle and NTS = non treated skin on the volar aspect of the forearm. $12 \mathrm{~h}$ after first application, visible blanching at TA occl site and both CP sites. 


\section{Measurement setting:}

Measurements were made under standard conditions with respect to posture and premeasurement equilibration time $(30 \mathrm{~min})$ to constant room temperature $\left(23-25^{\circ} \mathrm{C}\right.$ ). The subjects were asked not to talk or move during the readings. During the study vasoconstrictive substances (e.g. coffee, tea, and nicotine) were prohibited. Subjects werc asked to avoid scratching any area of the test site. The only light permitted during the measurements was that emitted by the computer monitor at its lowest setting.

\section{Control measurements:}

Control measurements after intracutaneous injection of histamine $(2 \mu \mathrm{mol} / \mathrm{L})$ respectively a solution of adrenaline $(1 / 10.000$ in $\mathrm{NaCl})$ on the contralateral volar forearm, were performed once in at random 9 of the 17 volunteers in order to evaluate the minimum and maximum reference values of the tested site.

\section{Measurement equipment: \\ LDI:}

As described before the instrument generates a colour-coded image of the spatial distribution of tissue perfusion (Wårdell et al, 1993). All measurements were performed with the PIM.Lisca 1.0 version 2.4 (Lisca development $A B$, Linköping, Sweden). The LDI comprises a 1 -mW heliumneon laser $(632 \mathrm{~nm})$ whose beam is directed at the tissue via an optical scanner. This consists of two mirrors controlled by two stepping motors that sequentially address a maximum of 4,096 points (pixels). The back-scattered light is detected by a photo diode at a distance of $18 \mathrm{~cm}$ from the tissue surface. The scanner is controlled by a personal computer, which is also used for image display and storage. A low-resolution mode was used, with an image format of $20 \times 20$ pixels. The intensity of an individual perfusion point is expressed in arbitrary units $(\mathrm{aU})$ with a perfusion range between 0 and $10 \mathrm{aU}$ and a background threshold level of $6.1 \mathrm{aU}$. The perfusion values obtained are converted to a colour coding and eventually presented in an image.

\section{DRS:}

Visible diffuse reflectance spectroscopy (DRS) (Douven and Lucassen, 2000) was done using a HP8452A photo-spectrometer (Hewlet Packard, Waldbronn, Germany) with a photodiode array detector with $2 \mathrm{~nm}$ spectral resolution in the $400-820 \mathrm{~nm}$ wavelength range. Data acquisition time is $0.1 \mathrm{~s}$ per spectrum. The spectrometer is equipped with a hand-held probe with an integrating cylinder with an entrance port diameter of $10 \mathrm{~mm}$ (Labsphere RSA-HP-84F). A 6Whalogen lamp provides illumination of the skin. The (specular and) diffuse reflectance is captured in the cylinder and transmitted to the spectrometer by a glass fibre. Calibration was performed using a $99 \%$ reflectance standard. Measurements were repeated 5 times per test site and the mean value is calculated in the $400-820 \mathrm{~nm}$ range and used for further calculations.

The mean reflectance $(\mathrm{Rm})$ over the spectral wavelength range of $400-820 \mathrm{~nm}$ is a simple measurement for the amount of reflectance from the skin. The blanching results in a higher mean reflectance. Another output parameter from the reflectance spectta is the erythema index (EI) as defined by Andersen and Bjerring (Andersen and Bjerring, 1990). This parameter is sensitive to 
skin 'tedness'. Morc skin redness gives a higher EI value, skin blanching on the other hand gives a lower EI value. Therefore we used the negative EI as a "blanching index".

\section{Measurement timing:}

LDI measurements were performed before the first and $8,24,30,48$ and $72 \mathrm{~h}$ after the last steroid application. Measurement timing was planned according to expected changes in microcirculation after steroid application as known from literature. DRS measurements were performed before the first and $8,12,24,30,48$ and 72 after the last steroid application. DRS is a less time consuming technique and therefore additional measurements were performed at $12 \mathrm{~h}$ after application. To minimize the influence of a circadian thythm and diurnal variations on microcirculation, the study design was planned on same time steps on subsequent days $(0$, 24,48,72 h) (Houben et al, 1994).

\section{Statistical analysis:}

Statistical analysis was performed with SPSS software (SPSS version 9.0 for Windows). A nonparametric test was used (Wilcoxon-Rank-test) for independent variables, such as sex, steroids, and measurement device. Data are presented as means \pm S.E.M.

Table 1. Mean of maximum effect of all subjects for occluded and non-occluded test sites

\begin{tabular}{|c|c|c|c|}
\hline & $\begin{array}{l}\text { NON/ } \\
\text { OCCL }\end{array}$ & $\begin{array}{c}\Delta \text { L.DI } \\
n=17\end{array}$ & $\underset{\mathrm{n}=17}{\Delta \text { DRS }}$ \\
\hline \multirow[t]{2}{*}{$\mathrm{CP}$} & non & $0.20 \pm 0,04$ & $6.7 \pm 0.15$ \\
\hline & occl & $0.27 \pm 0,09$ & $9.9 \pm 0.6$ \\
\hline \multirow[t]{2}{*}{ TA } & non & $0.13 \pm 0,02$ & $3.5 \pm 0.9$ \\
\hline & occl & $0.12 \pm 0,02$ & $7.2 \pm 0.6$ \\
\hline \multirow[t]{2}{*}{$\mathrm{V}$} & non & $0.08 \pm 0,02$ & $-0.9 \pm 0.6$ \\
\hline & ocd & $0.11 \pm 0,02$ & $2.5 \pm 0.6$ \\
\hline \multirow[t]{2}{*}{ NTS } & non & $0.09 \pm 0,02$ & $-0.5 \pm 0.7$ \\
\hline & occl & $0.08 \pm 0,04$ & $2.8 \pm 0.1$ \\
\hline
\end{tabular}

1

${ }^{1} \mathbf{C P}=$ clobetasol-17-propionate, $\mathbf{T A}=$ triamcinolon $0.1 \%, \mathrm{~V}=$ vehicle and $\mathbf{N T S}=$ non treated skin. $\triangle \mathrm{LDI}$ values are shown in arbitrary units (aU) at $\mathrm{t} 30$ - t0 and $\triangle \mathrm{DRS}$ as erythema index $(\Delta \mathrm{EI})$ at $\mathrm{t} 12-\mathrm{t} 0$. occl=occluded; non=non-occluded.

Error definition: mean - SEM 


\section{Results}

All data were collected within a total measurement period of 2 weeks. All subjects (17 volunteers), 10 women (mean age: 28.8 years, $22-40$ years), 7 men (mean age: 33.1 years, 26-56 years) completed the trial. No adverse events occurred during the study period.

1. Occluded clobetasol-17-propionate induced the most prominent changes of values for both devices. For the other test sites results are shown in Table 1. The effect of occlusion and nonocclusion has already been described in an earlier study of our group (Sommer et al, 1998) and will not be discussed again. In short, occlusion prolongs the bioavailability of corticosteroids but does not influence the speed of onset.

Changes in values are calculated as a difference between treated skin and the vehicle site at each time step (Fig 2a). For clobetasol-17-propionate LDI shows a change of values $8 \mathrm{~h}$ after application of the steroid and a maximum in LDI values (aU) was reached at $30 \mathrm{~h}$ after application of the corticosteroid ( $\triangle$ clobetasol-17-propionate - vehicle at $8 \mathrm{~h}:-0.04 \mathrm{aU} \pm 0.02 \mathrm{SEM}$, $\mathrm{n}=17$; at $30 \mathrm{~h}: 0.18 \mathrm{aU} \pm 0.04, \mathrm{n}=17)$. The mean DRS reflectance curves as a function of time show a peak at 8-12 $\mathrm{h}$ after application (Fig $2 b$ ). In the erythema index (EI) curves this peak also occurs (Table 1, Fig 2c), and an additional peak occurs at $30 \mathrm{~h}$ for the occlusive site corticosteroid ( $\Delta$ clobetasol-17-propionate - vehicle at $8 \mathrm{~h}: 1.49 \pm 0.6, \mathrm{n}=17$; at $30 \mathrm{~h}: 0.52 \pm 0.36$, $\mathrm{n}=17$ ).

2. Control measurements in 9 subjects after intracutaneous injection of histamine (hist) (1-3 $\mu \mathrm{mol} / \mathrm{L})$, respectively a solution of adrenaline $(1 / 10.000 \mathrm{NaCl}$ solution), showed a significant difference in values. Both LDI (Fig 3) and DRS (Fig 4) values for histamine were significantly different from adrenaline values.

3. The absolute differences between the LDI values obtained at $30 \mathrm{~h}$ of application of the corticosteroid clobetasol-17-propionate and before application are higher for men than for women (clobetasol-17-propionate under occlusion $\Delta \mathrm{t}_{30}-\mathrm{t}_{0}$ men: 0.47 aU $\pm 0.18 \mathrm{SEM}, \mathrm{n}=7 ; \Delta \mathrm{t}_{30}-\mathrm{t}_{00}$ women: 0.14 aU $\pm 0.02, \mathrm{n}=10 ; \mathrm{p}=0.025$ ) (Fig 5). For DRS the reflectance data show minor differences between sexes. The most prominent difference between women and men is seen in the erythema index curves at the occlusive sites after $30 \mathrm{~h}$. However, these differences are not statistically significant (clobetasol-17-propionate under occlusion $\Delta \mathrm{t}_{3,1}-\mathrm{t}_{\mathrm{t}}$ men: $-8.05 \pm 0.74, \mathrm{n}=7$; $\Delta \mathrm{t}_{30}-\mathrm{t}_{0}$ women: $\left.-9.72 \pm 0.6, \mathrm{n}=10 ; \mathrm{p}=0.10\right)$.

The difference in sex is almost in accordance with the responders-group and non-respondersgroup. For the LDI the responders are defined by the occurrence of a peak at 8 and $30 \mathrm{~h}$ after clobetasol-17-propionate application with at least a value change of $0.15 \mathrm{aU}$, see table 1 ( $\triangle \mathrm{LDI}$ ). This is found in 1 woman and 6 men (mean $\Delta \mathrm{t}_{30}-\mathrm{t}_{0}: 0.21 \mathrm{aU} \pm 0.03, \mathrm{n}=7$ ). Non-responders did not show a prominent change in $\mathrm{LDI}$ values compared with the first measurement. This is found in 9 women and 1 man (mean $\Delta \mathrm{t}_{30}-\mathrm{t}_{0}: 0.09 \mathrm{aU} \pm 0.009, \mathrm{n}=9$ ). For the DRS, responders are defined by the occurrence of a peak in mean reflectance $(\mathrm{Rm})$. 6 women and 6 men belong to the responder group (mean $R m$ responders: $1.08 \pm 0.004, n=12$; mean $R m$ non-responders: $1.02 \pm 0.01, n=5$ ). 


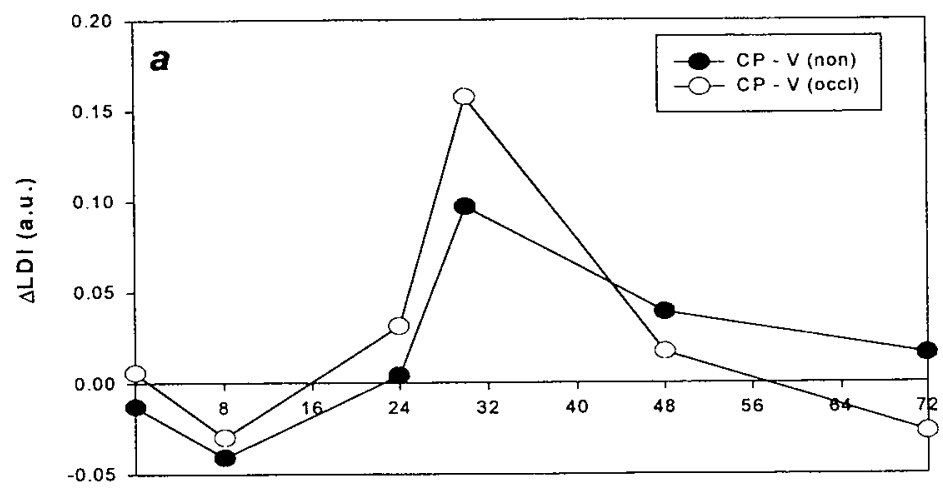

Time (hrs)
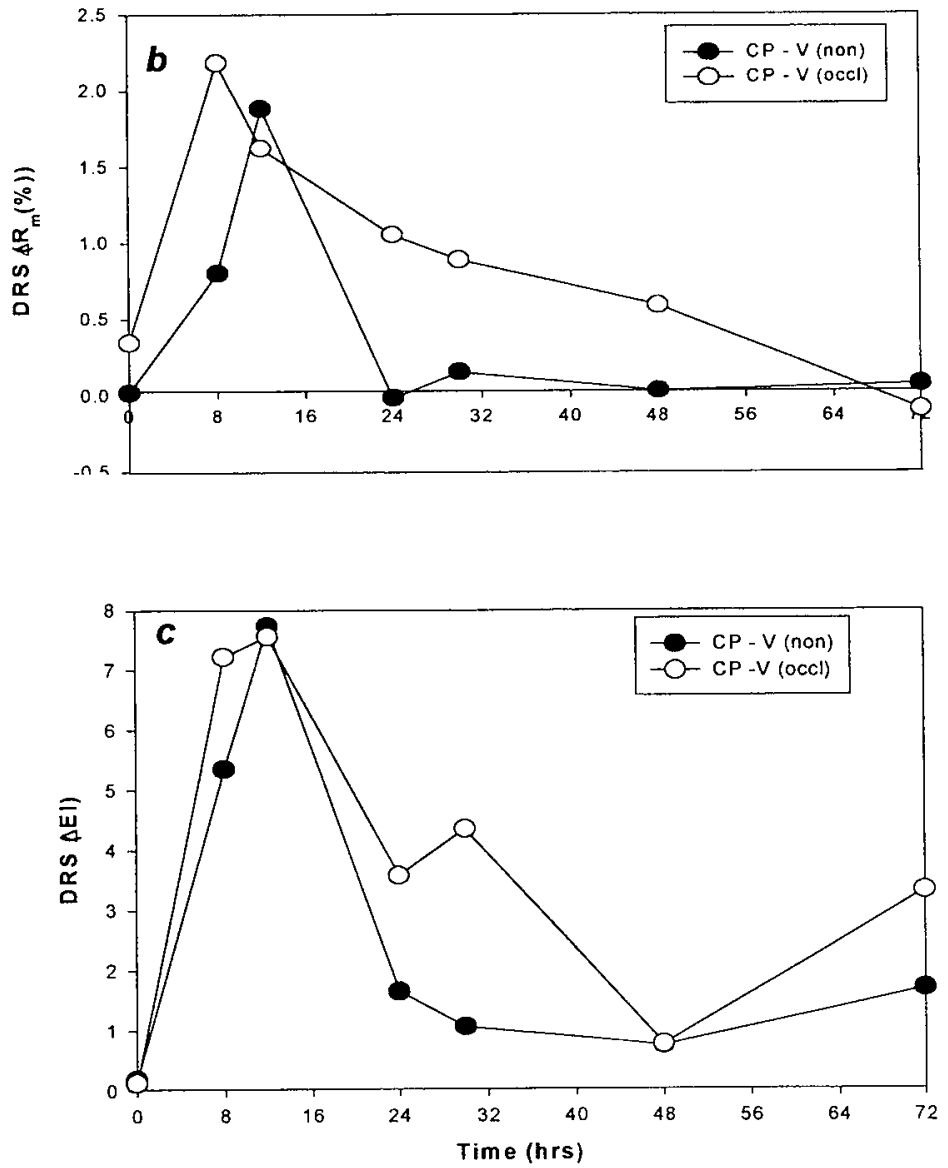

Fig. 2: Clobetasol-17-propionate (CP) minus vehicle (V). Mean values for occluded (occl) and non-occluded (non) test sites. (a) $\triangle \mathrm{LDI}$ values, (b) $\triangle \mathrm{Rm}$ of DRS values, (c) $\triangle \mathrm{EI}$ of DRS values 


\section{Discussion}

In the study by Sommer et al. (1998) it was demonstrated that LDI is able to measure changes in microcirculation after topically applied corticosteroids. The present study shows that LDI is of inferior value to DRS in detecting the blanching effect after steroid application, yet both devices can detect the hyperemic response $30 \mathrm{~h}$ after application. Most prominent changes from baseline measurements appeared after clobetasol-17-propionate application. The differences between measurements of triamcinolon sites and clobetasol-17-propionate sites are not statistically significant, but the values are consistently higher for clobetasol-17-propionate. The vehicle sites and the non-treated skin sites show lower values.

In DRS the blanching phenomenon yields a pronounced change in $\mathrm{Rm}$ and $\mathrm{EI}$ values, which reflect changes in blood concentration predominantly in the superficial plexus rather than changes in blood concentration over the whole depth of the dermis. From inspection of the DRS spectra (in the $400-820 \mathrm{~nm}$ wavelength region) these changes are found in the region of high absorption by haemoglobine (510-610 $\mathrm{nm}$ ).

In LDI the dominant contribution to the LDI signal measured at $632 \mathrm{~nm}$ stems from several hundred micrometers deep i.e. in the dermal layer (Warrdell et al, 194), which explains the lower sensitivity to detect the changes in the superficial blood plexus compared to DRS. This suggests that the blanching phenomenon originates in the superficial plexus rather than blood flow decrease over the whole dermis, possibly related to the penetration depth of the steroid.

Corticosteroids are widely prescribed by dermatologists. From the beginning corticosteroids were introduced in dermatology, the phenomenon of blanching is known and the underlying mechanism is presumed to be a change in microcirculation. It is also presumed that blanching is an indicator for the potency and therapeutic effect of corticosteroids on skin diseases (Mc Kenzie Stoughton, 1962). Still the precise influence on the microcirculation responsible for the blanching phenomenon is not known.

As mentioned above the most prominent changes from baseline measurements appeared after clobetasol-17-propionate and will therefore be discussed exemplary. Results will be discussed by means of maximal blanching- ( $8 \mathrm{~h}$ ) and maximal hyperemic ( $30 \mathrm{~h}$ ) effect, supported by the earlier described working mechanism of the influence of corticosteroids on the microcirculation (Smith et al, 1976).

\section{Diffuse reflectance spectrophotometry:}

In DRS the effect of the corticosteroid leads to a peak of the $\mathrm{Rm}$ value $8-12 \mathrm{~h}$ after application. This is also seen in the EI plot. The Rm value is an average value of the reflectance over the whole wavelength range, whereas EI is more sensitive to changes in light absorption due to vasoconstriction (Andersen and Bjerring 1990), both representing the blanching of the skin probably due to vasoconstriction of the superficial plexus. Thirty $h$ after steroid application DRS values are still elevated from baseline but already decreased comparing to their maximum at $8 \mathrm{~h}$. After $30 \mathrm{~h}$ the vasoconstrictive effect of the steroid has diminished and microcirculation in the superficial plexus is returning to the output value. A decrease of the $\mathrm{Rm}$ and EI values possibly indicate the fact that vasoconstriction is replaced by an upcoming hyperemia. 


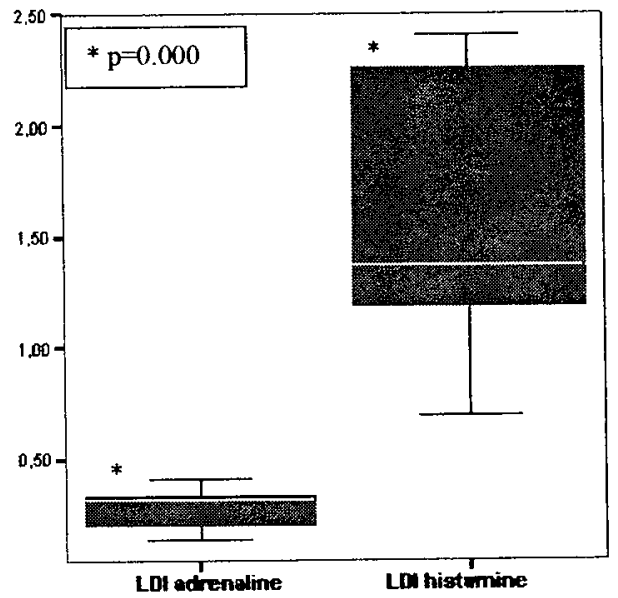

Fig.3: LDI values (aU) after intracutaneous injection of histamine/adrenaline

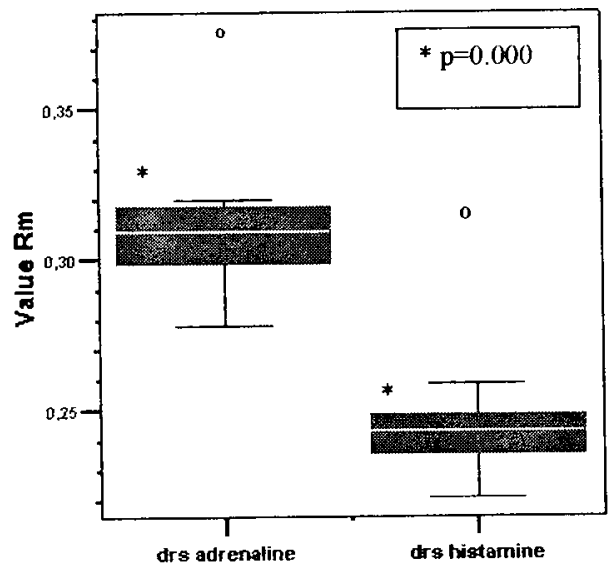

Fig. 4: DRS values $(\mathrm{Rm})$ after intracutaneous injection of histamine/ adrenaline. 


\section{Laser Doppler Imaging:}

In LDI vasoconstriction leads to no significant signal changes $8 \mathrm{~h}$ after starting the measurements in all the subjects. As LDI measures microcirculation as a product of the number of erythrocytes and erythrocyte velocity it would be expected that LDI values decrease due to the vasoconstriction. In a former study (Sommer et al, 1998) a biphasic curve after steroid application with a slight peak $8 \mathrm{~h}$ and a more prominent peak after $30 \mathrm{~h}$ was found. The observed increase in signal intensity at $8 \mathrm{~h}$ was interpreted to present vasoconstriction presuming that due to a smaller diameter in constricted vessels the erythrocytes have a higher velocity. Now, being able to compare the LDI results with DRS values we consider the higher values of the LDI in the former study to be a reaction to the application of the occlusive dressing that has not been removed in time prior to the measurement $8 \mathrm{~h}$ after application of the corticosteroid. The occlusive dressing probably induced skin irritation of the tested area leading to an increased blood flow and thus an increase in LDI values. This effect overlaid the blanching effect of the corticosteroids. Probably the layer in which LDI measures is not influenced by topically applied steroids after $8 \mathrm{~h}$. Thirty $\mathrm{h}$ after application LDI shows a prominent peak representing an increase in signal strength and thus a higher flux as seen in hyperperfused skin (Mayrovitz et al, 1999). The reaction after $30 \mathrm{~h}$ can therefore be explained as a reactive hyperaemia after corticosteroid application.

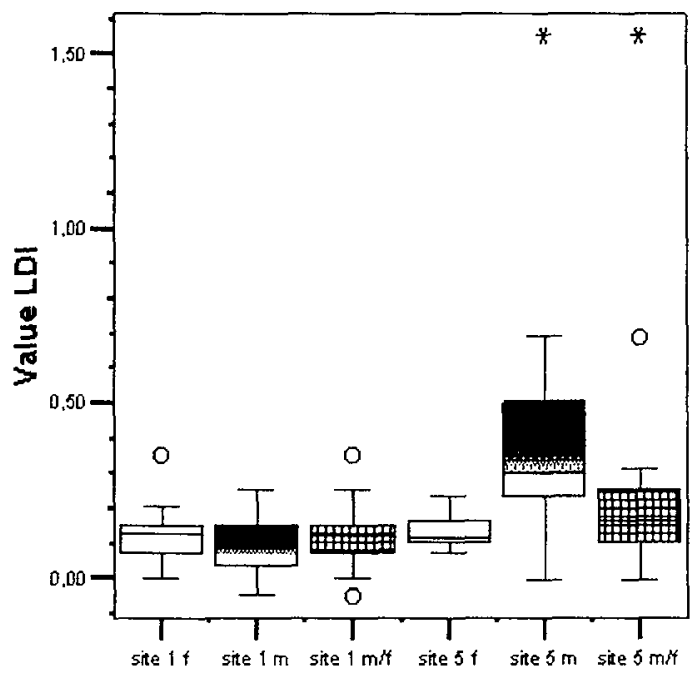

Fig. 5: Differences in sexes:

$\Delta \mathrm{Ldi}$ values $\mathrm{t} 30-\mathrm{t} 0$ of occlusive and non occlusive sites

site $1 \mathrm{f}: \Delta \mathrm{t} 30$-t0 values of women of non treated skin; site $1 \mathrm{~m}: \Delta \mathrm{t} 30$-t0 values of men of non treated skin; site $\mathrm{m} / \mathrm{f}: \Delta \mathrm{t} 30-\mathrm{t} 0$ values of men and women of non treated skin; site $5 \mathrm{f}$ : $\Delta \mathrm{t} 30$ - $\mathrm{t} 0$ values of women of the clobctasol-17-propionate site; site $5 \mathrm{~m}: \Delta \mathrm{t} 30$-t0 values of men of the clobetasol-17-propionate site; site $5 \mathrm{~m} / \mathrm{f}: \Delta \mathrm{t} 30$-t 0 values of men and women of the clobetasol-17-propionate site. 


\section{General considerations}

Although laser Doppler techniques and reflectance spectroscopy have a different approach in measuring changes in microcirculation, previous measurements on erythema have shown good correlation (Andersen et al, 1991). DRS irradiates the skin with polychromatic light and measures the fraction of incident light which is diffusely reflected in the wavelength range of 400-820 nm. Using a monochromatic laser beam $(632 \mathrm{~nm})$ directed on to the skin surface, LDI determines the Doppler shift, caused by moving erythrocytes and their amount. LDI was found to be less sensitive of assessing corticosteroid induced blanching.

Histamine, producing inflammation, induces erythema and oedema. LDI should be able to measure the erythema component. The effect of adrenaline, a potent vasoconstrictor, is comparable to the blanching effect after applying corticosteroids. Therefore, it can be postulated that the effect of adrenaline and the blanching mechanism should evoke the same effect in LDI measurements. DRS is known to measure both, blanching and erythema. Both techniques were tested after dermal histamine and adrenaline injection. Indeed LDI and DRS measure both blanching due to vasoconstriction after adrenaline application and erythema after histamine application. However, LDI values of vasoconstriction are similar to normal perfused skin whereas LDI values in erythema are in a 2 - to 3 fold higher range. Therefore it can be concluded that the LDI device is a very useful tool for measuring erythema.

From clinical experience we consider corticosteroids to be as potent in women than in men. Therefore it was not the aim of this study to investigate the influence of gender on the blanching effect. Yet, during statistical analysis differences in sexes were found in this study. Thirty hours after clobetasol-17-propionate LDI values are significantly higher in men than in women. To our knowledge so far it has not been published that sex differences have been found in studies using the McKenzie protocol. As we know from several parameters of the skin, e.g. transepidermal water loss, women and men do react different on skin tests (Chilcot and Farrar, 2000). Skin texture and thickness differ between men and women even at the volar aspect of the forearm (Bravermann et al, 1990; Chilcott and Farrar, 2000). The literature about microcirculation provides conclusive evidence that regional variations in the basal skin blood flow are present (Tur et al, 1983). It has to be further investigated whether e.g. the penetration depth of topically applied steroids or the receptor density for corticosteroids differs within sexes. It is also possible that sex hormones influence the effect of topical applied corticosteroids. The DRS shows only a slight difference in sexes. Confirm to the finding of sex differences responders and nonresponders form different groups in LDI and DRS. The LDI group of responders consisted of 1 woman and 6 men. With DRS, 6 women and 6 men were considered to be responders. The 7 responders in LDI do also belong to the DRS responder group. It can be concluded, that the stronget response in men is detectable with LDI measurements and that DRS due to its higher sensitivity in measuring vasoconstriction can detect also slighter changes in microcirculatory changes.

Visual scoring still seems to be a practical and useful approach for assessing clinical potency of corticosteroids, however gender differences and underlying microcirculatory mechanisms need an instrumental objective approach. 


\section{Conclusions}

The blanching effect is probably based on a reduced blood flow in the supcrficial plexus rather than microcirculatory changes over the whole dermis. Therefore it can be assessed casily by DRS. LDI is less sensitive in measuring vasoconstriction, but it shows an obvious response in hyperperfused skin and should be rather used for the assessment of inflammatory skin reactions. In the future it is necessary to compare our data of microcirculation with that of new devices that give more anatomical information about the dermal blood supply such as Colour Doppler Optical Coherence Tomography (Kehlet et al, 1999). 


\section{References}

Andersen PH, Bjerring P. Spectral reflectance of human skin in vivo. Photoderm Photoimmun Photomed 1990;7: 5-12.

Andersen PH, Abrams K, Bjerring P, et al . A time correlation study of UVB-induced erythema measured by reflectance spectroscopy and laser Doppler flowmetry. Photoderm Photoimmunol Photomed 1991;8: 123-128.

Arildsson M, Asker CL, Salerud EG, et al. Skin capillary appearance and skin microvascular perfusion due to topical application of analgesia cream. Microvasc Res. 2000;59:14-23.

Braverman IM, Keh A, Goldminz D. Correlation of laser Doppler wave patterns with underlying microvascular anatomy. J Invest Dermatol 1990;95:283-286.

Chilcott RP, Farrar R. Biophysical measurements of human forearm skin in vivo: effects of site, gender, chirality and time. Skin Research and Technology 2000;6:64-69.

Douven LFA, Lucassen GW. Retrieval of optical properties of skin from measurement and modelling the diffuse reflectance. Proc SPIE 3914, Progr in biomedical optics and imaging,1:312-23.

Feather JW, Ryatt KS, Dawson JB et al: Reflectance spectrophotometric quantification of skin colour changes induced by topical steroid preparations. Br J Dermatol 1982;106:437-443.

Haigh JM, Kaufer I. Assessment of topical corticosteroid preparations: the human skin blanching assay. Int J Pharm 1984;19:245-262.

Houben AJHM, Slaaf DW, Huvers FC, et al. Diurnal variations in total forearm and skin microcirculatory blood flow in man. Scand J Lab Invest 1994;54:161-168.

Kehlet B, Izatt JA, Kulkarni MD. Three-dimensional reconstruction of blood vessels from in vivo colour Doppler optical coherence tomography images. Dermatology1999;198:355-361.

Kelly RI, Pearse R, Bull R, Leveque JL, et al. The effects of aging on the cutaneous microvasculature. J Am Acad Dermatol 1995;33:749-756.

Kristensen JK, Wadskov S, Henriksen O. Dose-dependent effect of topical corticosteroids on bloodflow in human cutaneous tissue. Acta Derm Venereol (Stockb)1978;58:145-148.

Mayrovitz HN, Macdonald J, Smith JR. Blood perfusion hyperaemia in response to graded loading of human heels assessed by laser-Doppler imaging. Clin Physiol 1999;19:351-359.

McKenzie AW, Stoughton RB. Method for comparing percutaneous absorption ofsteroids. Arch Dermatol 1962;86:608-610.

Meyer E, Smith EW, Haigh JM. Sensitivity of different areas of the flexor aspect of the human forearm to corticosteroid-induced skin blanching. BrJ Dermatol 1992;127:379-381.

Noon JP, Evans CE, Haynes WG, et al. A comparison of techniques to assess skin blanching following the topical application of glucocorticoids. Br J Dermatol 1996;134:837-842.

Petersen LJ, Kristensen JK. Time-course of corticosteroid-induced blood flow in normal cutaneous tissue - quantitative measurements during $72 \mathrm{~h}$ of treatment. Clin Exp Dermatol 1989;14:210-213.

Smith JG, Wehr RF, Chalker DK. Corticosteroid induced cutaneous atrophy and teleangiectasia. Arch Dermatol 1976;112:1115-1117.

Sommer A, Veraart J, Neumann M, et al. A. Evaluation of the vasoconstrictive effects of topical steroids by laser- Doppler-perfusion-imaging. Acta Derm Venereol 1998;78:15-18.

Tur E, Tur M, Maibach HI. Basal perfusion of the cutaneous microcirculation: measurements as a function of anatomic position. J Invest Dermatol 1983;81:442-446.

Wardell K, Braverman IM, Silverman DG, et al. Spatial heterogeneity in normal skin perfusion recorded with laser Doppler imaging and flowmetry. Microvasc Res 1994;48:26-38.

Wårdell K, Jakobsson A, Nilsson GE. Laser Doppler perfusion imaging by dynamic light scattering. IEEE Trans Biomed Eng 1993;40:309-316. 


\section{Chapter VII}

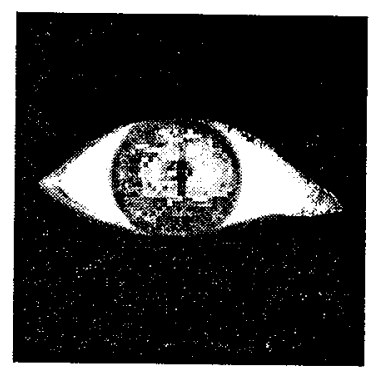

\section{GENERAL DISCUSSION}

\&

SUMMARY 


\section{General Discussion}

To study microcitculation, selecting the appropriate technique is equally important as mastering the technology. With the great number of measurement devices for the quantification of the skin circulation, the question rises when it is reasonable to use them and which devices should be chosen. Presently, the capillary microscopy, transcutaneous oxygen measurement and laser Doppler fluxmetry are the most frequently used means for the quantification of the cutaneous microcirculation. These means can be taken as the basis of the clinical and experimental microcirculation diagnostic. LDI is an easy to handle technique and can be regarded as a laser Doppler multipurpose measuring system that allows the user to specify the number of measuring points and number of necessary consecutive readings. This option implies that the primary limiting factor of conventional LDF, which is the small measuring volume in combination with the localised flow variations in tissue, can be effectively circumvented by the LDI system. Since no physical contact is necessary between the scanner head and the skin, the potential risk of influencing the skin perfusion has been effectively discriminated. In experimental settings as well as in clinical use LDI should therefore be positioned on the first place of all the laser Doppler devices.

During the studies described in this thesis the LDI application was simply practicable in all situations and did not induce any complications or restrictions due to the study design.

As analysed in this thesis, laser Doppler Imaging is a sophisticated development of the laser Doppler technique. Systematic analysis of the currently published articles led to the conclusion that LDI is a suitable tool for experimental study designs, as it provides quantitative assessment of alteted microcirculation. The data show a good reproducibility, yet the number of performed studies is still too small (a total of 59 included dermatological studies) to establish a link with clinical implications. An attempt was made by several investigators to analyse physiological and pathological states of the skin as a response to different stimuli on the microcirculation using the advantage of quantitative analysis of LDI. It is an upcoming idea to establish measurement scales in e.g. patch test reactions, healing tendencies of ulcers, monitoring of treatment, or reactions to vasoactive substances and to introduce these scales internationally. These scales could lead to a uniform international approach of interpreting changes in microcirculation. This has been tried in the field of assessing patch testing. It still has not been described that LDI can provide extra information for the clinician to distinguish between irritant and allergic reactions. Therefore, conclusions must be guarded until comprehensive studies of diverse irritants and allergens have been completed. 


\section{Phlebology}

CVI shows disturbances in microcirculation detectable by LDI measurements. It has been shown that telangiectasias, as a major part of clinical manifestation of CVI, show higher flows than the surrounding tissue, often induced by an underlying feeder-vein. The clinical differentiation between red and blue telangiectasias, which is also found by astrup blood gas analysis (red higher oxygenated than blue), could not be detected by LDI. As LDI measures the etythrocytes and their velocity measurement data of LDI and clinical manifestation do agree with each other, both implying a higher flow due to an altered diameter. Yet, the velocity in the telangiectasias is low, so that the amount of erythrocytes probably is of greater importance for the increased LDI values. In atrophie blanche, which is a severe clinical symptom of CVI with a poor prognostic factor, it could be shown that the basic resting flux in atrophie blanche lesions measured with LDI is increased compared with clinically normal skin and healthy controls, and that the flux is decreased more by venous occlusion in atrophy blanche lesions. The increase of LDI values could be interpreted as an imbalance between reduced number of capillaries and an increased velocity due to the high venous pressure in CVI. We can state that LDI is a useful tool in measuring microcirculatory changes in regions with atrophie blanche. In the future, it should be analysed whether different stages of CVI can be recognised by typical findings in L.DI measurements. It has to be investigated whether LDI can provide a critical value as a prognostic factor of the development of ulcera cruris in patients with CVI.

\section{Corticosteroids}

In detecting a decrease of microcirculation, as found after topical application of corticosteroids, LDI was proven not to be sensitive enough, since differences between normal perfused skin and vasoconstriction of the dermal blood flow provide similar results. Thus, LDI remains a measurement device for increased microcirculation seen in inflammatory and vasculatory dermatoses. During the studies performed with LDI, it has been found that LDI can be easily used for follow-up treatment. Measurement sites can be marked and easily found back the next days and the time of a single measurement allows simultaneous recording of several test sites.

When we combined LDI measurements with diffuse reflectance spectroscopy after application of corticosteroids it could be concluded that diffuse reflectance spectroscopy easily detects the blanching effect. Combining the results of both devices the blanching effect is probably based on a reduced blood flow in the superficial plexus rather than microcirculatory changes over the whole dermis. Therefore, it can be assessed easily by diffuse reflectance spectroscopy and is not accessible by LDI. Yet, in order to monitor the entire spectrum of microcirculatory responses to topically applied corticosteroids, blanching and reactive hyperaemia, visual scoring should be neglected. For this approach the combination of LDI and diffuse reflectance spectroscopy gives complementary information. 


\section{General considerations}

Summarising, LDI bundles most of the technical advantages necessary for optimal measurement of microcirculation. The question remains whether the information obtained by LDI has found its relevance for the dermatologist yet.

Of course, every new speciality requires a dedicated cadre of believers to creatc a curriculum that will attract the attention of the orthodox establishment. Enthusiasm is a necessary propelling force. However, exaggerations and excessive zeal must be controlled if bioengineering is to gain respectability in the medical establishment, which is a destination to which we all fervently aspire. The diagnosis and treatment of skin cancer, for example, furnishes a telling example of the evils of overstatement. To be sure, vascularisation is altered and is one criterion of malignancy. However, prognosis depends on many factors other than altered microcitculation, whereby histopathology is necessary to give an answer.

In reference to the title of this thesis (Laser Doppler Imaging in dermatology: experimental and clinical applications. Time to replace the dermatologist's eye?) it can be concluded that LDI surely is of importance to establish an objective approach of changes in microcirculation, no matter what might be the cause for this. In our opinion bioengineering techniques, such as LDI, provide useful supporting information hidden for the dermatologist's eye. Support but not replace! 


\section{Summary}

Information in dermatology about function in normal condition and under pathological circumstances is essential for our insight in the skin microcirculation. Non-invasive measurement techniques have been used during the last 20 years to assess the microcirculation in various experimental and clinical setrings. Although there is still no ideal microcirculatory non-invasive technique available, LDI combines important features, such as non-invasiveness and application to almost any site of the skin surface. LDI is easy to use, immediately provides the measured data set and offers the possibility for image storage and further software analysis as well. LDI is applicable in clinical and in experimental settings.

The aim of this thesis is to assess the place of LDI in experimental and clinical settings in dermatology.

\section{Chapter II}

In this chapter the literature has been systemically reviewed. The first studies using LDI were published in the early $1990 \mathrm{~s}$. Since then over a hundred studies in the different specialities of medicine were conducted. A selection of 59 atticles was made dealing with dermatology. The studies summarised represent the initial results of the potential usefulness of LDI in a variety of experimental and clinical settings.

LDI offers a possibility to assess patch testing objectively. It still has not been described that LDI can provide extra information for the clinician to distinguish between irritant and allergic reactions. Therefore, conclusions must be guarded untl comprehensive studies of diverse irritants and allergens have been completed.

Until now LDI measurements cannot provide a prognostic factor for healing tendencies of ulcera cruris or a severity scale for wound healing, which would be of clinical interest. Therefore, LDI remains for study purposes until a parameter is defined that can answer those questions. It should be investigated whether LDI can provide a prognostic tool in estimating the severity of CVI. Ischemia measured by LDI shows a uniform decrease in LDI values, thus pootly perfused tissue corresponding with clinical findings. Patients with type 1 and type 2 diabetes are prone to develop dysfunction of the autonomic nervous system. Therefore, it would be of great interest to detect subclinical changes in autonomic sympathetic function. Blood flow reactions after provocation were disturbed in the patients and it was concluded that diabetic parients display a vascular disturbance in their skin which is aggravated by thermal provocation. Disturbances in microcirculation of diabetic patients can be quantified by LDI assessment. It remains to be investigated whether LDI can help in staging early changes.

Objective non-invasive examination techniques are required to monitor the wound healing of flaps in addition to clinical parameters. With LDI it is possible to measure and visualise microcirculation continuously, non-invasively and without contact to the wound. Studies have been conducted to investigate the clinical use of LDI in wound healing of flaps. 
Necrotic areas, venous stasis and normal course of wound healing could be clearly visualised and differentiated from one another. In the last few years a number of burn treatment centres have tried the use of laser-Doppler imaging to evaluate non-invasive assessment of the depth of thermal burns. The scans were compared with histology reports and it was found that there was a consistently accurate correlation in all areas. Clinical assessment only agreed in $41 \%$ with the histological findings and often led to overdiagnosis.

In patients with skin tumours, the neovascularisation manifested as increased perfusion in the tumour area can be readily visualised by LDI. Malignant melanomas were significantly more perfused than basal cell carcinomas.

Changes in skin microcirculation due to vasoactive substances can be quantified by LDI measurement. Hyperperfusion seems to be easier to assess than hypoperfusion as studied after intradermal injection of vasodilators and vasoconstrictors. LDI is suitable to follow the working mechanism of vasoactive substances over several days.

In patients with scleroderma, increased cutaneous perfusion and greater use of microvascular reserve has been demonstrated using LDI. In the treatment of port wine stains with argon laser it was shown that cutaneous blood flow failed to correlate well with the clinical response to treatment and it was concluded that LDI is more useful in the research setting than as a predictive tool in the evaluation of treatment success.

LDI combines important qualities to measure microcirculation offering a non-invasive technique with a reasonable test size area, good reproducibility and a good correlation with clinical observations. The studies summarised above show that the experimental use of LDI is well studied. Yet, the translation into clinical relevance has not taken place. Therefore further studies have to be performed.

\section{Chapter III}

In this chapter it was investigated whether blue and red telangiectasias seen in CVI show a difference in blood gases and whether LDI is able to detect flow alterations in telangiectasias.

A difference in oxygenation correlated with the colour of the telangiectasias as seen in CVI. Blue and larger capillaries with a diameter $>0.5 \mathrm{~mm}$ had a higher carbon dioxide concentration and the red capillaries $(0.5 \mathrm{~mm})$ were higher oxygenated. As telangiectasias are assumed to be located in the capillary bed, the reason for differences in oxygenation could be found in underlying physiological and anatomical principles of the capillary loops with the red telangiectasia representing the arterial loop of the capillary and the blue telangiectasia representing the venous loop of the capillary. With LDI, microcirculation can be measured. Telangiectasias show higher flows than the surrounding tissue. This method still is not sensitive enough to make a distinction between different telangiectasias and therefore cannot detect differences in flow in red and blue telangiectasias. LDI could reveal an abnormal increased flow, due to an underlying vessel (feeder vein). It has to be investigated whether treatment of an undetlying feeder vein can reduce the total sclerosant dose for treating visible telangiectasias. 


\section{Chapter IV}

Results of a study are presented investigating the changes in skin microcirculation during artificially induced venous hypertension measured by transcutaneous oxygen measurement and LDI in patients with CVI with and without atrophie blanche. It is generally known that in atrophie blanche transcutaneous oxygen pressure are extremely low, nearly zero. A different reaction pattern on venous hypertension has been seen in the 3 study groups. In atrophie blanche a decrease in transcutaneous oxygen pressure was seen at $40 \mathrm{mmHg}$, in CVI without atrophie blanche at $60 \mathrm{mmHg}$ and in healthy controls at $80 \mathrm{mmHg}$ artificial induced venous hypertension.

Flux of the skin was measured using LDI.

Flux in patients with atrophie blanche was significant higher than in CVI skin without atrophie blanche or healthy controls. A decrease in flux was seen after artificially induced venous hypertension. This decrease was comparable in patients with atrophie blanche and healthy controls, that will say, the venoarteriolar response was the same in all study groups. No rebound phenomenon was seen in patients with atrophie blanche representing a decreased reserve capacity of the microcirculation.

\section{Chapter $V$ and $V T$}

We tested a group II corticosteroid (triamcinolonacetonide, TA) and a group IV corticosteroid (clobetasol-dipropionate, CP). Several measurements were performed on the subsequent days. TA only showed minor changes in LDI values whereas CP showed significant differences from baseline values. Corticosteroids were tested without and with occlusion. It was shown that occlusion prolongs the bioavailability of corticosteroids without influencing the time of onset. Concerning the site of steroid application a clear-cut gradient of decreasing blanching response from wrist to elbow was found. The exact nature of this site-dependent response to topically applied steroids is not known. It is likely that factors relating to the vasculature are responsible. Another possible explanation could be local differences of subcutaneous fatty tissue. At this moment it should be therefore recommended to test each preparation at several sites along the forearm of each volunteer, in order to obtain an accurate comparative assessment of corticosteroid release from topical delivery vehicles. A difference in gender has been determined after the application of corticosteroids with a main difference in LDI values after $30 \mathrm{~h}$ of application. So far potential sex differences have not been taken into account while assessing the blanching effect. It should be evaluated in the future whether those findings have clinical relevance. During the following days after application of the steroids LDI values showed a biphasic curve. In chapter VI an increase was found $8 \mathrm{~h}$ and $30 \mathrm{~h}$ after application. A biphasic reaction has been described earlier and represents possibly a vasoconstriction response after $8 \mathrm{~h}$ and a reactive hyperaemia response after $30 \mathrm{~h}$. First we tried to explain the increase at $8 \mathrm{~h}$ (where a decrease of LDI values was expected due to the vasoconstriction) because of a decrease in capillary diameter and subsequently a velocity increase. However, LDF data from other 
studies have shown that the capillary diameter is not influenced. Then the underlying arterioles must decrease probably the supply due to vasoconstriction. In the second study the biphasic curve showed a minimal change of $\mathrm{LDI}$ values at $8 \mathrm{~h}$ and a prominent increase at $30 \mathrm{~h}$. These data agree with the expected reaction pattern of LDI signal changes. Now being able to compare the LDI results with diffuse reflectance spectrophotometry (DRS) values, we consider the higher values of the LDI in chapter $V$ a reaction to the application of the occlusive dressing that has not been removed in time prior to the measurement $8 \mathrm{~h}$ after application of the corticosteroid. The occlusive dressing probably induced skin irritation of the tested area leading to an increased blood flow and thus an increase in LDI values. This effect overlaid the blanching effect of the corticosteroids. In conclusion, the layer in which LDI measures is not influenced by topically applied steroids after $8 \mathrm{~h}$.

Subsequently, the effect of the corticosteroids on the skin microcirculation was measured by LDI and DRS. Both measurement devices showed corresponding reaction patterns. In order to define the values of both devices on extreme vasoactive stimuli measurements have been performed after intradermal histamine- (maximal vasodilatation) and adtenaline-injection (maximal vasoconstriction). LDI and DRS measure both, blanching due to vasoconstriction after adrenaline application and erythema after histamine application. However, LDI values of vasoconstriction are similar to normal perfused skin whereas LDI values in erythema are in a 2 - to 3 fold higher range. LDI seems more sensitive for an increase of flux in hyperperfused skin as it is seen in erythema, e.g. induced by dermal injection of histamine or patch testing. DRS is sensitive in detecting both, blanching and erythema.

DRS is revealed to be of greater value for detecting blanching than LDI as it shows a more obvious response at the blanching phase after topical steroid application. Thus, DRS is suitable for further steroid research. LDI is suitable for measuring changes in microcirculation after steroid application, but is less sensitive than DRS in distinguishing between the potency of different steroids. 


\section{Samenvatting}

Inzicht in de functie van de microcirculatie van de huid onder normale en pathologische omstandigheden is van essentieel belang binnen de dermatologie. De afgelopen 20 jaar werden non-invasieve meettechnieken ontwikkeld om de microcirculatie van de huid te beoordelen in diverse experimentele en klinische settings. Alhoewel er tot op heden geen ideale meettechniek voorhanden is, combineert Laser Doppler Imaging (LDI) belangrijke factoren zoals het noninvasieve meten en de toepasbaarheid op vrijwel iedere plaats op het lichaam. LDI is gemakkelijk in het gebruik, de meetresultaten zijn direct beschikbaar en kunnen tevens verder geanalyseerd worden door het gebruik van geintegreerde software. Dit maakt LDI zowel geschikt voor experimentele als ook voor klinische settings.

Het doel van dit proefschrift is de toepassing van LDI voor de experimentele en klinische setting binnen de dermatologie te evalueren.

\section{Hoofdstuk II}

Een systematisch overzicht van de literatuur wordt gegeven met betrekking tot LDI. De eerste studies met LDI verschenen in het begin van de jaren ' 90 . Sindsdien zijn meer dan 100 studies met betrekking tot diverse specialismen binnen de geneeskunde gepubliceerd. 59 studies hiervan betreffen een dermatologisch onderwerp. De genoemde artikelen geven een overzicht van de eerste resultaten over potentiële toepassingen van LDI in diverse experimentele en klinische settings.

LDI kan gebruikt worden bij het objectiveren van epicutaan allergologisch onderzoek. LDI als extra middel bij het onderscheiden tussen irritatieve en allergische reacties, is echter nog niet beschreven. Dus, totdat er uitvoerig onderzoek is verricht naar verschillende irritanten en allergenen, moeten conclusies voorzichtig getrokken worden.

Tot op heden kan LDI niet ingezet worden bij het stellen van de prognose voor de genezing van het ulcus cruris of de mate van wondgenezing. Dit zijn voor de praktijk echter belangrijke parameters.

LDI wordt gebruikt voor onderzoeksdoeleinden totdat een nieuwe parameter is gedefinieerd die beantwoord aan bovengenoemde parameters.

Verder onderzoek zal nodig zijn om de waarde van LDI als prognostisch hulpmiddel bij de ernst van CVI te bepalen. Bij ischaemie worden met LDI lage waarden gemeten, dus slechte perfusie. Patiënten met type 1 en type 2 diabetes mellitus hebben kans dysfunctie van het autonome zenuwstelsel te ontwikkelen. Daarom is het van belang subklinische veranderingen van het autonome sympatische zenuwstelsel te detecteren. De bloeddoorstroming na provocatie bij diabeten was gestoord en geconcludeerd werd dat bij patiënten met diabetes mellitus de bloedvoorziening van de huid gestoord is en dit wordt versterkt door provocatie met warmte. De gestoorde microcirculatie bij patiënten met diabetes mellitus kan gekwantificeerd worden met LDI. Onderzocht dient te worden of dit reeds in een vroeg stadium kan. 
Necrose, veneuze stasis en het proces van de wondgenezing kunnen duidelijk gevisualiseerd worden en onderscheiden worden van elkaar. De laatste jaren hebben een aantal brandwondencentra het gebruik van laser-doppler imaging geëvalueerd om non-invasief de diepte van brandwonden vast te kunnen stellen.

Vergelijkingen tussen de LDI scans en histologie van de brandwonden leverde een sterke correlatie voor alle huidgebieden. Bij klinische evaluaties was er slecht in $41 \%$ van de gevallen overeenstemming met de histologische bevindingen, vaak was er sprake van overdiagnose.

Bij patiënten met huidtumoren kan de LDI de neovascularisatie, die zich kenmerkt door toegenomen doorbloeding, in het gebied van de tumor goed in beeld brengen. Maligne melanomen hebben een significant toegenomen doorbloeding vergeleken met basaalcelcatcinomen.

Veranderingen in de microcirculatie van de huid door vasoactieve stoffen kunnen door LDI gekwantificeerd worden. Volgens een studie met intradermale injectie van vasodilatoren en vasoconstrictoren, is hyperperfusie gemakkelijker aan te tonen dan hypoperfusie. LDI is geschikt om het effect van vasoactieve stoffen gedurende enkele dagen te bestuderen.

Bij patiënten met sclerodermie hebben metingen met LDI een toegenomen huiddoorbloeding en een groter gebruik van microcirculatoire reserves aangetoond.

Bij de behandeling van naevus flammeus met de argon laser daarentegen werd geen goede correlatie gezien tussen de doorstroming en de behandelrespons. Hieruit werd geconcludeerd dat LDI meer van nut is in de experimentele setting dan als klinisch hulpmiddel om behandelresultaten te evalueren.

LDI biedt de mogelijkheid de microcircualtie non-invasief te bestuderen wegens het grote testoppervlak, goede reproduceetbaarheid en goede correlatie met de klinische diagnostiek. De bovenbeschreven onderzoeken tonen aan dat LDI in onderzoeks settings uitgebreid is beschreven. De correlatie van LDI met de klinische relevantie (in de dermatologie) is nog niet voldoende onderzocht. Hiervoor zijn toekomstige onderzoeken gewenst.

\section{Hoofdstuk III}

In dit hoofdstuk werd bepaald of er een verschil in bloedgassen bestaat bij blauwe en rode teleangiëctasieën voorkomend bij CVI en of LDI bloedstroom veranderingen in teleangiëctasieën kan meten.

Een verschil in oxygenatie correleerde met de kleur van de teleangiëctasieën voorkomend bij CVI. Blauwe en grotere capillairen met een diameter $>0.5 \mathrm{~mm}$ hadden een hogere concentratie koolzuur dioxide en de rode capillairen $(0.5 \mathrm{~mm})$ waren beter geoxygeneerd.

Verondersteld wordt dat teleangiëctasieën zich in het capillairbed bevinden en de reden voor verschillen in oxygenatie moet dus gezocht worden in de onderliggende fysiologie en anatomie van de capillairen. De rode teleangiëctasieën vormen het arteriële deel van de capillaire lus en de blauwe teleangiëctasieën vormen het veneuze deel van de capillaire lus. Met LDI kan de microcirculatie gemeten worden. Teleangiëctasieën hebben een hogere flow dan het omringende weefsel. Toch is deze methode niet sensitief genoeg om een onderscheid te maken 
tussen de verschillende teleangiëctasieën en kan daardoor niet het verschil aantonen tussen flow in rode en blauwe teleangiëctasieën.

LDI kan abnormale toegenomen flow aantonen, als gevolg van een onderliggend vat ('feeder vein'). Of behandeling van een 'feeder vein' de hoeveelheid sclerosans die nodig is voor behandeling van klinisch zichtbare teleangiëctasieën kan reduceren, vereist aanvullend onderzoek.

\section{Hoofdstuk $I V$}

In dit hoofdstuk worden de resultaten gepresenteerd van een studie waarin de veranderingen in de microcirculatie van de huid bij patiënten met CVI, met en zonder atrophie blanche werden gemeten. Tijdens artificieel geïnduceerde veneuze hypertensie worden door middel van transcutane zuurstofspanning en LDI deze metingen verricht. Bekend is dat de zuurstofspanning in atrophie blanche extreem laag is, vrijwel nul. In de drie studiegroepen werd een verschillend reactiepatroon gezien op veneuze hypertensie. Een afname van de transcutane zuurstofspanning werd gezien bij een druk van $40 \mathrm{mmHg}$ in atrophie blanche, bij $60 \mathrm{mmHg}$ bij CVI zonder atrophie blanche, en bij $80 \mathrm{mmHg}$ artificiele veneuze hypertensie in gezonde proefpersonen.

Met de LDI werd de flux in de huid gemeten (flux $=$ liter $/ \mathrm{min} / \mathrm{m}^{2}$ ). De flux bij patiënten met atrophie blanche was significant hoger vergeleken met de flux bij patiënten met CVI zonder atrophie blanche en met de gezonde proefpersonen. $\mathrm{Na}$ een artificieel opgelegde veneuze hypertensie trad er een daling van de flux op. Deze daling was vergelijkbaar bij patiënten met atrophie blanche en gezonde proefpersonen, zodat geconcludeerd werd dat de venoarteriolaire reflex in alle groepen gelijk was.

Er werd "geen rebound" fenomeen gezien ten gevolge van een verminderde reservecapaciteit van de microcirculatie bij patiënten met atrophie blanche.

\section{Hoofdstuk V en VI}

In deze hoofdstukken werden een klasse II corticosteroid (triamcinolonacetonide, TA) en een klasse IV corticosteroid (clobetasol-diptopionaat, CP) getest. Verschillende metingen op opeenvolgende dagen werden verricht. TA liet slechts kleine veranderingen in LDI waarden zien, terwijl CP significante veranderingen ten opzichte van de uitgangswaarde liet zien. Corticosteroiden werden getest met en zonder occlusie. Hieruit bleek dat occlusie de biologische beschikbaarheid van corticosteroiden verlengt zonder dat het tijdstip waarop het corticosteroid begint te werken wordt beïnloedt. Er werd een gradiënt gezien waarbij de "blanching respons" afnam van pols naar elleboog. Het exacte mechanisme van deze plaats afhankelijke response op topicaal geappliceerde steroiden is niet bekend. Waarschijnlijk zijn vasculaire factoren hiervoor verantwoordelijk. Een andere verklaring is onderlinge verschillen in subcutaan vetweefsel. Geadviseerd wordt op dit moment een willekeurig preparaat op verschillende plaatsen op de onderarm van elk proefpersoon te testen, om een betrouwbaar overzicht te krijgen over het vrijkomen van steroïden uit hun vehiculum. 
$\mathrm{Na}$ de applicatie van corticosteroïden werd een verschil aangetoond tussen mannen en vrouwen met het grootste verschil 30 uur na applicatie. Tot op heden werd er geen rekening gehouden met potentiële verschillen tussen geslachten bij het "blanching effect". In de toekomst zal onderzocht moeten worden of deze bevindingen klinische relevantie hebben. Gedurende de dagen na het aanbrengen van de corticosteroiden, trad ex een bifasische curve op. In boofdstuk $V I$ werd een toename gevonden 8uur en 30 uur na applicatie. In eerdere studies werd een bifasische reactie beschreven waarbij de eerste piek na 8 uur optrad waarschijnlijk ten gevolge van vasoconstrictie en de tweede na 30 uur als gevolg van reactieve hyperaemie. In tegenstelling tot een verwachte afname na 8 uur door vasoconstrictie, vonden wij een toename met de LDI. Een verklaring hiervoor berust mogelijk op een afname van de capillaire diameter geinduceerd door het corticosteroid resulterend in toegenomen snelheid. Eerdere studies met de Laser Doppler flowmeter hebben geen verandering van de capillaire diameter kunnen aantonen. Het is waarschijnlijk vasoconstrictie in de onderliggende arteriolen die een afname in bloedtoevoer veroorzaakt. De tweede studie toonde in de bifasische curve geringe veranderingen in LDI waarden na 8 uur en een opvallende toename na 30 uur. Dit komt overeen met het verwachte reactiepatroon van de LDI. Nu we de resultaten van LDI en diffuse reflectie spectrofotometrie (DRS) kunnen vergelijken beschouwen wij de hoge waarden van de LDI in boofdstuk $V$ als een reactie op de applicatie van een occlusieve wondbedekker die niet op tijd verwijderd werd voor de meting. De occlusieve wondbedekker veroorzaakte waarschijnlijk irritatie van de huid in het testgebied, resulterend in een toegenomen doorbloeding en dus een toename in LDI waarden. Hierdoor werd het 'blaching effect' van corticosteroïden gemaskeerd. Concluderend, de huidlaag waarin LDI meet, wordt niet beïnvloedt door lokaal geappliceerde corticosteroïden na 8 uur.

Vervolgens werd het effect van de corticosteroiden op de microcirculatie van de huid gemeten door LDI en DRS. Beide meettechnieken toonden overeenkomstige resultaten. Om de uitkomsten van beiden te definiëren met betrekking tot metingen van sterke vasoactieve stimuli, werden metingen verricht na intracutane histamine- (maximale vasodilatatie) en adrenaline (maximale vasoconstrictie). LDI en DRS tonen beide 'blanching' ten gevolge van vasoconstrictie na applicatie van adrenaline en erytheem na histamine applicatie. Uitkomsten van LDI metingen van vasoconstrictie zijn vergelijkbaar met normaal doorbloede huid, terwijl LDI waarden bij erytheem een 2 à 3 maal waarde tonen. LDI lijkt meer sensitief bij een toename van flux in sterk doorbloede huid, dan wordt gezien bij erytheem, zoals wordt geinduceerd door intracutane injectie van histamine of door epicutane applicatie. DRS blijkt sensitief te zijn om zowel 'blanching' als erytheem vast te stellen. DRS blijkt van grotere waarde bij het vaststellen van 'blanching' zoals na corticosteroï applicatie dan LDI. Verdere onderzoeken met bettekking tot het effect van steroiden in de huid met behulp van DRS zijn gewenst. LDI is echter geschikt om veranderingen in huidmicrocirculatie na steroid applicatie vast te stellen, maar is minder sensitief dan DRS om de sterkte van de verschillende corticosteroïden te differentiëren. 


\section{Dankwoord}

Als je het dankwoord mag schrijven van je proefschrift dan is dat een heerlijk moment om wat er de afgelopen maanden allemaal gedaan, geschreven en gewerkt is nog een keer de revue te laten passeren. Nu het "grote" werk achter de rug is, is er plaats voor kleine eenvoudige probleempjes zoals het lettertype kiezen (Comic Sans of liever toch Garamond?) en ook leuke probleempjes, waar houden we feest?

Het assistenten-clubje wil ik het allereerst bedanken. Jullie zijn fantastisch!!! En dat in meerdere opzichten: er kwam heel veel steun van jullie in die zin dat jullie de afgelopen maanden altijd geinteresseerd waren hoe de stand van zaken was (Krijg je het manuscript op tijd af? Heeft de beoordelingscommissie het goedgekeurd? Heb je al een kaft? Weet je al wat je aandoet? Weet je dan waar je het moet kopen?....). De dagelijkse probleempjes kon ik bij jullie heel goed kwijt. En gelukkig heb ik van jullie ook de tijd gekregen om dagen lang aan het boekje te werken want ik hoefde geen spreekuren van anderen over te nemen en kon zelfs het een of andere eigen spreekuur aan jullie kwijt. En dan is het natuurlijk ook erg gezellig met jullie!!

De mensen van de Aio-kamer hebben mij geholpen om de computer niet uit het raam te gooien (wel een keer het manuscript) maar eerst even een kopje thee te drinken, de helpdesk te bellen (Marc, bij deze heel erg bedankt) of "wat wil je nou eigenlijk zeggen met deze grafiek? Wacht, dan pakken we toch even Excel voor Dummies". Onmisbare steun!! Erg bedankt!

En thuis was er ook iemand, die mij heel veel heeft gegeven: mein Thom, der lekker gekocht hat und immer gesellig in der Nähe blieb als ich hinterm laptop verschwand und der zwischendurch immer mal rüber rief: " $\mathrm{Na}$ fleissiges Liesschen....". Tja Thom, demnächst bist du dann auch der Herr Doktor...

En dan de mensen die zich meer met het gehecl dan met de dagelijkse begeleiding bezig hebben gehouden zoals Professor Neumann, die tot onzer beiden verbazing ineens een manuscript in zijn handen kreeg met het verzoek om hier "even" een oordeel over te geven. Een antwoord hierop kon ik in Keulen en in Banholt krijgen of per fax uit Rotterdam, maar ook natuurlijk in de jaren daarvoor, tijdens het schrijven van de artikelen, in het azM bij een lekkere espresso. Ik wil u danken voor uw talent om op een individueel onderwerp en de promovenda in te gaan en toch een Neumaniaanse promotie af te leveren.

Gerald Lucassen (Gerry) wil ik danken voor een gezellige en leuke samenwerking tijdens het LDI/DRS-project. Het lukt maar weinig mensen om twee weken bij $25^{\circ} \mathrm{C}$ continu te meten en het toch nog gezellig te houden. Gelukkig houden we beiden van dezelfde muziek en zo hebben we de mevrouw van de snelweg ook de een of andere keer naar de hemel gestuurd. Ook de Eindhoven-Maastricht connectie werkte goed in de daarop volgende maanden, zodat we de in het begin niet te overziene berg aan data tot een artikel hebben kunnen verwerken. Aan jou mijn 
hartelijke dank voor al je steun. En ook dank aan je collega Patricia van Kemenade, die ons artikel nog een keer kritisch heeft bekeken.

Joep Veraart wil ik hartelijk danken voor het kritische lezen van grote delen van dit boekje en voor het opzetten en begeleiden van de "cortico-studies". Jij hebt vele goede opmerkingen gehad om het verhaal meer "to the point" te brengen.

Birgitte Maessen wil ik danken voor ons gezamenlijk onderzoek over atrophie blanche. Jij hebt $\mathrm{mij}$ in het begin ook geholpen "Fuss zu fassen" in het academische wereldje.

Mijn bijzondere dank wil ik richten aan de "vrijwilligers", die mee hebben gedaan aan een of zelfs meer onderzoeken van dit proefschrift. Jullie zijn 's ochtends vroeg al naar het ziekenhuis gekomen, om "hormonen" op jullie armen te laten smeren en 's avonds nog lang gebleven (niet altijd veraangenaamd door een Chinees etentje) voor de laatste metingen in onze "klimaatkamer". Zonder jullie was het dus nooit zo ver gekomen.

Het secretariaat was er altijd voor lay-out tips, laser printen, stukjes vertalen en mooie officiële brieven. Ook aan jullie mijn dank. Los van het boekje wil ik de polikliniek dermatologie danken voor de goede en gezellige samenwerking.

Patty Nelemans bedankt voor de crashcursus "Epidemiologie: Do it yourself" en de duidelijke uitleg voor non-epidemiologen. Beterschap! Fons Kessels ook bedankt voor de statistische begeleiding.

De AV-dienst wil ik danken voor de professionele en snelle hulp bij het maken van foto's, posters en het omslagdesign van dit boekje (Geerdjan, jij weet er alles van, dank je wel!!!).

En last but not least mijn paranimfen, Judith en Karin, bedankt voor de praktische en emotionele steun; jullie zijn goede vrienden en lieve collegae!

Dit worden nu de laatste woorden van dit proefschrift en ik dank nogmaals iedereen, die mij geholpen heeft dit boekje te schrijven en ik dank de beoordelingscommissie voor de positieve reacties en de aanvullende suggesties! 


\section{List of Publications}

Sommer A, Neumann M. Basic aspects and clinical application of $20 \mathrm{MHz}$, ultrasound in dermatology. Scripta Pblebologica 1996;4:9-13.

Sommer A, Veraart J, NeumannM. Lipodermatosclerosis: Skin changes detectable by $20-\mathrm{MHz}$ ultrasound? North American Society of Pblebology, 9th annual congress 1996;2:25-27.

Sommer A. Lipodermatosclerose: Skin changes detectable with $20 \mathrm{MHz}$ ultrasound? Skin Research and Technology 1996;2:230.

Neumann M, Sommer A, Blaauw G. La lipodermatosclerose et l'epaisseur dermale. Phlebologie1996;1:25-28.

Sommer A. Rode en blauwe besenreiser: Verschil in zuurstofgehalte? NTDV 1997;7:245-6.

Peters FPJ, Sommer A, Vermeulen A, Cheriex EC, Kho TL. Fabry's disease: a multidisciplinary disorder. Postgrad Med J 1997, 73; 710-712.

Sommer A, Hoekzema R. Irreversibel leukoderma na gebruik van haarverf. NTDV 1997; 7: 3-5.

Sommer A, Neumann HAM. Case-report: Pseudo-kaposi met secundair lymfoedeem. Scripta Phlebologica 1998;6:36-8.

Sommer A. Syndroom van Comel-Netherton (trichorrhexis invaginata, ichthyosis linearis circumflexa en atopisch eczeem. NTDV 1998;8:145-7.

Sommer A, Steijlen PM. Ichthyosis bullosa van Siemens. NTDV 1998;8:147-50.

Sommer A. Varices ontstaan uit een veneuze malformatie. NTDV 1998;8:129-31.

Sommer A. Syndroom van Comel-Netherton (trichorrhexis invaginata, ichthyosis linearis circumflexa en atopisch eczeem. Ned Tijd Geneesk 1998;142:2709-10.8

Sommer A, Veraart JCJM, Neumann HAM. Veneus aneurysma van de fossa poplitea: wat te doen?. Scripta Pblebologica 1998;10:59-61. .

Sommer A. Comment on article Nilsson G. Laser Doppler Perfusion Imaging for assessment of cutaneous microcirculation. Phlebologie 1997;26:87-91. Phlebology Digest 1998;4:20.

Sommer A, Henquet C. Incontinentia pigmenti bij een pasgeborene. NTDV 2000;10:404-6. 


\section{Curriculum vitae}

Geboren: $\quad 25.03 .1967$ te Aken, Duitsland

School: $\quad 1973-1977 \quad$ Basisschool "Am Höfling" te Aken

1977 - 1986 Gymnasium "Rhein- Maas" te Aken

Studie:

begin geneeskunde studie te Bonn, Duitsland (Rheinische Friedrich-Wilhelm-Universität)

1991 - 1992 buitenlandse studie te Leiden ("Erasmus" uitwisselingsproject)

1995 arts-diploma te Bonn

Buitenlandse stage:

1986 - 1987 stage in het streekziekenhuis "Guayabetal" in Colombia

1987 begeleiding van Lepra - patiënten in het "Leprosy centre Karachi", Pakistan

1993 stage obstetrie te Dublin, Ierland

Opleiding:

1995

AGNIO Dermatologie te Maastricht, hoofd: Prof. Dr. M. Neumann (AZM)

1997

begin als AGIO Dermatologie te Maastricht, hoofd: Prof. Dr. M. Neumann (AZM)

1999

begin opleiding Mohs micrografische chirurgie te Maastricht

einde opleiding tot dermatoloog in februarie 